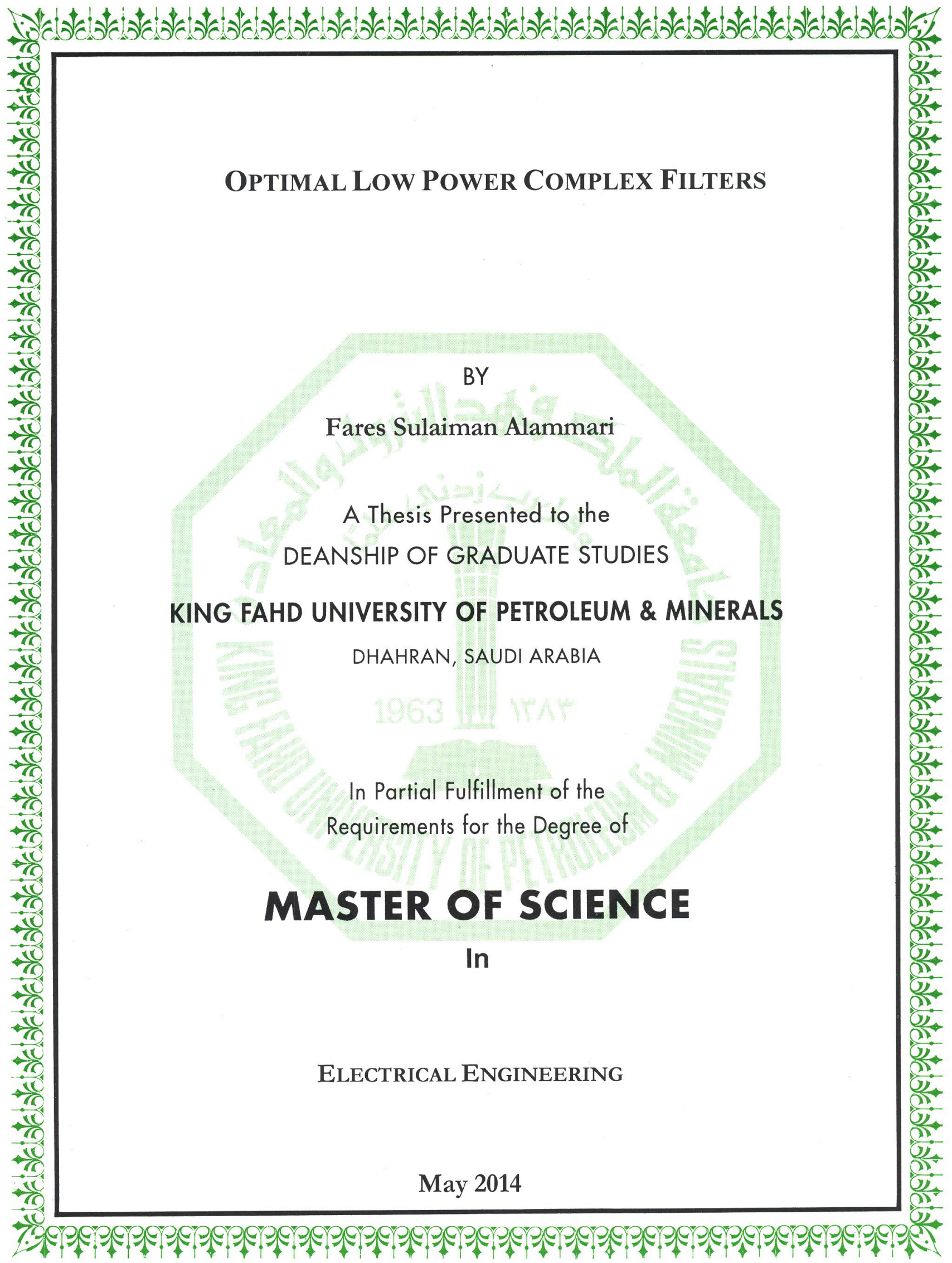




\section{OPTIMAL LOW POWER COMPLEX FILTERS}

FARES SULAIMAN ALAMMARI

ELECTRICAL ENGINEERING

May 2014 


\section{KING FAHD UNIVERSITY OF PETROLEUM \& MINERALS}

DHAHRAN- 31261, SAUDI ARABIA

\section{DEANSHIP OF GRADUATE STUDIES}

This thesis, written by FARES SULAIMAN ALAMMARI under the direction of his thesis advisor and approved by his thesis committee, has been presented and accepted by the Dean of Graduate Studies, in partial fulfillment of the requirements for the degree of MASTER OF SCIENCE IN ELECTRICAL ENGINEERING.

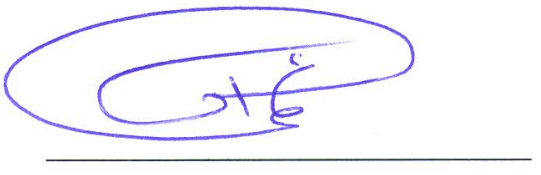

Dr. Ali Ahmad Al-Shaikhi

Department Chairman

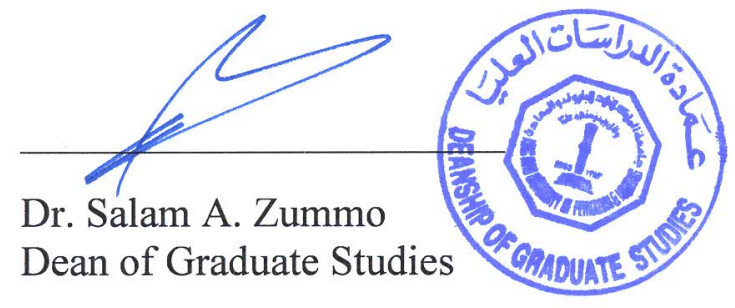

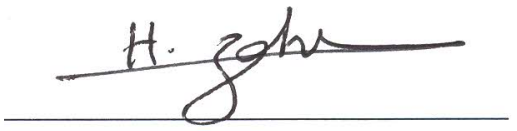

Dr. Hussain Al-Zaher (Advisor)

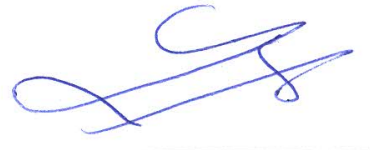

Dr. Munir Al-Absi (Member)

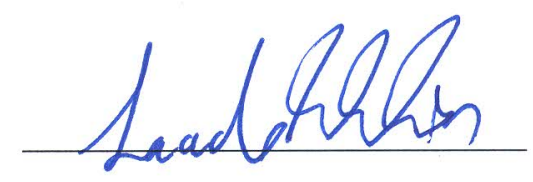

Dr. Saad Al-Shahrani (Member)

1311114

Date 
(C) Fares Sulaiman Alammari

2014 
This work is dedicated to my parents and my wife 


\section{ACKNOWLEDGMENTS}

I would like to thank my thesis advisor, Dr. Hussain Al-Zaher for his continuous support and encouragement to achieve and complete all thesis requirements. I am also grateful to thesis committee members, Dr. Munir Al-Absi and Dr. Saad Al-Shahrani for their support and excellent feedback on thesis proposal to completing my thesis. And I would like to thank my friends who have helped and inspire me during my master study.

Also, my deepest gratitude goes to my beloved parents and my wife for their endless love, prayers and encouragement. 


\section{TABLE OF CONTENTS}

ACKNOWLEDGMENTS

TABLE OF CONTENTS ......................................................................................

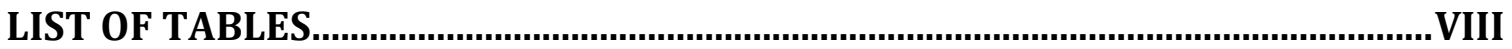

LIST OF FIGURES ...............................................................................................

LIST OF ABBREVIATIONS...................................................................................... X

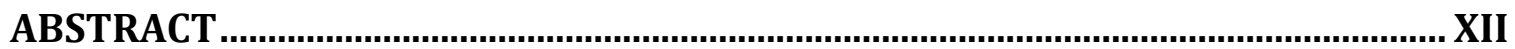

ARABIC ABSTRACT ….....................................................................................

CHAPTER 1 INTRODUCTION.............................................................................. 1

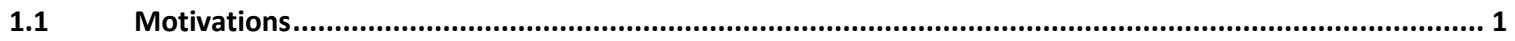

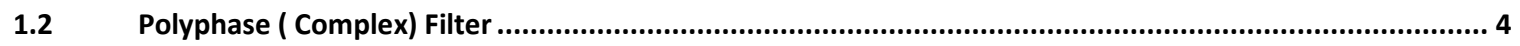

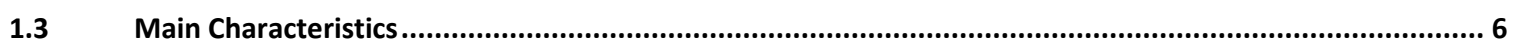

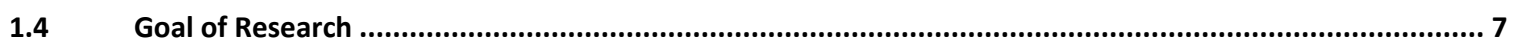

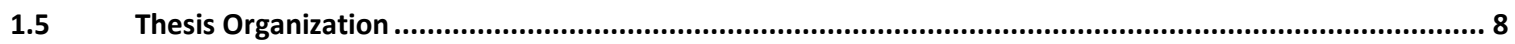

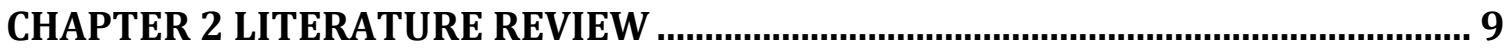

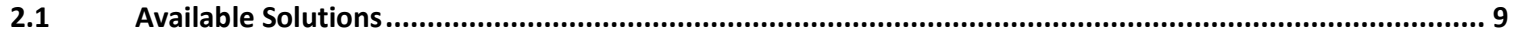

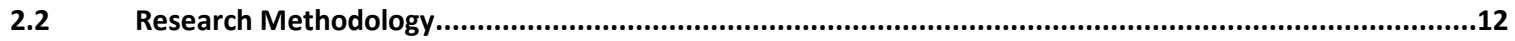

CHAPTER 3 POSSIBLE SOLUTIONS ........................................................................14 
3.1 Active- RC vs Gm-C Filter

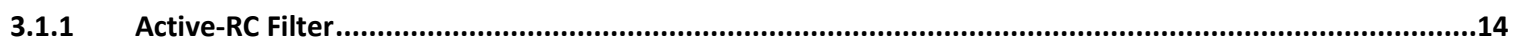

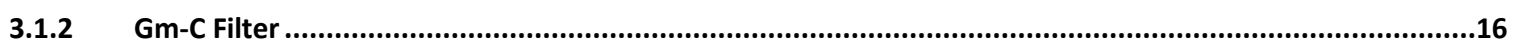

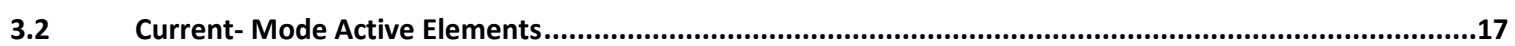

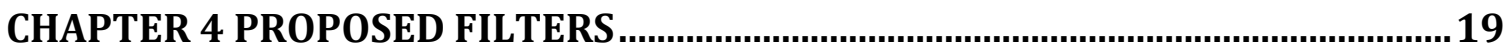

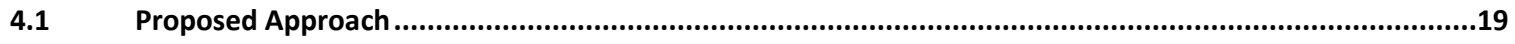

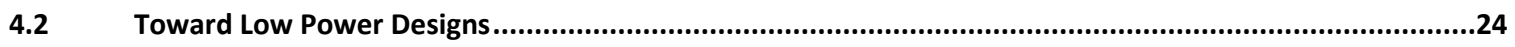

4.2.1 Voltage-mode Complex Filter Based TCA Realized with Single Output CCIIs........................................25

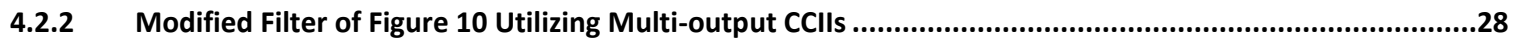

4.2.3 Voltage-mode Complex Filter Based on TRA realized with CFA ...........................................................31

4.2.4 A Novel Current-mode Complex Filter Based on TCA Realized with CClls ..............................................34

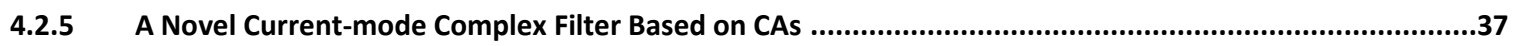

CHAPTER 5 OPTIMAL DESIGN.................................................................................. 40

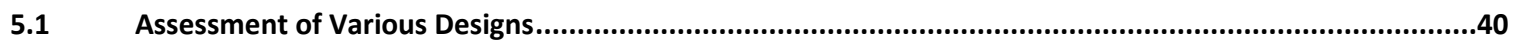

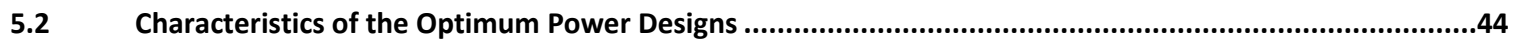

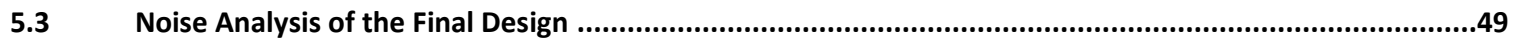

5.3.1 Derivative Equations to Find IoIInzIa2 =IoIInYIb = IoIInzQb3 of Figure 17(b):..........................50

5.3.2 Derivative Equations to Find IoIInzIa3 =IoIInYQa = IoIInzQb1 = IoIInzQa1 of Figure 17 (b):..........53

CHAPTER 6 SIMULATION RESULTS AND CONCLUSION ..........................................57

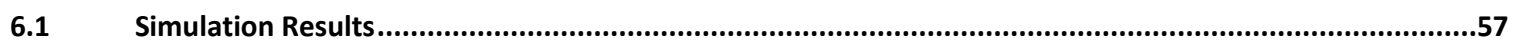

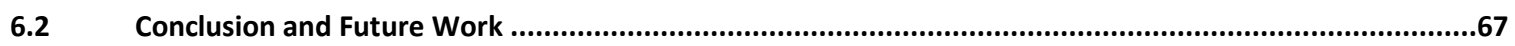

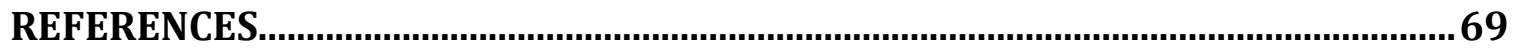

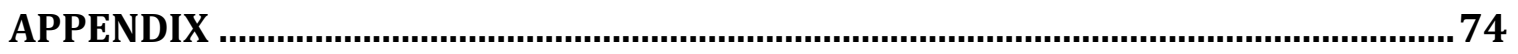

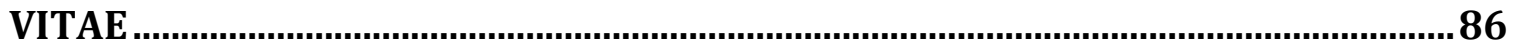




\section{LIST OF TABLES}

Table 1: Comparison between recent complex filters............................................... 11

Table 2: Compatibility of various amplifiers with complex filters................................. 43 


\section{LIST OF FIGURES}

Figure 1: Zero IF Receiver..................................................................................... 2

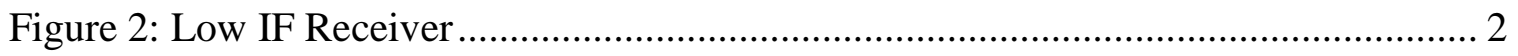

Figure 3: Image rejection architecture in the complex domain ..................................... 4

Figure 4: Frequency translation of a complex (quadrature) mixer: (a) before mixing (b) after mixing. .... 6

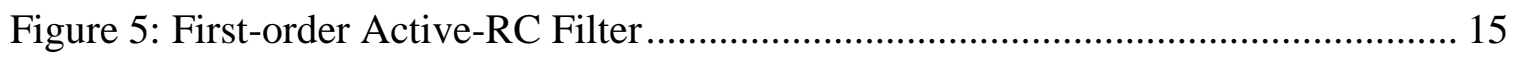

Figure 6: a) Frequency response of a non-ideal integrator; b) phase response of a non-ideal integrator. 15

Figure 7: An Gm-C implementation of an integrator ............................................ 17

Figure 8: Frequency shifting: (a) Basic concept (b) Realization ................................... 20

Figure 9: A block diagram of the two-integrator-loop complex filter ............................. 20

Figure 10: Voltage-mode complex filter based TCA realized with single output CCIIs . 25

Figure 11: Modified filter of Figure 10 utilizing multi-output CCIIs............................. 28

Figure 12: Voltage-mode complex filter based on TRA realized with CFA (CCII+VB) 31

Figure 13: A novel current-mode complex filter based on TCA realized with CCIIs...... 34

Figure 14: A novel current-mode complex integrator based on CAs ............................ 37

Figure 15: A novel current-mode complex filter based on CAs ..................................... 37

Figure 16: A class AB CCII+ obtained from opamp based buffer ............................... 41

Figure 17: Filters based on CCII and CA including noise sources ................................. 48

Figure 18: A low power CMOS CA with two complementary outputs .......................... 49

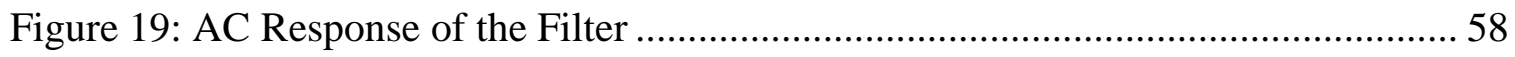

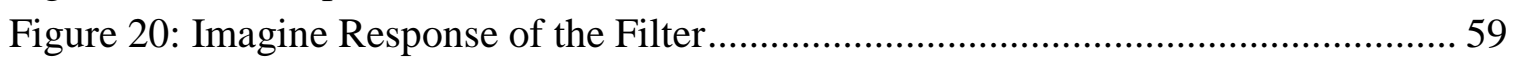

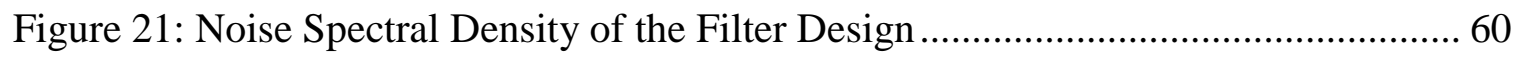

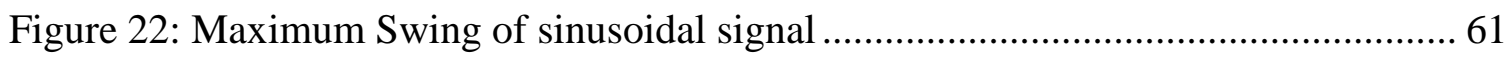

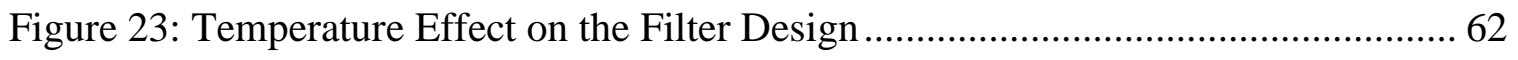

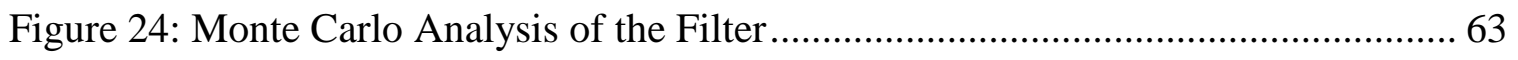

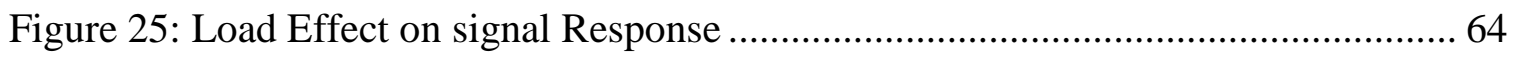

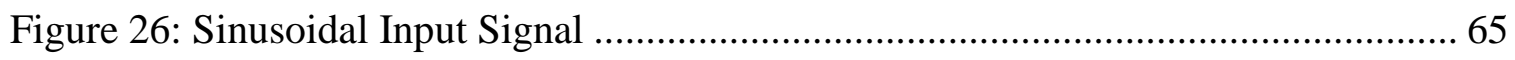

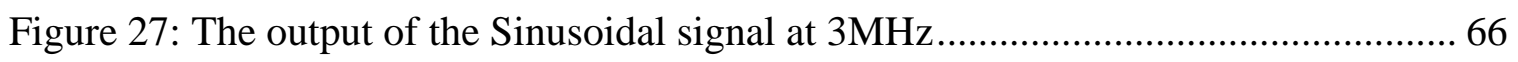

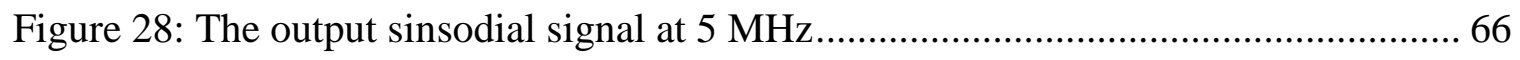

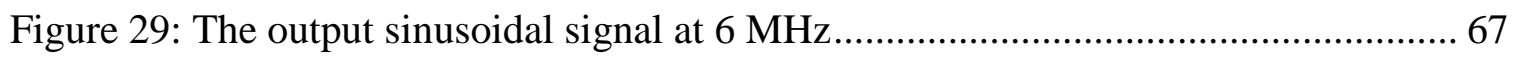




\section{LIST OF ABBREVIATIONS}

\begin{tabular}{|c|c|c|}
\hline IF & : & Intermediate Frequency \\
\hline CCII & : & Second generation current conveyor \\
\hline TCA & : & Transconductance Amplifier \\
\hline TRA & : & Transresistance Amplifier \\
\hline BT & : & Bluetooth \\
\hline $\mathrm{CA}$ & : & Current Amplifier \\
\hline CMOS & & Complementary Metal-Oxide Semiconductor \\
\hline RF & : & Radio Frequency \\
\hline $\mathrm{ADC}$ & : & Analog to Digital \\
\hline LO & : & Local Oscillator \\
\hline $\mathrm{BPF}$ & : & Band Pass Filter \\
\hline LPF & : & Low Pass Filter \\
\hline CFA & : & Current Feedback Amplifier \\
\hline \multicolumn{2}{|c|}{ Op-Amp: } & Operational Amplifier \\
\hline I-patl & & In-phase Path \\
\hline
\end{tabular}




$\begin{array}{lll}\text { Q-path : } & \text { Quadrature Path } \\ \tau & : & \text { The time constant of the complex integrator } \\ \omega_{c} \quad: & \text { Ponter Frequency } \\ \omega_{o}, \quad: & \text { Pole Quality Factor } \\ \text { Q } & \text { Voltage Buffer } \\ \text { VB } \quad: & \text { Current Follower } \\ \text { CF } \quad: & \text { Low Noise Amplifier }\end{array}$




\begin{abstract}
Full Name $\quad$ : FARES SULAIMAN ALAMMARI

Thesis Title : OPTIMAL LOW POWER COMPLEX FILTERS

Major Field : EE

Date of Degree : MAY 2014
\end{abstract}

Active complex filters are of particular interest as they, unlike traditional filters, perform image rejection in addition to filtering. Complex filters are considered one of the most effective techniques for discarding the image signals in low intermediate frequency (IF) receivers such as Bluetooth applications.

Alternatives of realizing voltage and current-mode complex filters based on transconductance, transresistance, and current amplifiers are systematically developed. Several new complex filters are presented. These designs are developed from their respective basic complex integrator which is utilized to obtained complex filters from their second-order two-integrator loop lowpass biquad. It is shown that this approach leads to not only most efficient circuit realizations but also advantageous features in terms of image rejections and selectivity characteristics. Detailed frequency domain analysis of the proposed filters is giving and their frequency characteristics are identified. Various amplifiers are realized utilizing the second generation current conveyor (CCII) to promote objective comparison between filters based on different building blocks. Consequently, the comparison shows that the optimum designs in terms of power consumptions are current-mode filters based on the second generation current conveyor and current amplifiers. But further comparisons based on noise performance and filter signal swings show potential advantage of the CA based complex filter. Comprehensive 
noise analysis and maximum possible signal swing calculations are provided. It demonstrates clearly that the CA based complex filter is expected to provide a better dynamic range. As an-application example, a 4th-order complex filter based on the CA is designed for low-IF Bluetooth receiver. Simulation results obtained from a standard $0.18 \mu \mathrm{m}$ CMOS technology verify its proper operation. Simulation results also show that the attainment of the selectivity requirements of the Bluetooth specifications. The filter is designed with $3 \mathrm{MHz}$ center frequency and $1 \mathrm{MHz}$ bandwidth. The filter shows $43 \mathrm{~dB}$ and $56 \mathrm{~dB}$ attenuations of blockers at $5 \mathrm{MHz}$ and $6 \mathrm{MHz}$, respectively. It is found that the filter exhibits total input referred noise of $180 \mathrm{nA}$ and maximum signal swing of $850 \mathrm{uA}$. The filter operates from $\pm 1.5 \mathrm{~V}$ supply and consumes total power of $1.3 \mathrm{~mW}$. 


\section{ملخص الرسالة}

الاسم الكامل: فارس سليمان العماري عنوان الرسالة: المرشح الامثل لتوفير الطاقة

التخصص: الهندسة الكهربائية

\section{تاريخ الارجة العلمية: رجب 1435}

المرشح من النوع متعدد الاوجه الحساس لزاوية المدخلات له أهمية خاصة على عكس المرشحات التقليدية، لانها تبعد اشارات موجات الصور المصاحبة مع الموجات الأصلية بالاضافه الى عملها الاساسي وهو التصفية. تعتبر المرشحات ذات الاوجه المتعددة واحدة من أهم التقنيات الأكثر فاعليه لتجاهل إثار ات الصور في الترددات المتوسطة مثل تطبيقات البلوتوث ويتم تطوير هذه المرشحات بناء على أسس وضع التبار او الجهد وذلك اما ان يكون على أساس تحويل الجهد الى تيار أو تحويل التيار الى جهد أومكبرات التيار بشكل منهجي.

العديد من المرشحات ذات الأوجه المتعددة التي سيتم عرضها في هذا التقرير تم نطوير ها من خلال تصاميمها الاساسية وذلك من خلال استخدام المرشحات التي تم الحصول عليها من الدرجة الثانية وتبين أن هذه الطريقة ليست تؤدي فقط لإنجاز الدو ائر الأكثر كفاءة ولكن أيضا هناك مميز ات أخرى مفيدة من حيث استبعاد اشارات الصورة و الخصائص الانتقائية. التحليل المفصل لمجال التردد للمرشحات المقترحة سوف تعطى وسوف يتم تحديد خصائص وتيرتها. أيضا تتحقق مكبرات الصوت المختلفة باستخدام الجيل الثاني من الناقل الحالي (CCII) لتعزيز المقارنة الموضو عية بين المرشحات على أساس تصاميم مختلفة وبالتالي تُظهر المقارنة ان التصميم الامثل من ناحيه توفير استهلاك الطاقه يتم من خلال استخدام الجيل الثاني من ناقل التيار ومن خلال استخدام مكبر التيار ايضا. لكن المقارنات الاخرى من ناحية اداء تداخل الموجات وتقلبات اشارة المرشح تظهر ميزه محتمله للمرشح ذات الاوجه المتعدة ذات تصميم مكبر التيار. من ناحيه اخرى, التحليل الثامل لتداخل الموجات وتقلبات الموجات سيتم عرضها و انه يدل بوضوح على ان المرشح ذات التصميم مكبر التيار يقدم افضل مدى ديناميكي للموجات. كمثال للتطبيق, المرشح من النوع متعدد الاوجه الحساس لزاوية المدخلات من الدرجة الر ابعة على اساس تصميم مكبر التيار صمم لمستقبل البلوتوث ذات الترددات المتوسطة ـ ايضا, نتائج المحاكاة التي تم الحصول عليها من التكنلوجيا $0.18 m$ 
CMOS تم التحقق من عملها الصحيح. تظهر نتائج المحاكاة أيضا أن تحقيق متطلبات الانتقائية للمو اصفات بلوتوث. تم تصميم المرشح بمركز تردد 3 ميغاهيرتز وعرض النطاق الترددي 1 ميغاهيرتز. المرشح يظهر تقليل ب 43 و56 دي بي من المعوقات في 5 و6 ميغاهيرنز على التوالي ـ ولقد وجد ان المرشح ابدى مجموع 180 من الضوضاء و 850 uAA كأقصى حد من معالجة الإشارة. المرشح يعمل على 1.5 ل امداد الطاقة ومجموع استهلاك الطاقة هي 1.3ملي و اط. 


\section{CHAPTER 1}

\section{INTRODUCTION}

\subsection{Motivations}

When you use a computer, entertainment system or telephone, the various pieces and part of the system make up a community of electronics devices. These devices communicate with each other using a variety of wires, cable and even greater variety of connector's plugs and protocols. The world now looking for communication without using cables. To achieve this goal, many devices have to be multi-application to avoid complexity in connection grid. One of these devices is a receiver. In last decade, many researchers published papers that have an idea to develop the filters that have low power, small size and large dynamic range that can be used in receivers and can be used for multiapplication. Bluetooth is one of the most important examples of these applications.

At the beginning, Bluetooth will be described to be able to understand the properties of this technology and then the appropriate filter/receiver can be investigated. Bluetooth is an open wireless technology standard for exchanging data over short distance and it is characterized by relaxed dynamic range, noise image rejection specifications to allow development of fully integrated and inexpensive Bluetooth modules. Zero IF is a radio receiver design that demodulates the incoming signal by mixing it with a local oscillator signal. The RF signal is mixed directly to baseband paths to keep the negative frequency 
information low pass filter will be used to do channel selectivity. See Figure 1. Since the local oscillator signal is in-band, this architecture (ZIF) suffers from non-linear DC offset problems caused by self-mixing. DC offset correction must be used to remove that DC component from L.O.

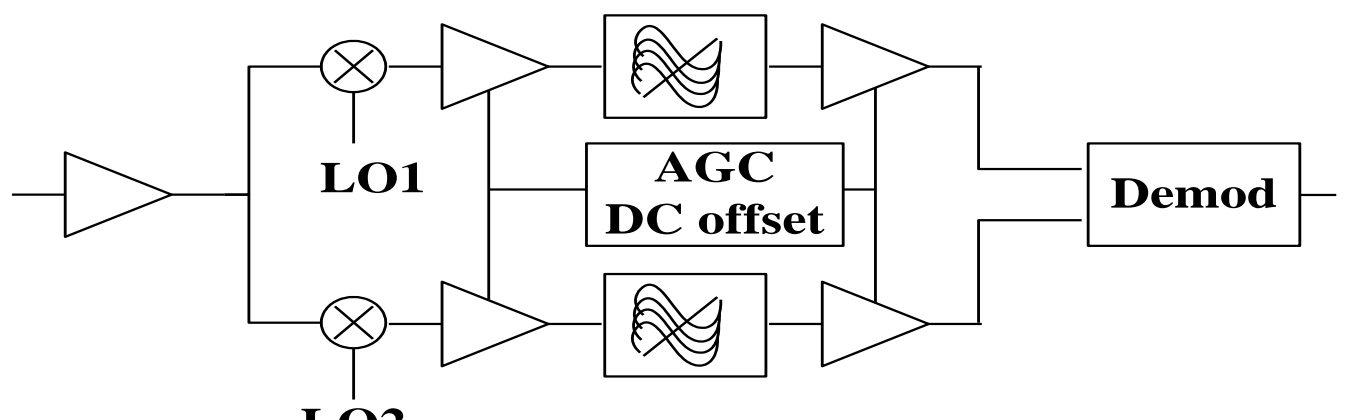

Figure 1: Zero IF Receiver

In general, ZIF is not suitable for Bluetooth (BT) application because of dc offset and flicker noise problems associated with zero-IF topology. By using Low -IF for Bluetooth application, it will solve these previous drawbacks.

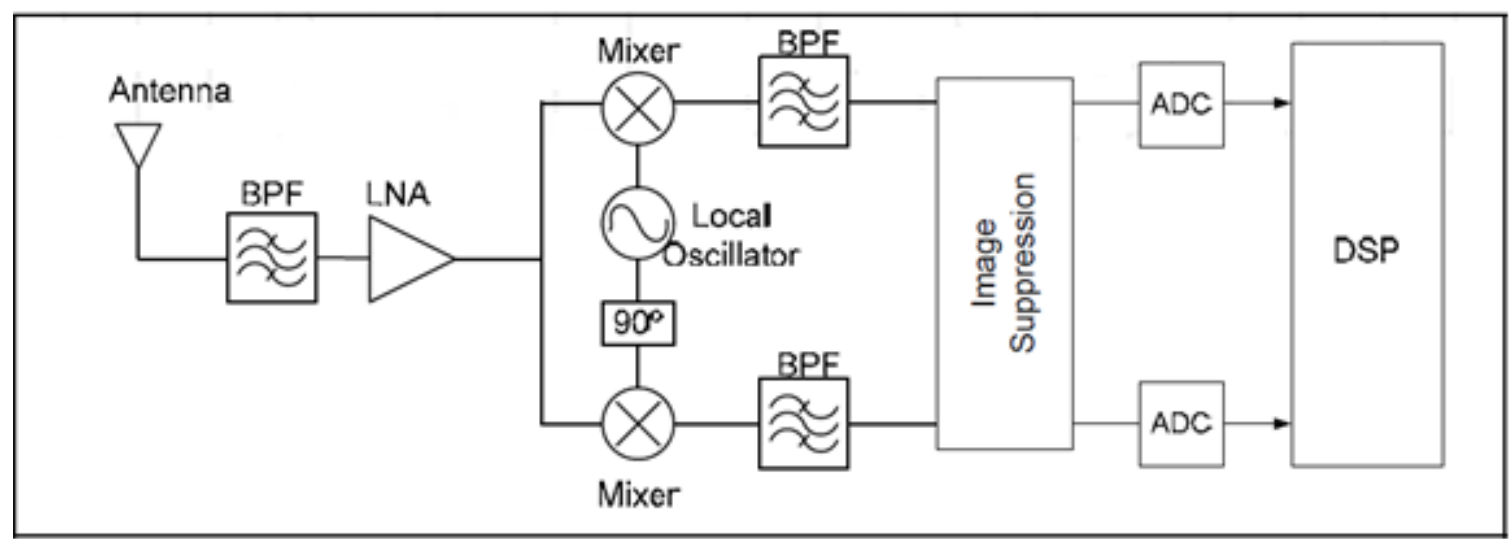

Figure 2: Low IF Receiver 
Figure 2 is a low IF receiver in which the RF signal is mixed down to a nonzero low or moderate IF (few hundred $\mathrm{kHz}$ to several $\mathrm{MHz}$ ) instead of going directly to $\mathrm{DC}$ as in Zero IF receiver, using quadrature RF down-conversion. Like zero-IF receiver, the received signal passes through a channel-selection filter at RF and is amplified by a Low Noise Amplifier (LNA). After this step, the signal is down converted to a low IF, instead of zero IF , and used an image suppression block in order to cancel the negative effects from frequency image. Finally, an ADC converts the signal to digital domain.

Although Low-IF receiver does not suffer from the DC problems, since the desired signal is not situated around DC, Low-IF suffers from problems of image signal, which can be larger sometimes than the wanted signal. On the other hand, there are two techniques to solve this problem which are by using quadrature mixer or by using polyphase (complex) filter. Using polyphase filter, three advantages can be obtained:

- The frequency response of a polyphase filter depends on the phase difference between its two input signals, therefore it has a passband response for the target signal and an attenuating response for the image signal

- The bandpass response is symmetrical around the passband's center frequency, independent of its Q. (The frequency response of conventional low-Q bandpass filters is not symmetrical around the passband's center frequency).

- For the same degree of image suppression, the matching of polyphase filter components is less stringent than the required matching in separate IF filters and in the subsequent image rejecter. 


\subsection{Polyphase ( Complex) Filter}

Active complex (polyphase) filters are renewed as they provide the solution for image rejection in low-IF wireless applications such as Bluetooth (BT) receiver [1]-[13]. To understand the ability of complex filters in rejecting the image signal, the complex representation of the receiver block diagram shown in Figure 3 is considered. For the sake of illustration, it is assumed that only the desired signal and its image are present at the mixer input. Assume the signal and the image frequencies are $\omega_{L O}+\omega_{I F}$ and $\omega_{L O}-\omega_{I F}$, respectively. After eliminating the double LO frequency term by the mixer output lowfrequency pole, the result of mixing the LO and RF signals in the complex domain can be expressed as:

$$
B=G_{\text {mixer }}\left(X_{\text {sig }} e^{j w_{i f} t}+X_{\text {image }} e^{-j w_{i f} t}\right)=B_{I}+j B_{Q}
$$

Where $B_{I}$ and $B_{Q}$ are the real and imaginary parts of the mixer output given by:

$$
\begin{aligned}
& B_{I}=G_{\text {mixer }}\left(X_{\text {sig }} \cos \left(w_{\text {if }} t\right)+X_{\text {image }} \cos \left(w_{\text {if }} t\right)\right) \\
& B_{Q}=G_{\text {mixer }}\left(X_{\text {sig }} \sin \left(w_{\text {if }} t\right)-X_{\text {image }} \sin \left(w_{\text {if }} t\right)\right)
\end{aligned}
$$

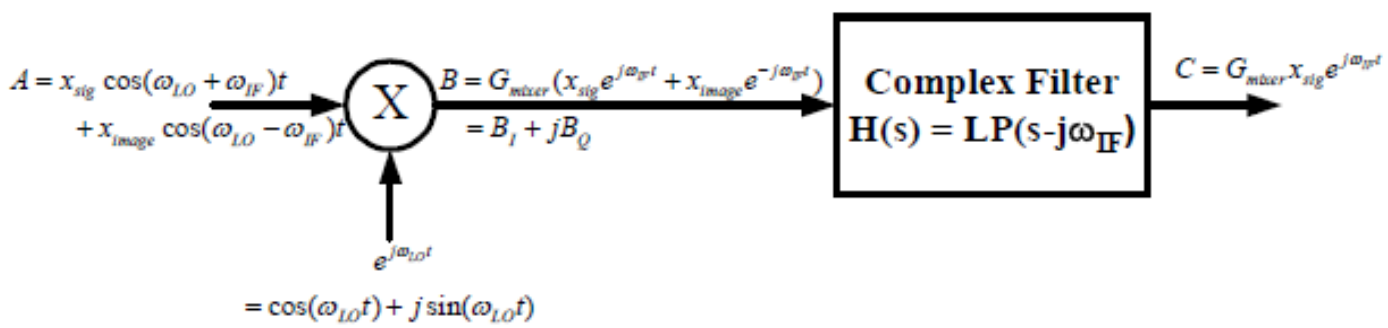

Figure 3: Image rejection architecture in the complex domain 
Note that in the above equation the desired (image) signal in the I branch leads (lags) the $\mathrm{Q}$ branch by $90^{\circ}$. Figure 4 illustrates the complex mixing operation on the desired signal and its image. Note that after down-conversion, the $2 \omega_{\mathrm{IF}}$ frequency separation between the signal and the image is still preserved. The complex channel select filter is then a frequency-shifted version of a low pass filter response. This means that the filter can pass the signal at $\omega=\omega_{I F}$, while attenuating the signal at $\omega=-\omega_{I F}$. Since the filter has unsymmetrical frequency response around the $j \omega$ axis, its time domain response is complex. However, the complex filter frequency response is symmetrical around the $\omega_{I F}$. Since the blocking specifications of a receiver are symmetrical around the desired signal frequency, this is considered an advantage of complex filter over real BPF that has unsymmetrical frequency response around its center frequency. 


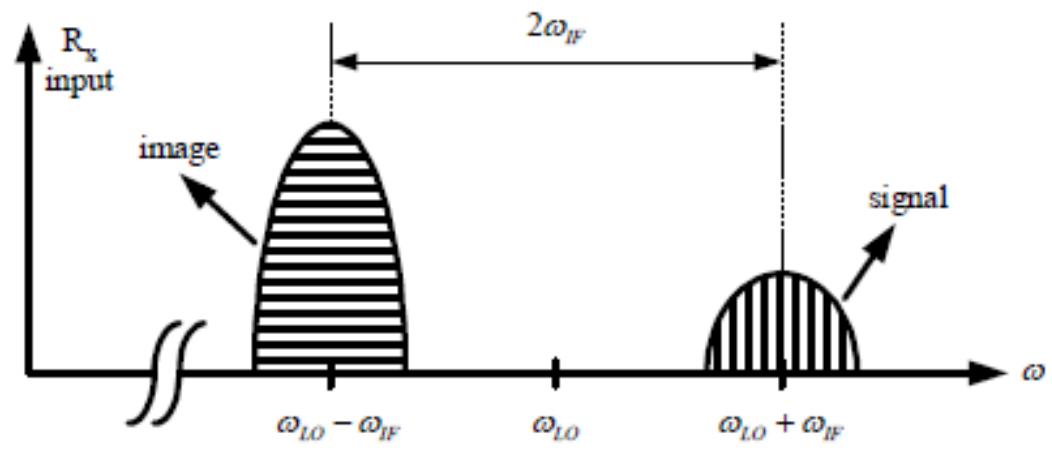

(a)

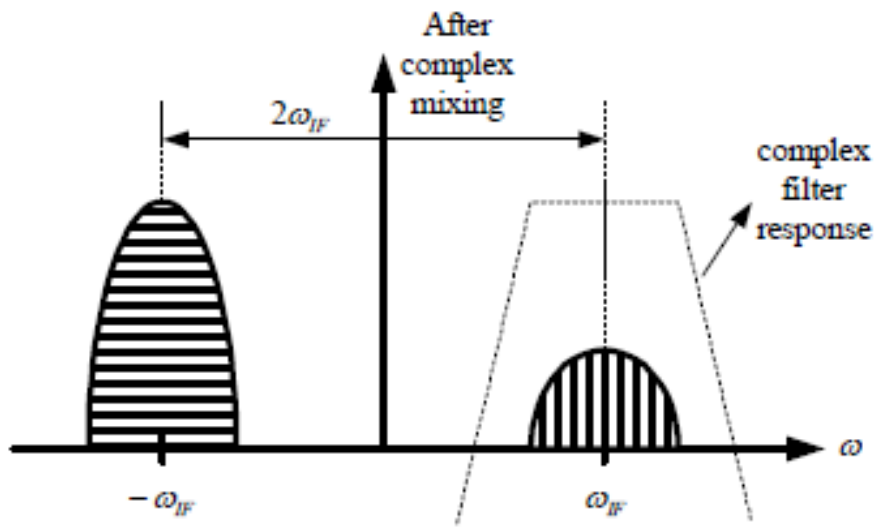

Figure 4: Frequency translation of a complex (quadrature) mixer: (a) before mixing (b) after mixing.

\subsection{Main Characteristics}

Developing filters exhibiting low power, small size and large dynamic range for wireless applications has been under extensive research for the past decade. As mentioned earlier, Active complex (known also as polyphase) filters are of particular interest as they, unlike traditional filters, perform image rejection in addition to filtering. Indeed, they are renewed to provide solutions for image rejection in low-IF wireless applications such as Bluetooth receiver [1]-[13]. Using active polyphase filters in receivers reduces 
component count, and hence provides low power and cost-efficient solution. The low power application Active complex filters can be designed based on various amplifier types. In fact, complex filters utilizing active- $\mathrm{RC}, \mathrm{Gm}-\mathrm{C}$, or current mode techniques have been suggested. The main important filter characteristics include dynamic range, power consumption, frequency range, and area.

Dynamic range can be defined as the ratio between maximum signal amplitude that can be processed by the filter to the total internal noise of the filter. The other main important characteristic is power consumption. In fact, power is considered as the most important constraint in embedded systems. Minimizing the power consumption in the system is important for longer battery life. In addition to above two main important characteristic, frequencies range and design area are considered as main characteristics of the design. The mentioned characteristics will be explained in details in this thesis and will be used in comparison between active- $\mathrm{RC}, \mathrm{Gm}-\mathrm{C}$, or current mode techniques to show optimal low power complex filters.

\subsection{Goal of Research}

The objectives of this work are as follows:

- To develop several new complex filters based on transconductance amplifier (TCA), transresistance amplifier (TRA) and CAs.

- Comparison between the different complex filters in term of power consumption, noise analysis and dynamic range.

- Verify the operation of the best proposed filter with simulations 


\subsection{Thesis Organization}

The following chapter presents summary of the literature survey and the research methodology. Chapter 3 discusses the general characteristics of possible solutions. Chapter 4 presents the proposed approach and consequently shows the design of several new complex filters. Chapter 5 compares the proposed solutions in order to converge to optimal designs through assessments of power, non-ideal frequency operation (parasitic poles). Also, it provides comparison between the two best filters in terms of large signal limitations and noise. Moreover, it gives a comprehensive noise analysis of the final complex selected filter. Finally simulation results are given in Chapter 6. 


\section{CHAPTER 2}

\section{LITERATURE REVIEW}

\subsection{Available Solutions}

Several polyphase filter realizations based on the second generation current conveyors (CCIIs), current feedback amplifiers (CFAs), current amplifiers (CAs) and current mirrors can, for example, be found in [14]-[25]. These filters can be classified based on their synthesis method into three categories: element substitution techniques of LC prototypes ([1]-[3], [6]-[9], [13]-[15], and [24]-[25]), cascading of first-order complex sections ([16]-[21] and [23]), and cascading of second-order complex biquads ([4]-[5], [10]-[12] and [22]).

Complex filters based on LC simulation often use extensive number of active devices. For example, the filter in [8] employs 30 transconductance amplifiers (TCAs) to realize $5^{\text {th }}$ order filter while $32,48,66$ TCAs were respectively incorporated to achieve $3^{\text {rd }}, 5^{\text {th }}$, $9^{\text {th }}$ order complex responses in [9]. In fact, it is found that the most efficient design among this category requires "3.7” TCAs per pole [1] (please refer to Table II in Chapter 5 for more details). Whereas, the first-order filters of [18]-[19], [21], and [23] are found to require only two devices. However, such filters would exhibit poor stopband attenuation since they are obtained from their first-order LPF counterpart having quality factor of one-half. Consequently, redundant sections would be needed to satisfy the selectivity requirement of a given application. On the other hand, the complex biquad filters 
suggested in [4]-[5], [10], [11], [12], and [22] incorporate 12 TCAs, 4 op-amps, 8 opamps, 4 op-amps, and 10 CCIIs, respectively. It can be observed that adopting 4 devices per complex biqaud section represents the most efficient solution since a complex integrator requires at least two active elements (one per path). This may also imply that other filtering techniques such as those based on inductor simulation or gyrator cannot be more efficient. Since active-RC filters require large current to operate at IF frequencies [10]-[12], filters based on CCII and CA are mainly presented, since despite some limitations they have more degrees of freedom for design because gain and bandwidth are independent [26]-[27]. In conclusion, the first-order filters and LC simulation filters are not efficient to be used compare to second order filters so according to Table I which is the comparison between recent published complex filters, research methodology will be presented . 
Table 1: Comparison between recent complex filters

\begin{tabular}{|c|c|c|c|c|c|c|c|c|c|}
\hline Ref. & $\begin{array}{l}\text { Technology } \\
\text { (Technique) }\end{array}$ & $\begin{array}{c}\text { Approach } \\
\qquad \& \\
\text { Total Devices }\end{array}$ & Order & $\begin{array}{c}f_{c}(\mathrm{MHz}) \\
\& \\
\text { Bandwidth } \\
\text { (MHz) }\end{array}$ & $\begin{array}{l}\text { Noise } \\
\left(\mathbf{V}_{\text {rms }}\right)\end{array}$ & $\begin{array}{l}\text { IRR } \\
(\mathbf{d B})\end{array}$ & $\begin{array}{l}\text { Area } \\
\left(\mathrm{mm}^{2}\right)\end{array}$ & $\begin{array}{c}\text { Supply } \\
\text { (V) }\end{array}$ & $\begin{array}{l}\text { Power } \\
(\mathrm{mW})\end{array}$ \\
\hline$[1]-[3]$ & $\begin{array}{c}0.35 \mu \mathrm{m} \text { CMOS } \\
(\mathrm{gm}-\mathrm{C})\end{array}$ & $\begin{array}{c}\text { LC prototype } \\
\& \\
\text { (26 TCAs) }\end{array}$ & 7 & $\begin{array}{l}3 \\
\& \\
1\end{array}$ & $170 \mu$ & $>53$ & 0.374 & 2.3 & 7.36 \\
\hline$[4]-[5]$ & $\begin{array}{c}0.35 \mu \mathrm{m} \text { CMOS } \\
(\mathrm{gm}-\mathrm{C})\end{array}$ & $\begin{array}{c}\text { Biquad } \\
\& \\
36 \text { TCAs }\end{array}$ & 6 & $\begin{array}{l}2 \\
\& \\
1\end{array}$ & $29 \mu$ & $>45$ & 1.68 & 2.7 & 12.7 \\
\hline [6] & $\begin{array}{c}0.18 \mu \mathrm{m} \text { CMOS } \\
(\mathrm{gm}-\mathrm{C})\end{array}$ & $\begin{array}{c}\text { LC prototype } \\
\& \\
30 \text { TCAs }\end{array}$ & 5 & $\begin{array}{c}1 \\
\& \\
1.17\end{array}$ & $50.4 \mu$ & $>48$ & 0.23 & 1.2 & 1 \\
\hline $\begin{array}{l}\text { [7] } \\
\text { Fig. } 13\end{array}$ & $\begin{array}{c}0.35 \mu \mathrm{m} \\
\text { BiCMOS } \\
(\mathrm{gm}-\mathrm{C})\end{array}$ & $\begin{array}{c}\text { LC prototype } \\
\& \\
48 \text { TCAs }\end{array}$ & 6 & $\begin{array}{c}2 \\
\& \\
1.06\end{array}$ & $46 n$ & $>45.7$ & NA & 1.2 & 10.9 \\
\hline $\begin{array}{c}\text { [7] } \\
\text { Fig. } 17\end{array}$ & $\begin{array}{c}0.35 \mu \mathrm{m} \\
\text { BiCMOS } \\
\text { (Log domain) }\end{array}$ & $\begin{array}{c}\text { LC prototype } \\
\& \\
\text { NA }\end{array}$ & 6 & $\begin{array}{c}2 \\
\& \\
0.81\end{array}$ & $48 n$ & $>46$ & NA & 1.2 & 15.4 \\
\hline [11] & $\begin{array}{c}0.18 \mu \mathrm{m} \text { CMOS } \\
\text { (Active-RC) }\end{array}$ & $\begin{array}{c}\text { Biquad } \\
\qquad \\
16\end{array}$ & 4 & $\begin{array}{l}2 \\
\& \\
1\end{array}$ & $46 \mu$ & $>52$ & 0.2 & 1.8 & 5.4 \\
\hline [12] & $\begin{array}{c}0.09 \mu \mathrm{m} \text { CMOS } \\
\text { (Active-RC) }\end{array}$ & $\begin{array}{c}\text { Biquad } \\
\& \\
12\end{array}$ & 6 & $\begin{array}{l}1 \\
\& \\
1\end{array}$ & $130 \mu$ & 33 & NA & 0.6 & 6 \\
\hline [13] & $\begin{array}{c}0.09 \mu \mathrm{m} \text { CMOS } \\
(\mathrm{gm}-\mathrm{C})\end{array}$ & $\begin{array}{c}\text { LC prototype I } \\
\qquad \\
18\end{array}$ & 3 & $\begin{array}{l}2 \\
\& \\
2\end{array}$ & $2.1 \mu$ & 30 & NA & 1.2 & 1.2 \\
\hline
\end{tabular}




\begin{tabular}{|c|c|c|c|c|c|c|c|c|c|}
\hline [13] & $\begin{array}{c}0.09 \mu \mathrm{m} \text { CMOS } \\
(\mathrm{gm}-\mathrm{C})\end{array}$ & $\begin{array}{c}\text { LC prototype II } \\
\qquad \begin{array}{c}\& \\
18\end{array}\end{array}$ & 3 & $\begin{array}{l}2 \\
\& \\
2\end{array}$ & $2.1 \mu$ & 30 & NA & 1.2 & 1.2 \\
\hline [14] & $\begin{array}{c}0.18 \mu \mathrm{m} \text { CMOS } \\
(\mathrm{gm}-\mathrm{C})\end{array}$ & $\begin{array}{c}\text { LC prototype } \\
\qquad \\
32\end{array}$ & 5 & $\begin{array}{l}2 \\
\& \\
2.4\end{array}$ & NA & $>45$ & 1.37 & 1.8 & 8.8 \\
\hline [15] & $\begin{array}{c}0.35 \mu \mathrm{m} \text { CMOS } \\
(\mathrm{gm}-\mathrm{C})\end{array}$ & $\begin{array}{c}\text { LC prototype } \\
\qquad \\
18\end{array}$ & 3 & $\begin{array}{l}1 \\
\& \\
1\end{array}$ & $18.5 \mu$ & $>28$ & NA & 3.3 & 6.9 \\
\hline [23] & $\begin{array}{c}0.18 \mu \mathrm{m} \text { CMOS } \\
(\mathrm{CA}-\mathrm{RC})\end{array}$ & $\begin{array}{c}\text { First-order } \\
\qquad \begin{array}{c}\& \\
12\end{array}\end{array}$ & 6 & $\begin{array}{l}3 \\
\& \\
1\end{array}$ & $89 \mu$ & $>54$ & 0.61 & 2.7 & 2.38 \\
\hline $\begin{array}{c}\text { [24]-[25] } \\
\text { Fig. } 9\end{array}$ & $\begin{array}{l}0.35 \mu \mathrm{m} \text { CMOS } \\
\text { (current mirror- } \\
\text { C) }\end{array}$ & $\begin{array}{c}\text { LC prototype } \\
\qquad \begin{array}{c} \\
24\end{array}\end{array}$ & 6 & $\begin{array}{c}2 \\
\& \\
1.6-2.5\end{array}$ & $1.2 \mathrm{~m}$ & 28.2 & NA & 1.5 & 4.71 \\
\hline $\begin{array}{c}{[24]-[25]} \\
\text { Fig. } 10\end{array}$ & $\begin{array}{l}0.35 \mu \mathrm{m} \text { CMOS } \\
\text { (current mirror- } \\
\text { C) }\end{array}$ & $\begin{array}{c}\text { LC prototype } \\
\qquad \\
60\end{array}$ & 6 & $\begin{array}{c}2 \\
\& \\
1.62-2.4\end{array}$ & $1.66 \mathrm{~m}$ & 27.9 & NA & 1.5 & 7.2 \\
\hline
\end{tabular}

\subsection{Research Methodology}

Developments of complex filters with low power consumptions and large dynamic range are investigated. As mentioned earlier, the all techniques other than current-mode active elements are not appropriate to design complex filter due to limited linearity or required more power so the new complex filters will be based on transconductance amplifier (TCA), transresistance amplifier (TRA) and CAs. CCII is utilized for their realizations to have fair comparison at device levels. It reveals that the current-mode filters based on 
TCAs or CAs are inherently capable of offering the lowest power consumption. The basic diagram of the proposed complex filter will be explained in chapter 4 . It shows that two complex integrators can be used in cascade to develop two integrator loop complex filters hence it will be the research basis to develop the proposed complex filters. 


\section{CHAPTER 3}

\section{POSSIBLE SOLUTIONS}

\subsection{Active- RC vs Gm-C Filter}

This section will discuss and explain the drawback of utilizing active-RC and Gm-C techniques.

\subsubsection{Active-RC Filter}

A typical first-order differential, active-RC filter, often known as an integrator, is shown in Figure 5. It requires capacitors $(\mathrm{C})$, resistors $(\mathrm{R})$, and an operational amplifier (opamp). The transfer function of an ideal integrator is given by Equation (3.1). An ideal integrator provides an infinite gain at DC and has a single pole frequency response. However, the finite gain $\left(a_{0}\right)$ and the finite gain-bandwidth product $(G B W)$ of an opamp moves the

dominant pole of the integrator from $\mathrm{DC}$ to $\frac{\omega_{0}}{a_{0}}=\omega_{\alpha}$, assuming that the $G B W$ of the opamp is higher than the pole frequency $\left(\omega_{0}\right)$ of the integrator. The modified magnitude and phase response of a non-ideal integrator are shown in Figure 6.a and Figure 6.b, respectively.

$$
H_{\text {int }}(s)=\frac{1}{s R C}=\frac{-\omega_{o}}{s}
$$




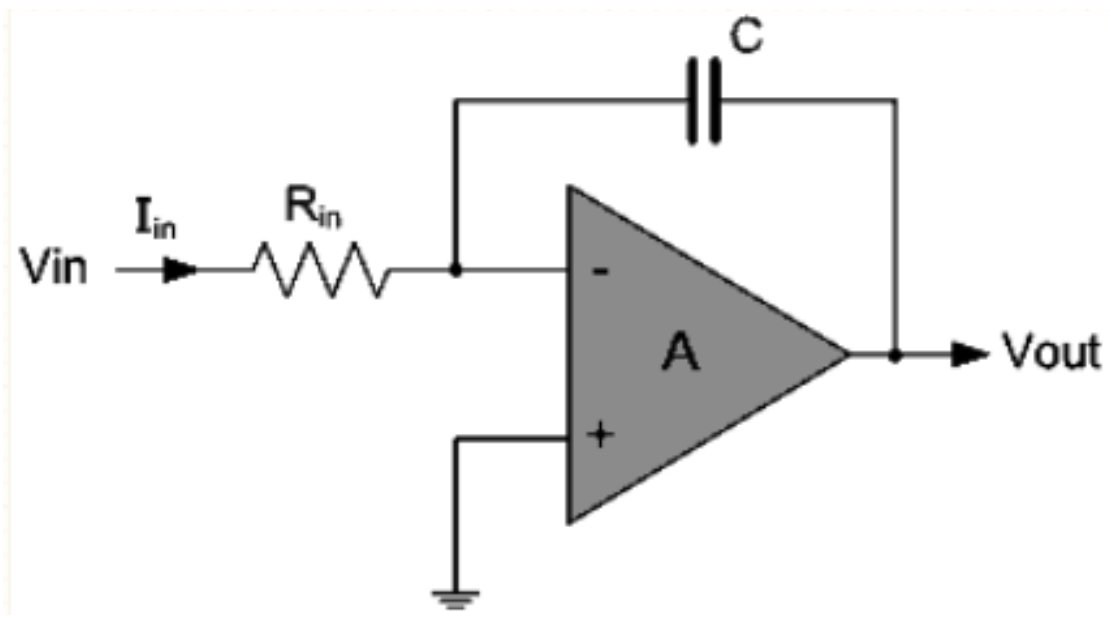

Figure 5: First-order Active-RC Filter
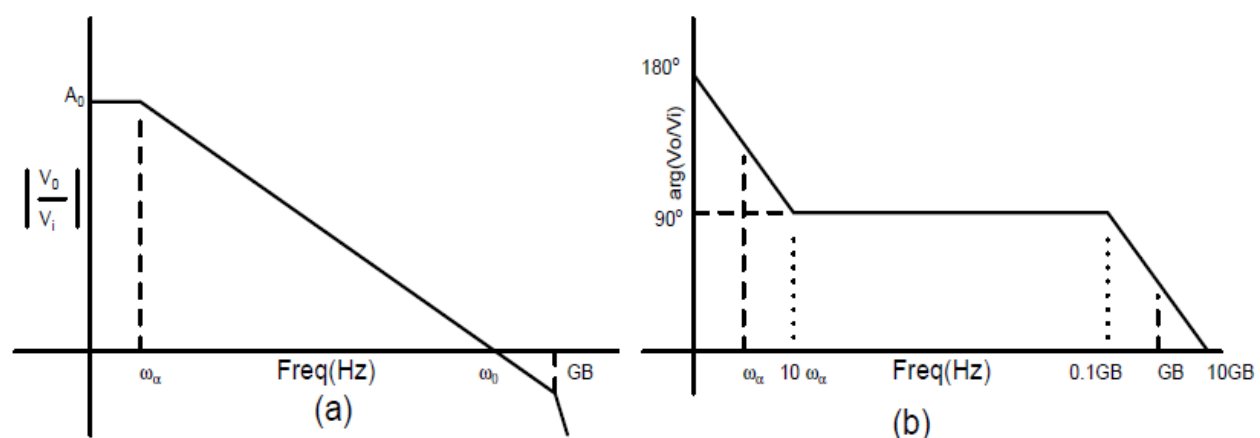

(b)

Figure 6: a) Frequency response of a non-ideal integrator; b) phase response of a non-ideal integrator

A non-ideal integrator performs as an integrator for the frequency range between $10 \times \omega_{o}$ and $\omega_{o}$, where $\omega_{o}<G B W / 10$. If this inequality is not met, then the integrator response will be limited to $10 \times \omega_{\alpha}$ and GBW/10. The non-zero finite pole ( $\left.\omega_{\alpha}\right)$ of the non-ideal integrator causes a phase lead, whereas non-dominant high-frequency poles of the opamp causes an excess phase lag. They cancel each other in the middle; however, at high frequency, the excess phase lag dominates and can bring instability to the system. Thus, the maximum operating frequency of this topology is limited to $\omega_{o}$ or $G B W / 10$. 
Opamps are compensated for a signal pole response up to $G B W$ to simplify their use in different applications. However, the compensating capacitor also limits their slew rate, which could potentially introduce distortion to the large signals. For example: A sinusoidal signal given by $v(t)=A_{0} \sin (\omega t)$ will require a minimum slew rate of $\mathrm{A}_{0} \times$ $\omega$. Thus, for a given slew-rate amplifier, the product of the maximum signal handling capacity and the maximum operating frequency is fixed. The maximum signal handling capacity can also be restricted by the power supply. An active-RC filter implementation is primarily used for discrete or low-frequency applications. Accordingly, active-RC approach can provide high dynamic range but it required large current to operate at IF frequency due to the op-amp constant gain bandwidth product problem.

\subsubsection{Gm-C Filter}

The $\mathrm{Gm}-\mathrm{C}$ architecture (Figure 7) is widely used to implement wide dynamic range, high-frequency, continuous-time filters. In this architecture, resistor and inductors are

emulated using active transconductors. A transconductor operates at higher frequency than an opamp for a given current, as it does not require an internal capacitive compensation and a low-impedance output stage. Opamps have a high impedance stage to generate gain, followed by a low- impedance output stage, so they can drive voltage with sufficient current. In the $\mathrm{Gm}-\mathrm{C}$ architecture, active transconductors replace the passive resistors and inductors of a filter. They are primarily used to convert an input voltage into an output current; therefore, they have a high-impedance output stage. Since these transconductors do not require an additional low-impedance output stage, they can use that extra current to bias their input stage for extra linearity or to save power so in 
general Gm-C filters are suitable for moderate and high frequency applications but they usually suffer from poor linearity which came from the non-linearity of input stage of the $\mathrm{Gm}-\mathrm{C}$ filter and hence limited dynamic range .So some configuration is required to be at input stage of the Gm-C to cancel the transistor non linearity but this solution will affect other characteristics.

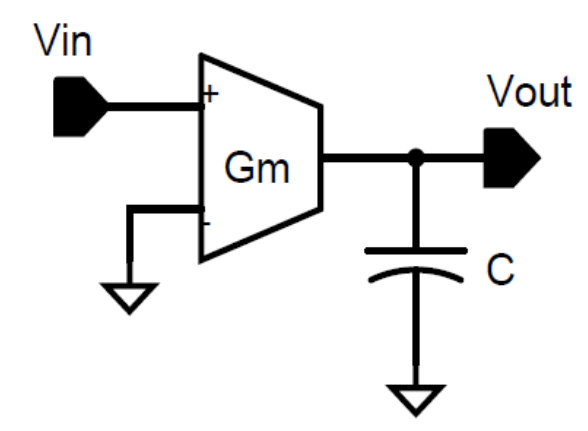

Figure 7: An Gm-C implementation of an integrator

\subsection{Current- Mode Active Elements}

Current-mode active elements like the second generation current conveyor (CCII) and the current feedback amplifier can both provide attractive characteristics such as wide frequency range, high linearity, high slew rate and simple circuitry [28]. Therefore, it is proposed to investigate all possible complex filter structures based on transconductance amplifier (TCA), transresistance amplifier (TRA) and current amplifier (CAs) in order to identify the optimum low power filters design. Then, the other characteristics of the optimum designs will be evaluated and possible solutions to enhance their performances will be addressed. Actually, all filters were published as described in literature review are obtain from their first order LPF counterpart and Higher order complex filter obtain 
from cascading first order section with exhibit low quality factor. As explained below for first order complex filter that the quality factor will be less than $1 / 2$.Thus, they exhibit poor stopband attenuation.

As of Figure 8, assume there are redundant sections of first order complex filter hence the characteristic equations of each section as follows:

$$
\begin{aligned}
& 1^{\text {st }} \text { section: } H_{1}(s)=\frac{a_{1}}{\left(s-j \omega_{c}\right)+\omega_{o 1}} \\
& 2^{\text {nd }} \text { section: } H_{2}(s)=\frac{a_{2}}{\left(s-j \omega_{c}\right)+\omega_{o 2}}
\end{aligned}
$$

So the characters equation of a complete $2^{\text {nd }}$ order filter is:

$$
\begin{aligned}
& H_{1}(s) * H_{2}(s)=\frac{a_{1} a_{2}}{\left(s-j \omega_{c}\right)^{2}+\left(s-j \omega_{c}\right)\left(\omega_{o 1}+\omega_{o 2}\right)+\omega_{o 1} \omega_{o 2}} \\
& \omega_{o}^{2}=\omega_{o 1} \omega_{o 2} \& \frac{\omega_{o}}{Q}=\omega_{o 1}+\omega_{o 2}
\end{aligned}
$$

Accordingly, $Q=\frac{\sqrt{\omega_{01} \omega_{o 2}}}{\omega_{o 1}+\omega_{o 2}} \leq \frac{1}{2}$

Consequently, redundant sections would be needed to satisfy the selectivity requirement of a given application. This would result in excessive power consumption and relatively high noise. A more efficient design solution starts with developing complex lossless integrators. Then, they are utilized to develop complex filters based on two-integrator loop topologies. This work presents several new complex filters based on transconductance amplifier (TCA), transresistance amplifier (TRA) and (CAs). CCII is utilized for their realization to have common ground for fair comparison. It is revealed that the current-mode filters based on TCAs or CAs are inherently capable of offering the lowest power consumption. The filter based on CAs enjoys the inherent advantage of true current mode signal processing. Two section of this filter are used in cascade to perform channel selection in low-IF BT receiver. 


\section{CHAPTER 4}

\section{PROPOSED FILTERS}

\subsection{Proposed Approach}

A systematic procedure is followed to develop the proposed filters starting from basic complex integrator. An arbitrary normal integrator with time constant of $\tau=1 / \omega o$ can be converted to a complex integrator when every frequency dependent element in the original integrator is modified to be a function of $s-j \omega c$ instead of $s$ as shown in Figure 8(a). In practice, the complex frequency multiplication by $j \omega c$, is realized by cross coupling between the In-phase (I) and Quadrature (Q) paths of the filter as shown in Figure $8(\mathrm{~b})$. It can be shown that the transfer characteristics are given by:

$$
\frac{X_{o I}}{X_{I}}=\frac{X_{o Q}}{X_{Q}}=\frac{\omega_{o}}{s-j \omega_{c}}
$$

Where input and output variables can be voltage or current signals. The time constant of the complex integrator is $\tau$, same as the original integrator. 


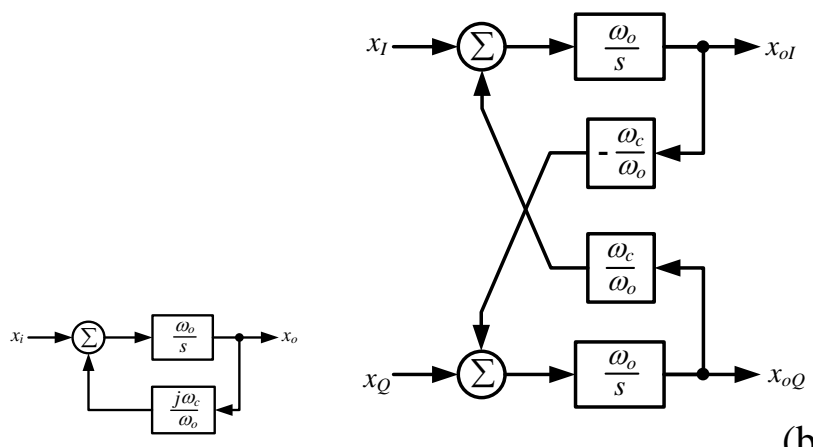

(a)

(b)

Figure 8: Frequency shifting: (a) Basic concept (b) Realization

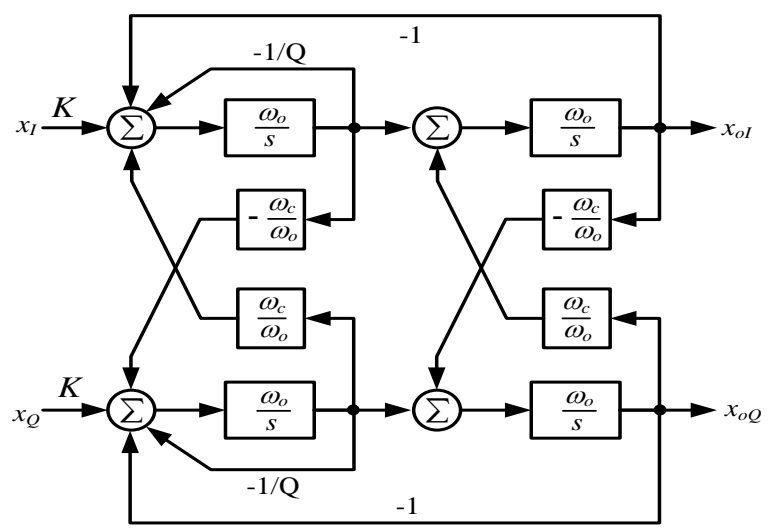

Figure 9: A block diagram of the two-integrator-loop complex filter

Two complex integrators can be used in cascade to develop two integrator loop complex filters as shown in Figure 9. The transfer function of figure 9 can be found as follows:

At input point of I path first stage :

$$
\begin{aligned}
& X_{1}=\left[K X_{I}-X_{o I}-\frac{X_{1}}{Q}+\frac{\omega_{c}}{\omega_{o}} X_{2}\right] \frac{\omega_{o}}{s} \\
& X_{1} \frac{s}{\omega_{o}}+\frac{X_{1}}{Q}=K X_{I}-X_{O I}+\frac{\omega_{c}}{\omega_{o}} X_{2}
\end{aligned}
$$


$X_{1}\left(\frac{s}{\omega_{o}}+\frac{1}{Q}\right)=K X_{I}-X_{o I}+\frac{\omega_{c}}{\omega_{o}} X_{2}$

Where $\mathrm{K}$ is a gain factor.

At input point of I path second stage:

$$
\begin{aligned}
& X_{O I}=\left(X_{1}+X_{O Q} \frac{\omega_{c}}{\omega_{o}}\right) \frac{\omega_{o}}{s} \\
& X_{1}=\frac{s}{\omega_{o}} X_{O I}-X_{O Q} \frac{\omega_{c}}{\omega_{o}}
\end{aligned}
$$

At input point of Q path second stage:

$$
\begin{aligned}
& X_{O Q}=\left(X_{2}-X_{O I} \frac{\omega_{c}}{\omega_{o}}\right) \frac{\omega_{o}}{s} \\
& X_{2}=\frac{s}{\omega_{o}} X_{O Q}+X_{O I} \frac{\omega_{c}}{\omega_{o}}
\end{aligned}
$$

Substitute (4.3) \& (4.4) in (4.2) with $X_{o Q}=j X_{o I}$, we will get

$$
\begin{aligned}
& \left(\frac{s}{\omega_{o}} X_{O I}-j X_{O I} \frac{\omega_{c}}{\omega_{o}}\right)\left(\frac{s}{\omega_{o}}+\frac{1}{Q}\right)=K X_{I}-X_{O I}+\frac{\omega_{c}}{w_{o}}\left(\frac{s}{\omega_{o}} j X_{O I}+X_{O I} \frac{\omega_{c}}{\omega_{o}}\right) \\
& X_{O I}\left(\frac{s^{2}}{\omega_{o}^{2}}+\frac{s}{\omega_{o} Q}-j \frac{s \omega_{c}}{\omega_{o}^{2}}-j \frac{\omega_{c}}{\omega_{o} Q}+1-j \frac{s \omega_{c}}{\omega_{o}^{2}}-\frac{\omega_{c}^{2}}{\omega_{o}^{2}}\right)=K X_{I}
\end{aligned}
$$

Multiply by $\omega_{o}^{2}$, we get

$$
X_{O I}\left[\left(s-j \omega_{c}\right)^{2}+\left(s-j \omega_{c}\right) \frac{\omega_{o}}{Q}+\omega_{o}^{2}\right]=K \omega_{o}^{2} X_{I}
$$


So the corresponding transfer functions of figure 9 is given by,

$$
\frac{X_{o I}}{X_{I}}=\frac{K \omega_{o}{ }^{2}}{\left(s-j \omega_{c}\right)^{2}+\left(s-j \omega_{c}\right) \frac{\omega_{o}}{Q}+\omega_{o}{ }^{2}}
$$

The complex bandpass filter given by (4.5) exhibits a center frequency of $\omega_{c}$, pole frequency of $\omega_{o}$, pole quality factor of $\mathrm{Q}$. Since the equation of complex bandpass filter is same as lowpass with the frequency shift of $\omega_{c}$ so its bandwidth will be double the bandwidth of the original lowpass filter which is $2 \omega_{o} / \mathrm{Q}$ ( Bandwith of low pass filter is $\left.\omega_{o} / \mathrm{Q}\right)$. The non-inverting integrators in Figure 9 can be replaced by inverting ones. However, maintaining proper negative feedback would require changing the sign of the feedback factor (1/Q).

It is essential for integrated continuous time filters to be associated with tunable parameters in order to achieve accurate frequency characteristics and compensate for process variations and temperature effects. The parameter $\omega_{c}$ and $\omega_{o}$ are functions of RC products which cannot be implemented accurately in ICs. On the other hand, Q is usually a function of resistor and/or capacitor ratios that can be implemented precisely. Therefore, it is desired to design the filters with independent control of $\omega_{c}$ and/or $\omega_{o}$ without changing quality factor $\mathrm{Q}$ since the bandwidth decrease with increase $\mathrm{Q}$. The tuning requirement of a complex filter depends on the nature of RC terms involved in $\omega_{c}$ and $\omega_{o}$. For the case when $\omega_{c}$ and $\omega_{o}$ have same RC product terms (identical relative error), it is sufficient to have common tuning scheme. However, when expressions of $\omega_{c}$ and $\omega_{o}$ have different RC products, then they would need separate tuning. Hence, the former case requires simpler automatic tuning schemes. In other words, it is sufficient 
and simpler to design of $\omega_{c}$ and $\omega_{o}$ have same RC products as well as independent from Q to avoid decrease of Bandwidth.

The image rejection ratio (IRR) of a complex filter obtained from two integrator loop topology can be expressed as:

$I R R=\left|\frac{\text { Signal }}{\text { Imagine }}\right|$, where signal substitute $s=j \omega_{c}$ and imagine substitute $s=-j \omega_{c}$

$I R R=\left|\frac{K}{\frac{K \omega_{o}^{2}}{\left(-2 j \omega_{c}\right)^{2}+\left(-2 j \omega_{c}\right) \frac{\omega_{o}}{Q}+\omega_{o}^{2}}}\right|$

$I R R=\sqrt{\left(1+4\left(\frac{\omega_{c}}{\omega_{o}}\right)^{2}\right)^{2}+\left(\frac{4}{Q^{2}}\right)\left(\frac{\omega_{c}}{\omega_{o}}\right)^{2}}$

Therefore, selecting higher center frequency for BT improves the IRR. On the other hand, it can be shown that the ideal image rejection ratio (IRR) of any complex filter obtained from first-order LPF is given by:

$I R R=\sqrt{1+4\left(\frac{\omega_{c}}{\omega_{o}}\right)^{2}}$

This means that the complex filters obtained from their biquad counterparts inherently exhibit better IRR than two cascaded stages of first-order. For example, the pole frequency fo is set to $1.43 \mathrm{MHz}$ for each section in [23] such that the overall bandwidth of a six stage design becomes $1 \mathrm{MHz}$. This leads to a nominal IRR per stage of $12.7 \mathrm{~dB}$. Whereas, the IRR of a second-order Butterworth biquad $(f o=0.5 \mathrm{MHz})$ is $43.3 \mathrm{~dB}$. 


\subsection{Toward Low Power Designs}

This section investigates the compatibility of various amplifier types with voltage-mode and current-mode complex filter designs. Realizations are given based on the CCII to allow comparison at device level. CCII is considered one of the most versatile current mode devices as it can be configured as TCA, TRA and CA. CCII is practically attractive because it can operate at higher frequency band than the op amp and provide better linearity than transconductance amplifier (gm) [29]. Basically, CCII is a voltage buffer (VB) whose output is sensed and conveyed to current output terminal Z. The terminal characteristics of the CCII can be described by $I_{y}=0, V_{x}=V_{y}, I_{x}=I_{z}$.

To realize a voltage mode cascadable integrator, the circuit has to have high input impedance and/or low output impedance. High input impedance integrator can be realized using the TCA whereas low output impedance design can be developed using the op-amp or TRA. The CA is not suitable to realize voltage mode cascadable circuits since its input and output impedances are low and high, respectively.

In the case of adopting the TCA (a CCII whose $\mathrm{X}$ terminal is loaded with a resistor) to realize voltage-mode complex integrator, an additional TCA (per path) would be required to realize the complex feedback loop. The voltage-mode complex filter based on such integrator is shown in Figure 10. Eight CCIIs are used to form the two complex integrators while four (two in each path) to implement the original negative feedbacks. Positive type CCII realizes non-inverting integrator while negative type CCII (often realized from positive type CCII with help of cross-couple current mirrors) is usually 
used in single-ended circuits to provide signal inversions. In fully differential topologies, signals are inverted through cross coupling between the positive and negative paths. This not only eliminates the need of inverters but also permit the selection of the device type associated with lowest power.

In the following sub-sections, alternative designs of complex filters will be presented to be compared then propose the optimal low power filter design.

\subsubsection{Voltage-mode Complex Filter Based TCA Realized with Single Output CCIIs}

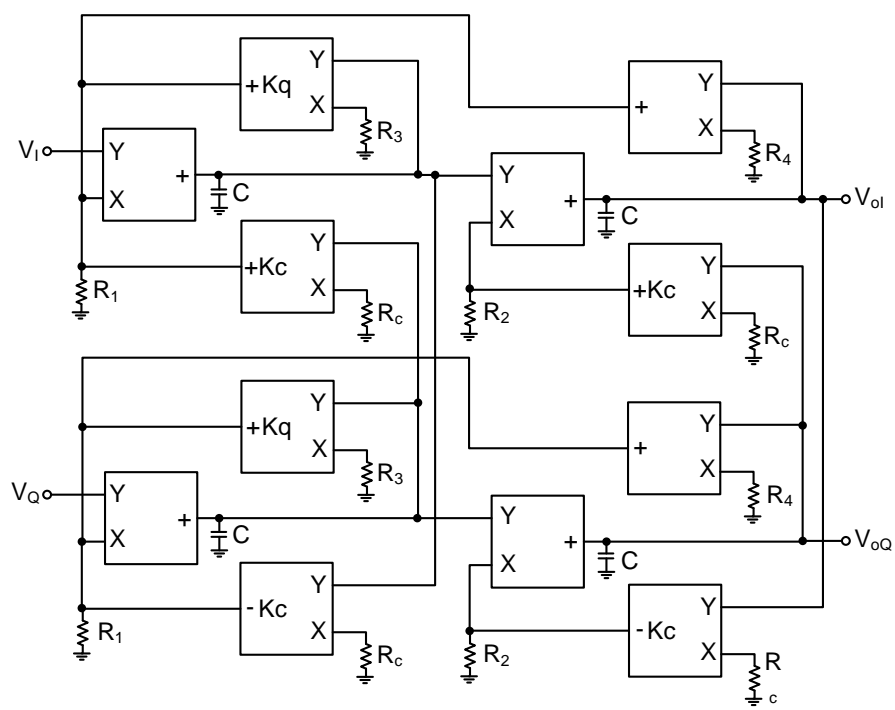

Figure 10: Voltage-mode complex filter based TCA realized with single output CCIIs

To find out the characteristic equation of Figure 10:

KCL at input point of I path first stage ;

$\operatorname{cs}_{x}=\frac{V_{I}}{R_{1}}-V_{x} \frac{K_{q}}{R_{3}}-\frac{V_{o I}}{R_{4}}+V_{y} \frac{K_{c}}{R_{c}}$ 
$V_{x}\left(c s+\frac{K_{q}}{R_{3}}\right)=\frac{V_{I}}{R_{1}}-\frac{V_{o I}}{R_{4}}+V_{y} \frac{K_{c}}{R_{c}}$

$\mathrm{KCL}$ at input point of Q path second stage ;

$\operatorname{csV}_{o Q}=\frac{V_{y}}{R_{2}}-V_{o I} \frac{K_{c}}{R_{C}}$

$V_{y}=R_{2} c s V_{o Q}+V_{o I} \frac{K_{c} R_{2}}{R_{c}}$

Substitute (4.9) in (4.8), we found

$V_{x}\left(c s+\frac{K_{q}}{R_{3}}\right)=\frac{V_{I}}{R_{1}}-\frac{V_{o I}}{R_{4}}+\frac{K_{c}}{R_{c}} R_{2} c s V_{o Q}+V_{o I} \frac{K_{c}{ }^{2} R_{2}}{R_{C}{ }^{2}}$

And $V_{o Q}=j V_{o I}$

$V_{x}\left(c s+\frac{K_{q}}{R_{3}}\right)=\frac{V_{I}}{R_{1}}-\frac{V_{o I}}{R_{4}}+\frac{K_{c}}{R_{c}} R_{2} c s j V_{o I}+V_{o I} \frac{K_{c}{ }^{2} R_{2}}{R_{c}{ }^{2}}$

KCL at input point of I path second stage ;

$c s V_{o I}=\frac{V_{x}}{R_{2}}+V_{o Q} \frac{K_{c}}{R_{c}}$

$V_{x}=R_{2} V_{o I}\left(c s-j \frac{K_{c}}{R_{c}}\right)$

Substitute (4.11) in (4.10)

$$
\begin{gathered}
R_{2} V_{o I}\left(c s-j \frac{K_{c}}{R_{c}}\right)\left(c s+\frac{K_{q}}{R_{3}}\right)=\frac{V_{I}}{R_{1}}-\frac{V_{o I}}{R_{4}}+\frac{K_{c}}{R_{c}} R_{2} c s j V_{o I}+V_{o I} \frac{K_{c}{ }^{2} R_{2}}{R_{c}{ }^{2}} \\
V_{o I}\left(R_{2} c^{2} s^{2}+K_{q} \frac{R_{2}}{R_{3}} c s-j K_{c} \frac{R_{2}}{R_{c}} c s-j K_{c} K_{q} \frac{R_{2}}{R_{3} R_{c}}\right) \\
=\frac{V_{I}}{R_{1}}+V_{o I}\left(-\frac{1}{R_{4}}+j \frac{K_{c}}{R_{c}} R_{2} c s+\frac{K_{c}{ }^{2} R_{2}}{R_{c}{ }^{2}}\right)
\end{gathered}
$$




$$
\begin{aligned}
V_{O I}\left(R_{2} c^{2} s^{2}+\right. & \left.K_{q} \frac{R_{2}}{R_{3}} c s-j K_{c} \frac{R_{2}}{R_{c}} c s-j K_{c} K_{q} \frac{R_{2}}{R_{3} R_{c}}+\frac{1}{R_{4}}-j \frac{K_{c}}{R_{c}} R_{2} c s-\frac{K_{c}{ }^{2} R_{2}}{R_{c}{ }^{2}}\right) \\
& =\frac{V_{I}}{R_{1}}
\end{aligned}
$$

Divide by $R_{2} c^{2}$, we got

$$
\begin{aligned}
V_{o I}\left(s^{2}+K_{q}\right. & \left.\frac{1}{R_{3} c} s-j K_{c} \frac{1}{R_{c} c} s-j K_{c} K_{q} \frac{1}{R_{3} R_{c} c^{2}}+\frac{1}{R_{4} R_{2} c^{2}}-j \frac{K_{c}}{R_{c} c} s-\frac{K_{c}{ }^{2}}{R_{c}{ }^{2} c^{2}}\right) \\
& =\frac{V_{I}}{R_{1} R_{2} c^{2}}
\end{aligned}
$$$$
V_{o I}\left(\left[s^{2}-2 j K_{c} \frac{1}{R_{c} c} s-\frac{K_{c}^{2}}{{R_{c}}^{2} c^{2}}\right]+K_{q} \frac{1}{R_{3} c}\left[s-j K_{c} \frac{1}{R_{c} c}\right]+\frac{1}{R_{4} R_{2} c^{2}}\right)=\frac{V_{I}}{R_{1} R_{2} c^{2}}
$$

And let $\omega_{c}=K_{c} \frac{1}{R_{c} c}$

$$
\frac{V_{o I}}{V_{I}}=\frac{\frac{1}{R_{1} R_{2} c^{2}}}{\left(s-j \omega_{c}\right)^{2}+\left(s-j \omega_{c}\right) \frac{K_{q}}{R_{3} c}+\frac{1}{R_{4} R_{2} c^{2}}}
$$

Hence, the filter exhibits center frequency, pole frequency, pole quality factor and gain of $\omega_{c}=K_{c} / C R_{c}, \omega_{o}=\frac{1}{C \sqrt{R_{2} R_{4}}}, Q_{o}=\frac{R_{3}}{K_{q} \sqrt{R_{2} R_{4}}}$ and $R_{4} / R_{1}$, respectively. It is possible to change this filter to active-C topology. This can be achieved by replacing CCII by CCCII [30]. In this case, the passive resistors would be replaced by the internal resistance of the $\mathrm{X}$ terminals of the CCCII. Although active-C topologies may save silicon area they would degrade the linearity performance. 


\subsubsection{Modified Filter of Figure 10 Utilizing Multi-output CCIIs}

Adopting multi-output CCIIs, allow the utilization of the CCIIs in the negative feedback to form the complex loops as shown in Figure 11.

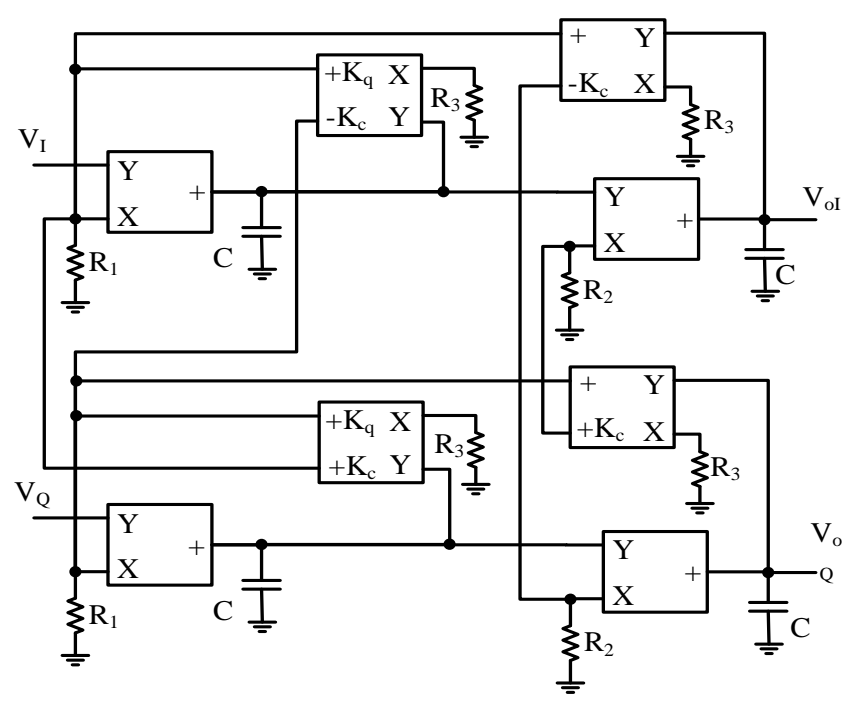

Figure 11: Modified filter of Figure 10 utilizing multi-output CCIIs

To find out the characteristic equation of Figure 11:

KCL at input point of I path first stage ;

$\operatorname{cs} V_{x}=\frac{V_{I}}{R_{1}}-V_{x} \frac{K_{q}}{R_{3}}-\frac{V_{o I}}{R_{3}}+V_{y} \frac{K_{c}}{R_{3}}$

$V_{x}\left(c s+\frac{K_{q}}{R_{3}}\right)=\frac{V_{I}}{R_{1}}-\frac{V_{o I}}{R_{3}}+V_{y} \frac{K_{c}}{R_{3}}$

$\mathrm{KCL}$ at input point of I path second stage ;

$c s V_{o I}=\frac{V_{x}}{R_{2}}+V_{o Q} \frac{K_{c}}{R_{3}}$ 


$$
V_{x}=R_{2} V_{o I}\left(c s-j \frac{K_{c}}{R_{3}}\right)
$$

KCL at input point of Q path second stage ;

$$
\begin{aligned}
& c s V_{o Q}=\frac{V_{y}}{R_{2}}-V_{o I} \frac{K_{c}}{R_{3}} \\
& V_{y}=R_{2} c s V_{o Q}+V_{o I} \frac{K_{c} R_{2}}{R_{3}}
\end{aligned}
$$

Now substitute (4.14) \& (4.15) in (4.13) and let $V_{o Q}=j V_{O I}$

$$
\begin{gathered}
R_{2} V_{o I}\left(c s-j \frac{K_{c}}{R_{3}}\right)\left(c s+\frac{K_{q}}{R_{3}}\right)=\frac{V_{I}}{R_{1}}-\frac{V_{o I}}{R_{3}}+\frac{K_{c}}{R_{3}} R_{2} c s j V_{o I}+V_{o I} \frac{K_{c}{ }^{2} R_{2}}{R_{3}{ }^{2}} \\
V_{o I}\left(R_{2} c^{2} s^{2}+K_{q} \frac{R_{2}}{R_{3}} c s-j K_{c} \frac{R_{2}}{R_{3}} c s-j K_{c} K_{q} \frac{R_{2}}{R_{3}{ }^{2}}\right) \\
=\frac{V_{I}}{R_{1}}+V_{o I}\left(-\frac{1}{R_{3}}+j \frac{K_{c}}{R_{3}} R_{2} c s+\frac{K_{c}{ }^{2} R_{2}}{R_{3}{ }^{2}}\right) \\
V_{O I}\left(R_{2} c^{2} s^{2}+K_{q} \frac{R_{2}}{R_{3}} c s-j K_{c} \frac{R_{2}}{R_{3}} c s-j K_{c} K_{q} \frac{R_{2}}{R_{3}{ }^{2}}+\frac{1}{R_{3}}-j \frac{K_{c}}{R_{3}} R_{2} c s-\frac{K_{c}{ }^{2} R_{2}}{R_{3}{ }^{2}}\right)=\frac{V_{I}}{R_{1}}
\end{gathered}
$$

Divide by $R_{2} c^{2}$, we got

$$
\begin{gathered}
V_{o I}\left(s^{2}+K_{q} \frac{1}{R_{3} c} s-j K_{c} \frac{1}{R_{3} c} s-j K_{c} K_{q} \frac{1}{R_{3}{ }^{2} c^{2}}+\frac{1}{R_{3} R_{2} c^{2}}-j \frac{K_{c}}{R_{3} c} s-\frac{K_{c}{ }^{2}}{R_{3}{ }^{2} c^{2}}\right) \\
=\frac{V_{I}}{R_{1} R_{2} c^{2}} \\
V_{O I}\left(\left[s^{2}-2 j K_{c} \frac{1}{R_{3} c} s-\frac{K_{c}{ }^{2}}{R_{3}{ }^{2} c^{2}}\right]+K_{q} \frac{1}{R_{3} c}\left[s-j K_{c} \frac{1}{R_{3} c}\right]+\frac{1}{R_{3} R_{2} c^{2}}\right)=\frac{V_{I}}{R_{1} R_{2} c^{2}}
\end{gathered}
$$


And let $\omega_{c}=K_{c} \frac{1}{R_{3} c}$ so It can be shown that the transfer function of the filter is given by:

$$
\frac{V_{o I}}{V_{I}}=\frac{\frac{1}{R_{1} R_{2} c^{2}}}{\left(s-j \omega_{c}\right)^{2}+\left(s-j \omega_{c}\right) \frac{K_{q}}{R_{3} c}+\frac{1}{R_{3} R_{2} c^{2}}}
$$

Hence, the filter exhibits center frequency, pole frequency, pole quality factor and gain of $\omega_{c}=K_{c} / C R_{3}, \omega_{o}=\frac{1}{C \sqrt{R_{2} R_{3}}}, \quad Q_{o}=\frac{R_{3}}{K_{q} \sqrt{R_{2} R_{3}}}$, and $R_{3} / R_{1}$, respectively. Since two integrator loop filters require at least two active devices, minimum of four devices are needed for complex structure. Thus, it is clear that the filter of Figure 10 still uses excessive number of active devices.

In fact, a complex voltage mode integrator can be realized with a single device only if it has both low output impedance and input virtual ground to facilitate the addition of the feedback signals. These two features are inherently available only in the TRA comprising low output impedance terminal and virtual ground input terminal. Without the virtual grounds the voltage signals must be first changed to current (additional devices) to allow proper addition otherwise the resulted integrator would not be lossless. A possible option to realize this toplogy through utilizing op-amp based inverting integrators is [10]. But the circuit would not be attractive for IF ranges due to limited gain bandwidth (GB) product of the op-amp. Alternatively, a TRA can be realized with a CCII whose Yterminal is grounded plus a VB connected between $\mathrm{Z}$ and the output terminal. The $\mathrm{X}$ terminal can be used as an input current terminal with low impedance for a CCII with grounded $\mathrm{Y}$ (equivalently $\mathrm{CF}$ or $\mathrm{CA}$ ), while it acts as an output terminal when the CCII is 
configured as a VB. Such configuration may better be represented by CFAs (CCII plus VB), known to exhibit independent gain bandwidth characteristics [31]. A complex filter developed through utilizing this configuration is shown in Figure 12.

\subsubsection{Voltage-mode Complex Filter Based on TRA realized with CFA}

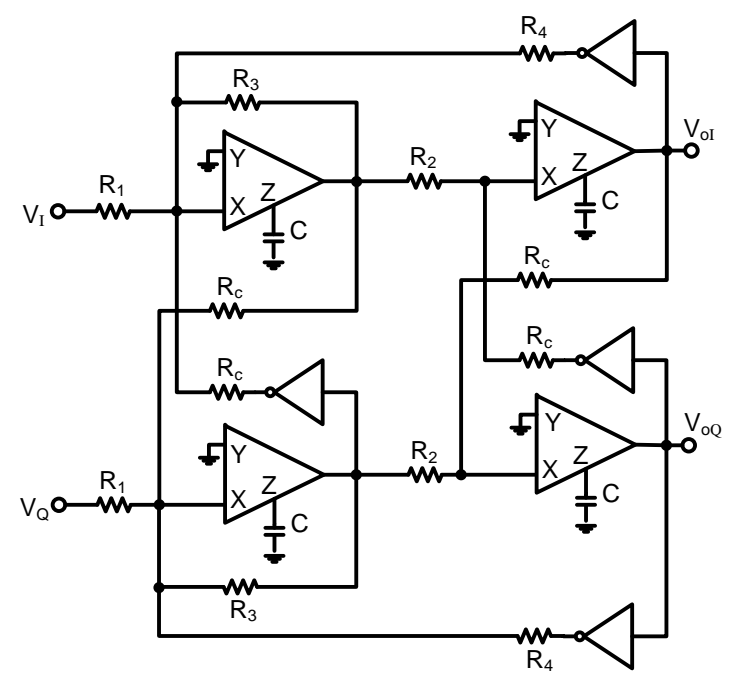

Figure 12: Voltage-mode complex filter based on TRA realized with CFA (CCII+VB)

To find out the characteristic equation of Figure 12:

KCL at input point of I path first stage;

$$
\begin{aligned}
& c s V_{x}=\frac{V_{I}}{R_{1}}-\frac{V_{x}}{R_{3}}-\frac{V_{o I}}{R_{4}}+\frac{V_{y}}{R_{c}} \\
& V_{x}\left(c s+\frac{1}{R_{3}}\right)=\frac{V_{I}}{R_{1}}-\frac{V_{o I}}{R_{4}}+\frac{V_{y}}{R_{c}}
\end{aligned}
$$

KCL at input point of I path second stage;

$$
\operatorname{cs} V_{o I}=\frac{V_{x}}{R_{2}}+\frac{V_{o Q}}{R_{3}}
$$




$$
V_{x}=R_{2} V_{o I}\left(c s-j \frac{1}{R_{3}}\right)
$$

KCL at input point of Q path first stage;

$$
\begin{aligned}
& c s V_{o Q}=\frac{V_{y}}{R_{2}}-\frac{V_{o I}}{R_{c}} \\
& V_{y}=R_{2} V_{o I}\left(j c s+\frac{1}{R_{3}}\right)
\end{aligned}
$$

Substitute (4.18) \& (4.19) in (4.17)

$$
\begin{aligned}
& R_{2} V_{O I}\left(c s-j \frac{1}{R_{c}}\right)\left(c s+\frac{1}{R_{3}}\right)=\frac{V_{I}}{R_{1}}-\frac{V_{o I}}{R_{4}}+\frac{R_{2}}{R_{c}} V_{o I}\left(j c s+\frac{1}{R_{3}}\right) \\
& V_{O I}\left(R_{2} c^{2} s^{2}+\frac{R_{2}}{R_{3}} c s-j \frac{R_{2}}{R_{c}} c s-j \frac{R_{2}}{R_{3} R_{c}}\right)=\frac{V_{I}}{R_{1}}+V_{o I}\left(-\frac{1}{R_{4}}+j \frac{R_{2}}{R_{c}} c s+\frac{R_{2}}{R_{c}{ }^{2}}\right) \\
& V_{O I}\left(R_{2} c^{2} s^{2}+\frac{R_{2}}{R_{3}} c s-j \frac{R_{2}}{R_{c}} c s-j \frac{R_{2}}{R_{3} R_{c}}+\frac{1}{R_{4}}-j \frac{R_{2}}{R_{c 3}} c s+\frac{R_{2}}{R_{c}{ }^{2}}\right)=\frac{V_{I}}{R_{1}}
\end{aligned}
$$

Divide by $R_{2} c^{2}$, we got

$$
\begin{aligned}
& V_{O I}\left(s^{2}+\frac{1}{R_{3} c} s-j \frac{1}{R_{c} c} s-j \frac{1}{R_{3} R_{c} c^{2}}+\frac{1}{R_{4} R_{2} c^{2}}-j \frac{1}{R_{c} c} s-\frac{1}{R_{c}{ }^{2} c^{2}}\right)=\frac{V_{I}}{R_{1} R_{2} c^{2}} \\
& V_{O I}\left(\left[s^{2}-2 j \frac{1}{R_{c} c} s-\frac{1}{R_{c}{ }^{2} c^{2}}\right]+\frac{1}{R_{3} c}\left[s-j \frac{1}{R_{c} c}\right]+\frac{1}{R_{4} R_{2} c^{2}}\right)=\frac{V_{I}}{R_{1} R_{2} c^{2}}
\end{aligned}
$$

And let $\omega_{c}=\frac{1}{R_{c} c}$

$$
\frac{V_{o I}}{V_{I}}=\frac{\frac{1}{R_{1} R_{2} c^{2}}}{\left(s-j w_{c}\right)^{2}+\left(s-j w_{c}\right) \frac{1}{R_{3} c}+\frac{1}{R_{4} R_{2} c^{2}}}
$$


Hence, the filter exhibits center frequency, pole frequency, pole quality factor and gain of $\omega_{C}=1 / C R_{C}, \omega_{o}=\frac{1}{C \sqrt{R_{2} R_{4}}}, Q_{o}=\frac{R_{3}}{\sqrt{R_{2} R_{4}}}$, and $R_{4} / R_{1}$, respectively.

On the other hand, it is more efficient to realize current mode cascadable complex integrators with high output impedances rather than with low input impedances. This is because the later case would require additional devices in order to realize the complex feedback loops. Since signal addition of currents unlike voltage signals does not require virtual grounds, it can be observed that two amplifier types namely TCA and CA can efficiently develop the current mode complex integrator of Figure 8. They allow the utilization of the basic device of the integrator to realize the complex feedback loop just by using an additional current output per device. The first current-mode complex filter is shown in Figure 13. It is based on four CCII but each having three current outputs. The filter can be utilized in cascade designs since it has high output impedances. In addition, like the filter of Figure 10, this structure allows the replacement of CCII by CCCII if desired. 


\subsubsection{A Novel Current-mode Complex Filter Based on TCA Realized with CCIIs}

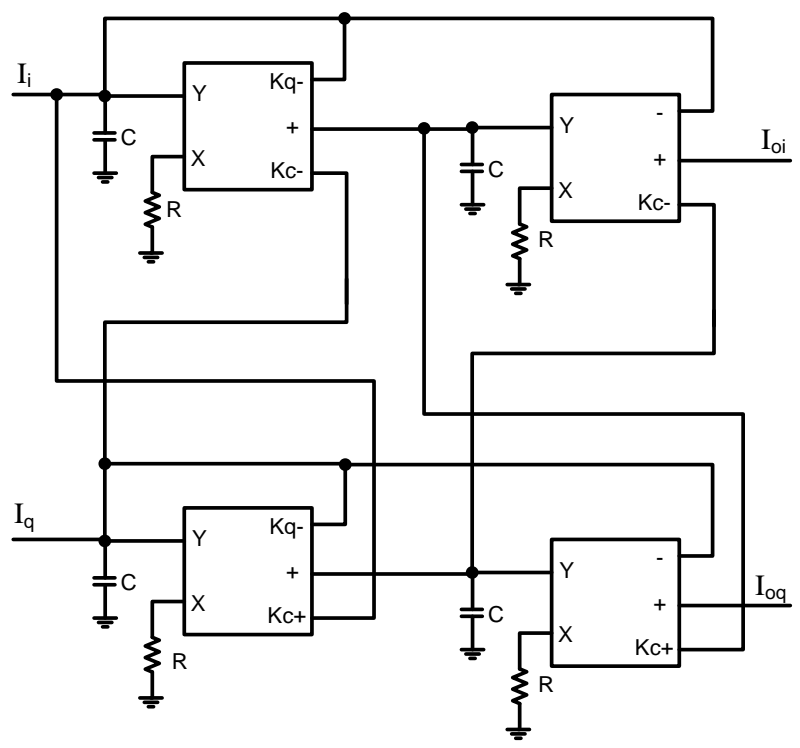

Figure 13: A novel current-mode complex filter based on TCA realized with CCIIs

To find out the characteristic equation of Figure 13:

KCL at input point of I path first stage;

$$
\begin{aligned}
& I_{x}=\frac{1}{R c s}\left(I_{i}-K_{q} I_{x}-I_{o i}+K_{c} I_{y}\right) \\
& R c s I_{x}+K_{q} I_{x}=I_{i}-I_{o i}+K_{c} I_{y} \\
& I_{x}\left(R c s+K_{q}\right)=I_{i}-I_{o i}+K_{c} I_{y}
\end{aligned}
$$

KCL at input point of I path second stage;

$$
\begin{gathered}
\operatorname{Rcs}_{o i}=I_{x}+K_{c} I_{o q} \\
I_{x}=R c s I_{o i}-K_{c} I_{o q} \\
I_{x}=R c s I_{o i}-j K_{c} I_{o i}
\end{gathered}
$$


$\mathrm{KCL}$ at input point of Q path second stage;

$$
\begin{aligned}
& R c s I_{o q}=I_{y}-K_{c} I_{o i} \\
& I_{y}=j R c s I_{o i}+K_{c} I_{o i}
\end{aligned}
$$

Sub (4.22) \& (4.23) in (4.21)

$$
I_{o i}\left(R c s-j K_{c}\right)\left(R c s+K_{q}\right)=I_{i}-I_{o i}+K_{c} I_{o i}\left(j R c s+K_{c}\right)
$$

$I_{o i}\left(R^{2} c^{2} s^{2}+K_{q} R c s-j K_{c} R c s-j K_{c} K_{q}\right)=I_{i}-I_{o i}+I_{o i}\left(j K_{c} R c s+K_{c}{ }^{2}\right)$

$$
I_{o i}\left(R^{2} c^{2} s^{2}+K_{q} R c s-j K_{c} R c s-j K_{c} K_{q}+1-j K_{c} R c s-K_{c}^{2}\right)=I_{i}
$$

Divide by $R^{2} c^{2}$, we got

$$
\begin{aligned}
& I_{o i}\left(s^{2}+\frac{K_{q} s}{R c}-\frac{j K_{c} s}{R c}-\frac{j K_{c} K_{q}}{R^{2} c^{2}}+\frac{1}{R^{2} c^{2}}-\frac{j K_{c} s}{R c}-\frac{K_{c}{ }^{2}}{R^{2} c^{2}}\right)=\frac{I_{i}}{R^{2} c^{2}} \\
& I_{o i}\left[\left(s^{2}-\frac{2 j K_{c} s}{R c}-\frac{K_{c}{ }^{2}}{R^{2} c^{2}}\right)+\left(\frac{K_{q} s}{R c}-\frac{j K_{c} K_{q}}{R^{2} c^{2}}\right)+\frac{1}{R^{2} c^{2}}\right]=\frac{I_{i}}{R^{2} c^{2}}
\end{aligned}
$$


Let $\omega_{c}=\frac{K_{c}}{R c}$, we got

$I_{o i}\left[\left(s-j \omega_{c}\right)^{2}+\left(s-j \omega_{c}\right) \frac{K_{q}}{R c}+\frac{1}{R^{2} c^{2}}\right]=\frac{I_{i}}{R^{2} c^{2}}$

$\frac{I_{o i}}{I_{i}}=\frac{\frac{1}{R^{2} c^{2}}}{\left(s-j \omega_{c}\right)^{2}+\left(s-j \omega_{c}\right) \frac{K_{q}}{R c}+\frac{1}{R^{2} c^{2}}}$

Hence, the filter exhibits center frequency, pole frequency, pole quality factor and gain of $\omega_{c}=K_{C} / C R, \omega_{o}=\frac{1}{C R}, Q_{o}=\frac{1}{K_{q}}$, and unity, respectively.

Unlike the cascadable current mode integrator based on CCII, developing its counterpart based on CA is more involved. Basically, there are two alternatives. The first option is through applying the input current at the X-terminal and connecting a shunt integrating capacitor at the output terminal $\mathrm{Z}$ to perform integration. Then, the voltage of the capacitor is converted again to an output current using voltage to current converter. A more efficient realization is obtained via converting the lossy current mode passive integrator to a lossless cascadable topology with the help of dual output CA. Utilizing a third output current terminal, the desired complex integrator is developed as shown in Figure 14. The input virtual ground is utilized to sense the current in the resistor whereas the three outputs with gains $K_{u}=1, K_{c}, K_{f}$ are utilized for converting the integrators from lossy to lossless, realizing the complex loops and cascading, respectively. 


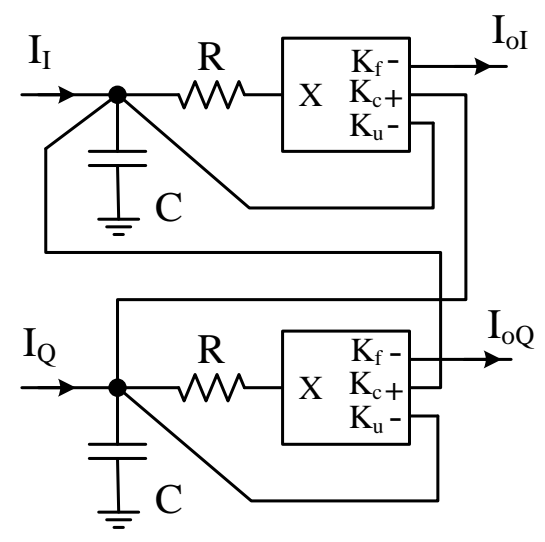

Figure 14: A novel current-mode complex integrator based on CAs

\subsubsection{A Novel Current-mode Complex Filter Based on CAs}

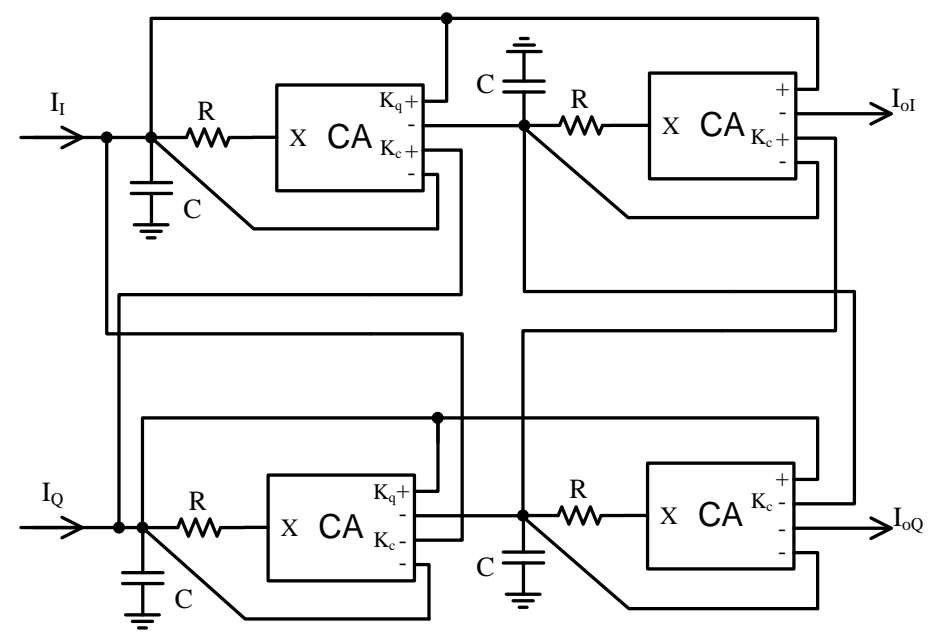

Figure 15: A novel current-mode complex filter based on CAs

To find out the characteristic equation of Figure 15:

KCL at input point of I path first stage;

$I_{x}=\frac{1}{R c S}\left(I_{i}-K_{q} I_{x}-I_{o i}+K_{c} I_{y}\right)$ 


$$
\begin{aligned}
& R c s I_{x}+K_{q} I_{x}=I_{i}-I_{o i}+K_{c} I_{y} \\
& I_{x}\left(R c s+K_{q}\right)=I_{i}-I_{o i}+K_{c} I_{y}
\end{aligned}
$$

KCL at input point of I path second stage;

$$
\begin{aligned}
& \operatorname{RcsI}_{o i}=I_{x}+I_{o i}-I_{o i}+K_{c} I_{o q} \\
& I_{x}=\operatorname{RcsI}_{o i}-K_{c} I_{o q} \\
& I_{x}=\operatorname{RcsI}_{o i}-j K_{c} I_{o i} \\
& I_{x}=I_{o i}\left(R c s-j K_{c}\right)
\end{aligned}
$$

KCL at input point of Q path second stage;

$$
\begin{aligned}
& R c s I_{o q}=I_{y}-K_{c} I_{o i} \\
& I_{y}=j R c s I_{o i}+K_{c} I_{o i} \\
& I_{y}=I_{o i}\left(j R c s+K_{c}\right)
\end{aligned}
$$

Sub (4.26) \& (4.27) in (4.25)

$$
I_{o i}\left(R c s-j K_{c}\right)\left(R c s+K_{q}\right)=I_{i}-I_{o i}+K_{c} I_{o i}\left(j R c s+K_{c}\right)
$$




$$
\begin{aligned}
& I_{o i}\left(R^{2} c^{2} s^{2}+K_{q} R c s-j K_{c} R c s-j K_{c} K_{q}\right)=I_{i}-I_{o i}+I_{o i}\left(j K_{c} R c s+K_{c}{ }^{2}\right) \\
& I_{o i}\left(R^{2} c^{2} s^{2}+K_{q} R c s-j K_{c} R c s-j K_{c} K_{q}+1-j K_{c} R c s-K_{c}{ }^{2}\right)=I_{i}
\end{aligned}
$$

Divide by $R^{2} c^{2}$, we got

$$
\begin{aligned}
& I_{o i}\left(s^{2}+\frac{K_{q} s}{R c}-\frac{j K_{c} s}{R c}-\frac{j K_{c} K_{q}}{R^{2} c^{2}}+\frac{1}{R^{2} c^{2}}-\frac{j K_{c} s}{R c}-\frac{K_{c}{ }^{2}}{R^{2} c^{2}}\right)=\frac{I_{i}}{R^{2} c^{2}} \\
& I_{o i}\left[\left(s^{2}-\frac{2 j K_{c} s}{R c}-\frac{K_{c}{ }^{2}}{R^{2} c^{2}}\right)+\left(\frac{K_{q} s}{R c}-\frac{j K_{c} K_{q}}{R^{2} c^{2}}\right)+\frac{1}{R^{2} c^{2}}\right]=\frac{I_{i}}{R^{2} c^{2}}
\end{aligned}
$$

Let $\omega_{c}=\frac{K_{c}}{R c}$, we got

$$
I_{o i}\left[\left(s-j \omega_{c}\right)^{2}+\left(s-j \omega_{c}\right) \frac{K_{q}}{R c}+\frac{1}{R^{2} c^{2}}\right]=\frac{I_{i}}{R^{2} c^{2}}
$$

The corresponding complex filter is shown in Figure 15. It can be shown that the transfer function of the filter is given by:

$$
\frac{I_{o i}}{I_{i}}=\frac{\frac{1}{R^{2} c^{2}}}{\left(s-j \omega_{c}\right)^{2}+\left(s-j \omega_{c}\right) \frac{K_{q}}{R c}+\frac{1}{R^{2} c^{2}}}
$$

Hence, the filter exhibits center frequency, pole frequency, pole quality factor and gain of $\omega_{c}=K_{c} / C R, \omega_{o}=\frac{1}{C R}, Q_{o}=\frac{1}{K_{q}}$ and unity, respectively. 


\section{CHAPTER 5}

\section{OPTIMAL DESIGN}

\subsection{Assessment of Various Designs}

A simple high performance low power CMOS realization of the CCII is shown in Figure 16. It consists of classical two stage op-amp configured as a buffer whose output current is sensed by current mirror transistors and conveyed to the high output terminal $\mathrm{Z}$. Connecting the opamp in unity feedback loop exploits the maximum possible bandwidth of the opamp. To avoid distortion caused by the body effect and ensure almost zero offset voltage between terminals $\mathrm{Y}$ and $\mathrm{X}$, a differential pair is employed as input stage of the CCII. A class AB output stage, consisting of level shifter M9 and M10 and gain stage of M11 and M12, is employed. Transistors M7 and M8 are used to control the standby current of the gain transistors. The negative feedback reduces X-terminal resistance by the amount of feedback. Transistors M13 and M14 form current mirror used to copy Ix to Iz. It can be shown that the standby currents of M11-M12 are set by ISB. The current in M9 and M10 can be set very low using relatively large transistors. 


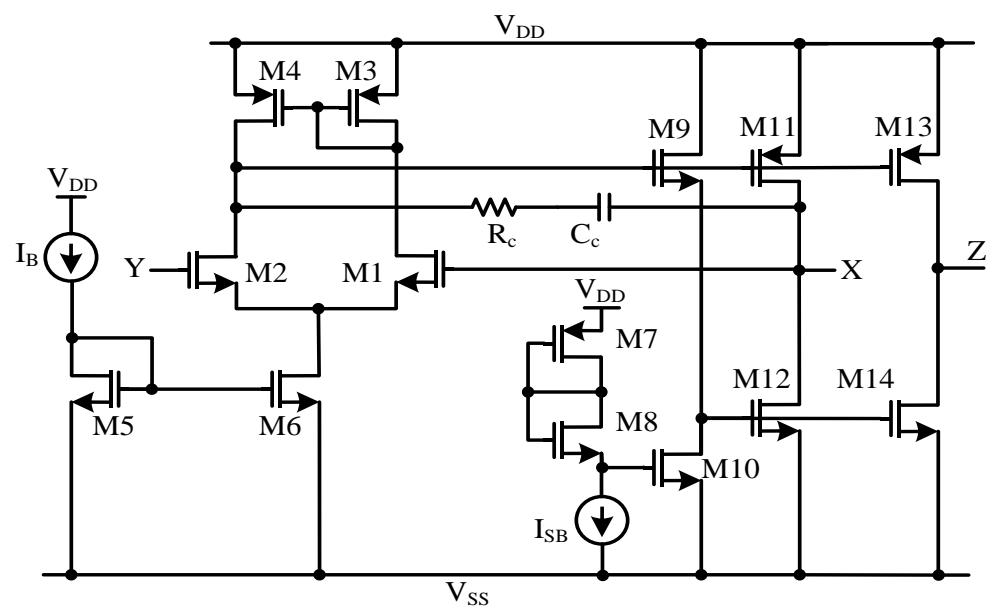

Figure 16: A class AB CCII+ obtained from opamp based buffer

The current consumption of the CCII is $I_{\mathrm{CCII}}=I_{B}+I_{\mathrm{M} 9}+3 I_{\mathrm{SB}}$. Typically, $I_{\mathrm{B}}$ is around 5 to 10 times the value of $I_{\mathrm{SB}}$. The current consumption of a CFA (CCII plus VB) would be $2 I_{\mathrm{CCII}}-I_{\mathrm{SB}}$. Therefore, the total current of the filters of Figure 10, Figure 11, Figure 12, Figure 13 and Figure 14 is given by $12 I_{\mathrm{CCII}}, 8 I_{\mathrm{CCII}}+4 I_{\mathrm{SB}}, 8 I_{\mathrm{CCII}}-4 I_{\mathrm{SB}}, 4 I_{\mathrm{CCII}}+8 I_{\mathrm{SB}}$, and $4 I_{\mathrm{CCII}}+12 I_{\mathrm{SB}}$. These results are calculated assuming positive and negative outputs CCII consume same power since final fully differential designs require no inverters. It can be seen that the current mode filters of Figure 13 and Figure 14 consume almost same amount of power, and they are significantly more power efficient than the voltage mode counterpart. In addition, it can be seen from the characteristics equations (4.12),(4.16),(4.20), (4.24) and (4.28) that the $\omega_{o}$ of all five filters can be tuned independently without disturbing $Q_{o}$ and gain. But the current mode filters of Figure 13 and Figure 14 have additional advantage of comprising same RC product terms for $\omega_{c}$ and $\omega_{o}$ and hence will require a single tuning circuit as discussed earlier. 
The non-ideal ac response of the filter can be found by considering the non-ideal terminal characteristic of the various active elements. They result in parasitic poles that limit the high frequency operation. Terminals with high impedances such as $\mathrm{Y}$ and $\mathrm{Z}$ of the CCII are dominated by shunt capacitances $\left(C_{Y}\right.$ and $\left.C_{Z}\right)$. Whereas terminals with low impedances such as $\mathrm{X}$ of CCII are modeled by series resistances $\left(r_{X}\right)$. It can be seen that there are two parasitic poles (PPs) associated with the filter of Figure 11 at $1 /\left(R_{1} \| r_{x}\right)\left(3 C_{Z}\right)$ and $1 /\left(R_{2} \| r_{x}\right)\left(C_{Z}\right)$. The proper operation of the filter requires its frequency response to be limited much lower than these poles. In contrast, the filter of Figure 12 has no parasitic poles (NPPs). This is because $\mathrm{Z}$ terminals of CFAs are connected to integrating capacitors. Similarly, the ac response of the filter of Figure 13 and Figure 14 will have NPPs. This is because the capacitors $C_{Z}$ for all CCIIs or CAs are in parallel with passive capacitances and hence their values can be absorbed. Moreover, it is interesting to observe that $r_{x}$ for all CCIIs and CAs can be lumped with series passive resistors. The main characteristics and results related to various filter topologies are highlighted in Table II. 
Table 2: Compatibility of various amplifiers with complex filters

\begin{tabular}{|c|c|c|c|c|c|}
\hline Mode & Features & VA & TCA & TRA & $\mathbf{C A}$ \\
\hline \multirow{4}{*}{ Voltage } & Devices & 4 & 8 & 4 & \multirow{4}{*}{$\begin{array}{l}\text { Not } \\
\text { suitable }\end{array}$} \\
\hline & CCIIs & 12 & 8 & 8 & \\
\hline & $\begin{array}{l}\text { Tuning } \\
\text { circuits }\end{array}$ & 2 & 2 & 2 & \\
\hline & $\begin{array}{l}\text { Frequency } \\
\text { limitations }\end{array}$ & $\begin{array}{l}\text { Gain } \\
\text { bandwi } \\
\text { dth } \\
\text { product }\end{array}$ & $\begin{array}{l}\text { Parasitic } \\
\text { poles }\end{array}$ & $\begin{array}{l}\text { No } \\
\text { parasitic } \\
\text { poles }\end{array}$ & \\
\hline \multirow{4}{*}{ Current } & Devices & \multirow{4}{*}{$\begin{array}{l}\text { Not } \\
\text { suitable }\end{array}$} & 4 & \multirow{4}{*}{$\begin{array}{l}\text { Not } \\
\text { suitable }\end{array}$} & 4 \\
\hline & CCIIs & & 4 & & 4 \\
\hline & $\begin{array}{l}\text { Tuning } \\
\text { circuits }\end{array}$ & & 1 & & 1 \\
\hline & $\begin{array}{l}\text { Frequency } \\
\text { limitations }\end{array}$ & & $\begin{array}{l}\text { No } \\
\text { parasitic } \\
\text { poles }\end{array}$ & & $\begin{array}{l}\text { No } \\
\text { parasitic } \\
\text { poles }\end{array}$ \\
\hline
\end{tabular}

Clearly, this table shows that filters of Figure 13 and Figure 14 utilizing current-mode signal processing offer advantageous features over their voltage-mode counterparts in terms of power consumption, simpler tuning, and more compatibility for high frequency operation free from parasitic poles. 


\subsection{Characteristics of the Optimum Power Designs}

This section discusses the two main parameters related to the dynamic range of the two filters of Figure 13 and Figure 15. First, signal limitations due to restricted proper operation of the active devices and power supply voltages are investigated. The voltage swing in CCII based filters are limited by the VB used to implement the $\mathrm{Y}-\mathrm{X}$ characteristic denoted by $\left(\left|\mathrm{V}_{\mathrm{VB}}\right|\right)$ whereas current signals are restricted by linear region of the $\mathrm{CF}$ forming the Z-X characteristic designated by $\left(\left|\mathrm{I}_{\mathrm{CF}}\right|\right)$. For the two CCIIs on the left of Figure 13, these restrictions can be mathematically expressed as follow:

$I_{o}=\frac{K_{g} /\left(C^{2} R^{2}\right)}{D(s)} I_{i}$, TF of Figure 13

To obtain $V_{x 2}$ and $V_{y 2}$, divide $I_{o}$ by $K_{g}$ and multiply by $R$ of left CCII side, We will get :

$V_{x 2}=V_{y 2}=\frac{1 /\left(C^{2} R\right)}{D(s)} I_{i}$

And to obtain $V_{x 1}$ and $V_{y 1}$, divide by complex integrator $\frac{s-j w_{c}}{R C}$,

$V_{x 1}=V_{y 1}=\frac{1 /(C)}{\left(s-j w_{C}\right) D(s)} I_{i}<V_{V B}$

The restrictions can be expressed as (5.1) shown below in which $\mathrm{D}(\mathrm{s})$ is the denominator polynomial of the TF of figure 15:

$\max \left\{V_{y 1}, V_{x 1}\right\}=\left|\frac{\left(s-j \omega_{c}\right) / C}{D(s)} \quad I_{i}\right|<\left|V_{V B}\right|$ 


$$
\max \left\{I_{x,} I_{z}\right\}=\max \left\{\left|\frac{\left(s-j \omega_{c}\right) / R C}{D(s)} \quad I_{i}\right|,\left|\frac{K_{q}\left(s-j \omega_{c}\right) / R C}{D(s)} \quad I_{i}\right|\right\},<\left|I_{C F}\right|
$$

When $K_{q}$ is greater than or equal one, this relation can be rewritten as:

$$
\left|I_{i}\right|<\min \left\{\left|\frac{D(s)}{\left(s-j \omega_{c}\right) / C} \quad V_{V B}\right|,\left|\frac{D(s)}{K_{q}\left(s-j \omega_{c}\right) / R C} \quad I_{C F}\right|\right\}
$$

Similarly, for the two CCIIs on the right of Figure 13, these restrictions can be mathematically expressed as:

$$
\left|I_{i}\right|<\min \left\{\left|\frac{D(s)}{1 / C^{2} R} \quad V_{V B}\right|,\left|\frac{D(s)}{1 / C^{2} R^{2}} \quad I_{C F}\right|\right\}
$$

On the other hand, the signal limitations are due to the node voltage $\left(\left|V_{R}\right|\right)$ and $C A$ current $\left(\left|\mathrm{I}_{\mathrm{CA}}\right|\right)$. Assuming the $\mathrm{CA}$ is implemented using CCII, results in $\left|\mathrm{I}_{\mathrm{CA}}\right|=\left|\mathrm{I}_{\mathrm{CF}}\right|$ and yields the following condition for the two CAs on the left of Figure 15:

$\left|I_{i}\right|<\min \left\{\left|\frac{D(s)}{\left(s-j \omega_{c}\right) / C} \quad V_{\text {supply }}\right|,\left|\frac{D(s)}{K_{q}\left(s-j \omega_{c}\right) / R C} \quad I_{C F}\right|\right\}$

Similarly, for the two CAs on the right of Figure 15, these restrictions can be mathematically expressed as:

$\left|I_{i}\right|<\min \left\{\left|\frac{D(s)}{1 / C^{2} R} \quad V_{\text {supply }}\right|,\left|\frac{D(s)}{1 / C^{2} R^{2}} \quad I_{C F}\right|\right\}$ 
By careful inspection of (5.2) and (5.5), the following significant conclusions are deduced. For the cases where $\mathrm{R}<\mathrm{K}_{\mathrm{q}}\left|\mathrm{V}_{\mathrm{VB}} / \mathrm{I}_{\mathrm{CF}}\right|$, the two integrators exhibit same signal swing. Assuming typical values of $\left|\mathrm{V}_{\mathrm{VB}}\right|=1 \mathrm{~V}$ obtained from supply voltage of $1.8 \mathrm{~V}$, $\left|\mathrm{I}_{\mathrm{CF}}\right|=1 \mathrm{~mA}$ and $\mathrm{K}_{\mathrm{q}}=1.42$ (Butterworth response), indicates that $\mathrm{R}$ must be selected to be less than $1.42 \mathrm{k} \Omega$ in order for the filter of Figure 13 to have same signal swing as its counterpart of Figure 15. Similarly, it can be shown that when $\mathrm{K}_{\mathrm{q}}$ is less than unity, the two filter will have same signal swing for $\mathrm{R}<\left|\mathrm{V}_{\mathrm{VB}} / \mathrm{I}_{\mathrm{CF}}\right|=1 \mathrm{k} \Omega$. This small resistance would require relatively large capacitances that might not be practically suitable for IC implementation. For example, a filter with a pole frequency of $500 \mathrm{kHz}$ would require capacitors of approximately $320 \mathrm{pF}$ when $\mathrm{R}=1 \mathrm{k} \Omega$. In conclusion, the CA-based filter would exhibit $\left(1+\left|\mathrm{V}_{\text {Supply }}-\mathrm{V}_{\mathrm{VB}}\right|\right)$ times the maximum input current of CCII-based filter which is typically $80 \%$ more signal swing. The linear range of a VB can be extended using more complex structures but they would usually be associated with more power consumption, less linearity, and/or more inherent noise.

The second parameter that decides on the dynamic range of a filter is noise. The internal thermal noise of a CCII can be modeled as voltage and current sources at the $\mathrm{Y}$ terminal denoted by $\mathrm{V}_{\mathrm{nY}}$, and $\mathrm{I}_{\mathrm{n}}$ as well as current sources of $\mathrm{I}_{\mathrm{nX}}$ at the $\mathrm{X}$ terminal and $\mathrm{I}_{\mathrm{nZi}}$ at every $\mathrm{Z}_{\mathrm{i}}$ terminal [32]. Whereas, the internal thermal noise of a $\mathrm{CA}$ can be characterized with voltage and current sources at the input-terminal denoted by $\mathrm{V}_{\mathrm{nX}}$, and $\mathrm{I}_{\mathrm{nX}}[33]$ as well as current sources of $\mathrm{I}_{\mathrm{nZi}}$ at every $\mathrm{Z}_{\mathrm{i}}$ terminal. Noise of a passive resistor can be modeled as a voltage source whose spectral density function is $V_{n R}{ }^{2}=4 k T R$ where $\mathrm{k}$ is Boltzmann's constant, $\mathrm{T}$ is absolute temperature, and $\mathrm{R}$ is the resistance size 
[31]. Figure 17 shows the two filters of Figure 13 and Figure 15 including various noise sources.

It can be observed that the TFs due to the resistors noise sources of the I-path $\left(\mathrm{V}_{\text {nRIa, }}\right.$, $\mathrm{V}_{\mathrm{nRIb}}, \mathrm{V}_{\mathrm{nRQ}}$, and $\mathrm{V}_{\mathrm{nRQb}}$ ) are same for both filter. Hence their noise contributions will be equivalent. Also, it can be shown that TFs due to $\mathrm{V}_{\text {nYIa }}, \mathrm{V}_{\mathrm{nYIb}}, \mathrm{V}_{\mathrm{nYQa}}$ and $\mathrm{V}_{\mathrm{nYQb}}$ in Figure 17(a) and their counterparts $\mathrm{V}_{\mathrm{nXIa}}, \mathrm{V}_{\mathrm{nXIb}}, \mathrm{V}_{\mathrm{nXQa}}$ and $\mathrm{V}_{\mathrm{nXQb}}$ in Figure 17 (b) are identical. In addition, it can be seen that the current noise sources of ( $\mathrm{I}_{\mathrm{nXI}}, \mathrm{I}_{\text {nzIa1 }}, \mathrm{I}_{\text {nzIa2}}, \mathrm{I}_{\text {nzIa3 }}, \mathrm{I}_{\mathrm{nXIb}}$, $\left.\mathrm{I}_{\mathrm{nZIb} 1}, \mathrm{I}_{\mathrm{nZIb} 2}, \mathrm{I}_{\mathrm{nZIb} 3}\right)$ and their Q path associates in both filters exhibit same TFs and hence they will have same noise contribution. Moreover, it can be shown that the respective noise sources $I_{n Y I a}, I_{n Y I b}, \quad I_{n Y Q a}, I_{n Y Q b}$ and $I_{n z I a 4}, I_{n z I b 4} I_{n z Q a 4}, I_{n z Q b 4}$ have similar contributions. Therefore, the two filters will have same noise performance for a common realization of CCII and CA.

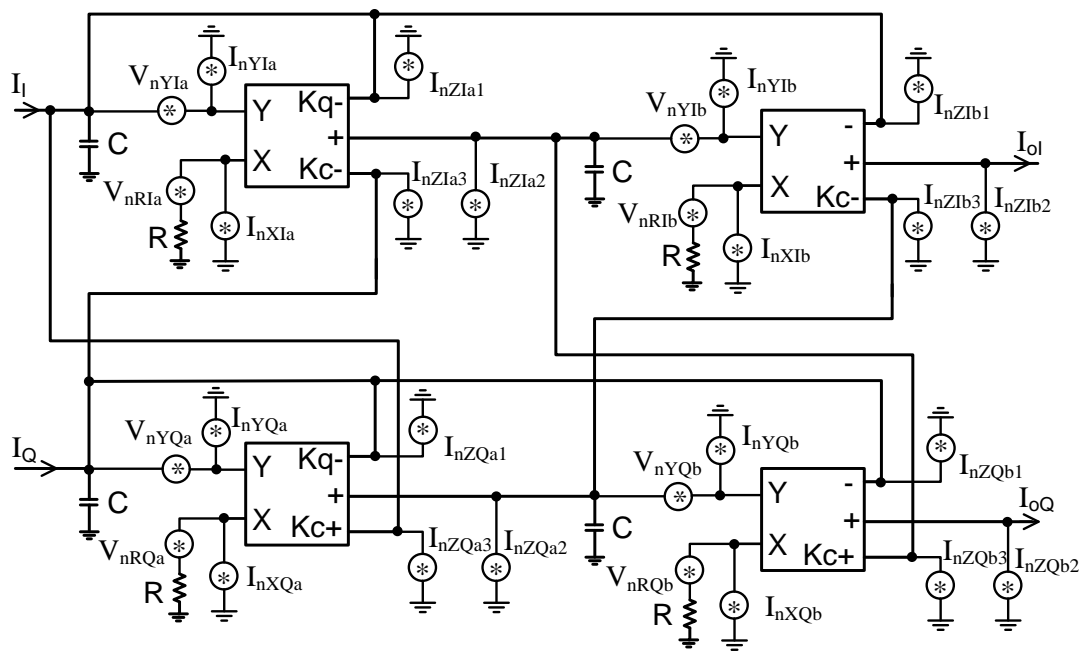

(a) 


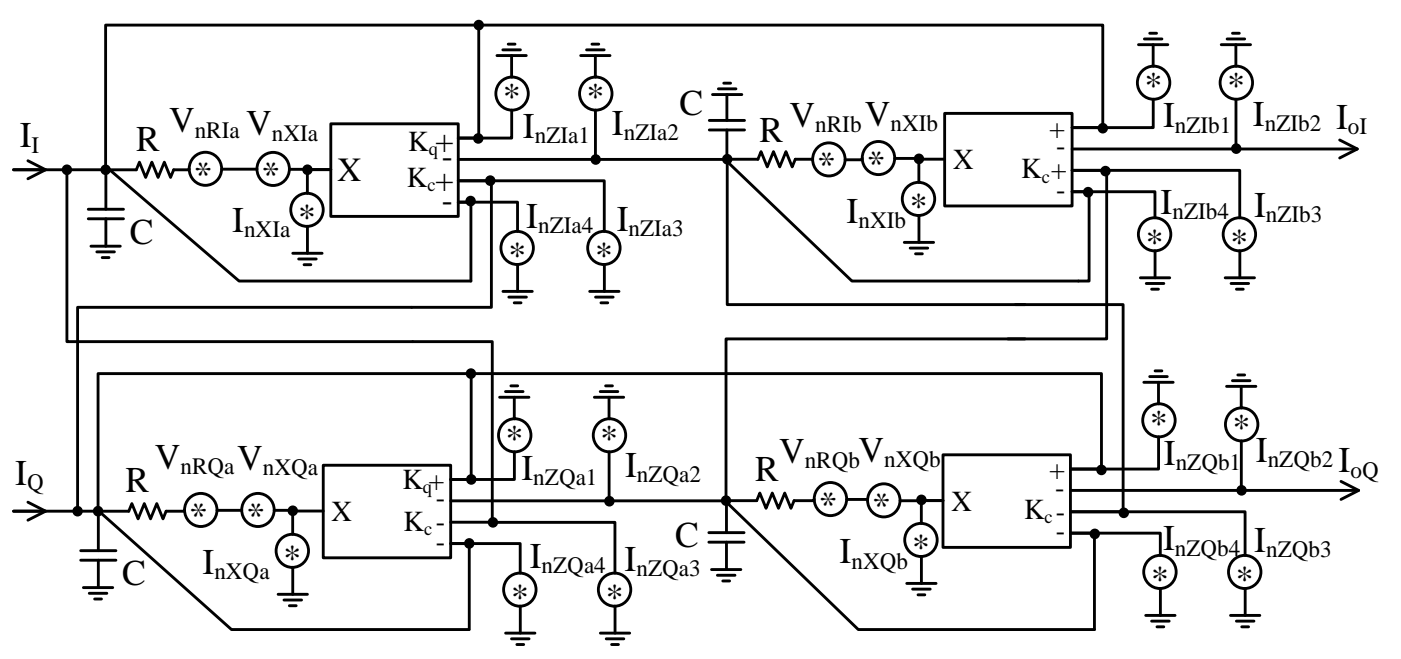

(b)

Figure 17: Filters based on CCII and CA including noise sources

In fact, the VB incorporated in the CCII not only limit the input/output signal swing but also the circuit bandwidth. For example, the bandwidth of the CCII of Figure 10 is the unity-gain frequency of the opamp (BW=gm1/CC) where gm1 is transconductance of the input stage and $\mathrm{CC}$ is the compensation capacitor. The location of the introduced dominant pole depends on the minimum value of stable closed-loop gain or equivalently the maximum value of the feedback factor. Thus, the largest $\mathrm{C}_{\mathrm{C}}$ is required for the case demanding stable closed loop gain as low as unity. In order to compensate for the large $\mathrm{C}_{\mathrm{C}}, \mathrm{gm} 1$ must be increased often through increasing the power consumption. In fact, the VB action is not required in the CA operation. This simplifies the design of the input stage of the CA. Adopting a simpler input stage in the CA design as shown in Figure 13 results in improved frequency response and/or reduced power consumption. Transistors M1-M2 biased with constant current provide the required virtual ground and the negative feedback formed by the class-AB output stage M3-M6 reduces the input resistance and improves the linearity of the input stage. The high frequency operation of the CA is 
limited by the dominant pole due to the high impedance node at the drain of M10 and M1. The pole will be at $1 / \mathrm{C}_{\mathrm{T}}(\mathrm{rds} 1 \| \mathrm{rds} 10)$ where $\mathrm{C}_{\mathrm{T}}$ is due to capacitances of M1, M10, M3, M6, M8 and M14.

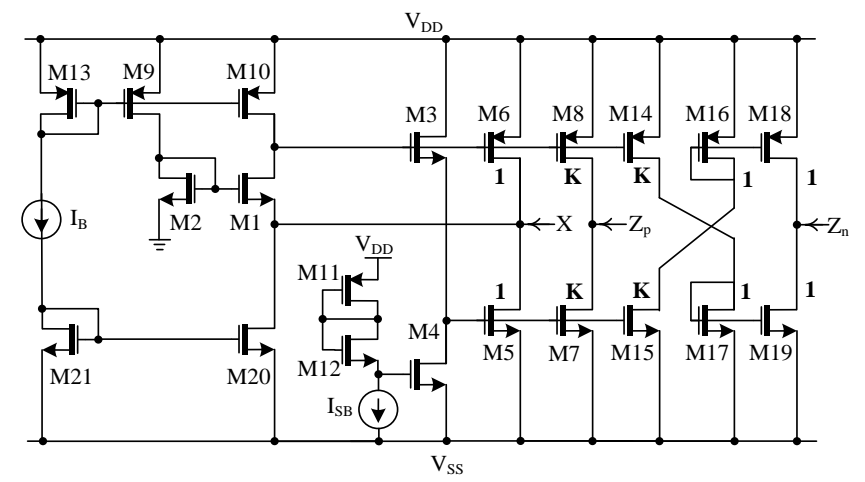

Figure 18: A low power CMOS CA with two complementary outputs

It has been shown that the CCII and CA based filters exhibit similar noise performance. However, the CA based filter exhibits better signal swings, provides higher commonmode rejection, and can support higher bandwidths. Therefore, it is expected that the CAbased filter would provide better dynamic range while consuming lower power and hence it is favorite.

\subsection{Noise Analysis of the Final Design}

Noise can be, in some cases, the main limitation of current-mode approach. This section investigates the noise performance of the proposed filter of Figure 15 based on CA in details. First, the noise terminal characteristics of the CA of Figure 18 are 
determined. The noise contribution of the class-AB output stage to $V_{n X}$ can be neglected since it is divided by the gain of the first stage.

$$
V_{n X}^{2}=V_{n M 1}^{2}+V_{n M 2}^{2}+\left(\frac{\mathrm{g}_{m 4}}{\mathrm{~g}_{m 1}}\right)^{2}\left(V_{n M 4}^{2}+V_{n M 5}^{2}\right)
$$

where $V_{n M i}$ are the equivalent input noise source of MOSFETs given by $V_{n M i}^{2}=$ $8 k T /\left(3 g_{m i}\right)$ [22] where $\mathrm{g}_{m}$ is the transconductance of the transistor. The matched transistors M1-M2 and M4-M5 have same noise. This noise source can be reduced by selecting large $g_{m 1}$. Whereas the noise spectral density functions of $I_{n X}$ and $I_{n Z}$ can be expressed as:

$$
\begin{aligned}
I_{n X}^{2} & =\left(\mathrm{g}_{m 10}\right)^{2} V_{n M 10}^{2}+\left(\mathrm{g}_{m 11}\right)^{2} V_{n M 11}^{2} \\
I_{n Z}^{2} & =\left(\mathrm{g}_{m 12}\right)^{2} V_{n M 12}^{2}+\left(\mathrm{g}_{m 13}\right)^{2} V_{n M 13}^{2}
\end{aligned}
$$

A $4^{\text {th }}$-order complex filter for implementing the channel-select filter in a low-IF BT receiver was realized by cascading two sections of the filter of Figure 15. The total output noise of the complete filter can be calculated as follows. The total output current noise spectral density of the second polyphase stage $\left(I_{\text {no_poly } 2}\right)$ due to the 24 noise sources is determined. The following sub-sections will show some of noise contributions derivatives equations.

5.3.1 Derivative Equations to Find $\frac{I_{0 I}}{I_{n z I a 2}}=\frac{I_{0 I}}{I_{n Y I b}}=\frac{I_{0 I}}{I_{n z Q b 3}}$ of Figure 17(b):

KCL at input point of I path first stage ;

$$
\begin{aligned}
& I_{x}=\frac{-K_{q} I_{x}-I_{o I}+K_{c} I_{y}}{R c s} \\
& I_{x}\left(R c s+K_{q}\right)=-I_{o I}+K_{c} I_{y}
\end{aligned}
$$


KCL at input point of I path second stage ;

$$
\begin{aligned}
& I_{o I}=\frac{I_{x}+I_{n z I a 2}+K_{c} I_{o Q}}{R c S} \\
& I_{x}=\operatorname{Rcs} I_{o I}-I_{n z I a 2}-K_{c} I_{o Q}
\end{aligned}
$$

KCL at input point of $\mathrm{Q}$ path first stage ;

$$
\begin{aligned}
& I_{y}=\frac{-K_{c} I_{x}-I_{o I}-K_{q} I_{y}}{R c s} \\
& I_{y}\left(R c s+K_{q}\right)=-I_{o Q}-K_{c} I_{x}
\end{aligned}
$$

KCL at input point of $\mathrm{Q}$ path second stage ;

$$
\begin{aligned}
I_{O Q} & =\frac{I_{y}-K_{c} I_{O I}}{R c s} \\
I_{y} & =\operatorname{Rcs} I_{o Q}+K_{c} I_{O I}
\end{aligned}
$$

Now sub (5.10) \& (5.12) in (5.9) \&(5.11)

$$
\begin{gathered}
\left(R c s I_{o I}-I_{n z I a 2}-K_{c} I_{o Q}\right)\left(R c s+K_{q}\right)=-I_{O I}+K_{c}\left(R c s I_{o Q}+K_{c} I_{o I}\right) \\
R^{2} c^{2} s^{2} I_{o I}+K_{q} R c s I_{O I}-R c s I_{n z I a 2}-K_{q} I_{n z I a 2}-K_{c} R c s I_{o Q}-K_{c} K_{q} I_{o Q} \\
=-I_{O I}+K_{c} R c s I_{o Q}+K_{c}{ }^{2} I_{o I} \\
I_{O I}\left(R^{2} c^{2} s^{2}+K_{q} R c s+1-K_{c}{ }^{2}\right) \\
=I_{o Q}\left(2 K_{c} R c s+K_{c} K_{q}\right)+I_{n z I a 2}\left(R c s+K_{q}\right)
\end{gathered}
$$

And 


$$
\begin{gathered}
\left(R c s I_{o Q}+K_{c} I_{O I}\right)\left(R c s+K_{q}\right)=-I_{o Q}-K_{c}\left(R c s I_{o I}-I_{n z I a 2}-K_{c} I_{o Q}\right) \\
R^{2} c^{2} s^{2} I_{O Q}+K_{q} R c s I_{o Q}+K_{c} R c s I_{O I}+K_{c} K_{q} I_{O I} \\
=-I_{O Q}-K_{c} R c s I_{O I}+K_{c} I_{n z I a 2}+K_{c}{ }^{2} I_{O Q} \\
I_{o Q}\left(R^{2} c^{2} s^{2}+K_{q} R c s+1-{K_{c}}^{2}\right)=I_{o I}\left(-2 K_{c} R c s-K_{c} K_{q}\right)+K_{c} I_{n z I a 2} \\
I_{O Q}=\frac{I_{O I}\left(-2 K_{c} R c s-K_{c} K_{q}\right)+K_{c} I_{n z I a 2}}{\left(R^{2} c^{2} s^{2}+K_{q} R c s+1-{K_{c}}^{2}\right)}
\end{gathered}
$$

Substitute (5.14) in (5.13)

$$
\begin{aligned}
I_{O I}\left(R^{2} c^{2} s^{2}+\right. & \left.K_{q} R c s+1-K_{c}{ }^{2}\right) \\
& =\frac{I_{O I}\left(-2 K_{c} R c s-K_{c} K_{q}\right)+K_{c} I_{n z I a 2}}{\left(R^{2} c^{2} s^{2}+K_{q} R c s+1-K_{c}{ }^{2}\right)}\left(2 K_{c} R c s+K_{c} K_{q}\right) \\
& +I_{\text {nzIa } 2}\left(R c s+K_{q}\right)
\end{aligned}
$$

Multiply by $\left(R^{2} c^{2} s^{2}+K_{q} R c s+1-K_{c}{ }^{2}\right)$

$$
\begin{aligned}
& \text { let } A=\left(R^{2} c^{2} s^{2}+K_{q} R c s+1-K_{c}{ }^{2}\right) \cdot\left(R^{2} c^{2} s^{2}+K_{q} R c s+1-K_{c}{ }^{2}\right) \\
& =R^{4} c^{4} s^{4}+2 K_{q} R^{3} c^{3} s^{3}+s^{2}\left(2 R^{2} c^{2}-2 K_{c}^{2} R^{2} c^{2}+K_{q} R^{2} c^{2}\right) \\
& +s\left(2 K_{q} R c-2 K_{c}{ }^{2} K_{q} R c\right)+\left(1+K_{c}{ }^{4}-2 K_{c}{ }^{2}\right) \\
& \text { let } \mathrm{B}=\left(2 K_{c} R c s+K_{c} K_{q}\right) \cdot\left(2 K_{c} R c s+K_{c} K_{q}\right)=4 K_{c}{ }^{2} R^{2} c^{2} s^{2}+4 K_{c}{ }^{2} K_{q} R c s+ \\
& K_{c}{ }^{2} K_{q}{ }^{2} \\
& \text { let } \mathrm{C}=K_{c}\left(2 K_{c} R c s+K_{c} K_{q}\right)+\left(R c s+K_{q}\right)\left(R^{2} c^{2} s^{2}+K_{q} R c s+1-K_{c}{ }^{2}\right)= \\
& 2 K_{c}{ }^{2} R c s+K_{q} K_{c}{ }^{2}+R^{3} c^{3} s^{3}+K_{q} R^{2} c^{2} s^{2}-K_{c}{ }^{2} R c s+R c s+K_{q} R^{2} c^{2} s^{2}+ \\
& K_{q}{ }^{2} R c s-K_{q} K_{c}{ }^{2}+K_{q} \\
& =R^{3} c^{3} s^{3}+2 K_{q} R^{2} c^{2} s^{2}+s\left(K_{c}{ }^{2} R c s+R c+K_{q}{ }^{2} R c\right)+K_{q}
\end{aligned}
$$




$$
\frac{I_{O I}}{I_{n Z I a 2}}=\frac{I_{O I}}{I_{n Y I b}}=\frac{I_{O I}}{I_{n z Q b 3}}=\frac{C}{A+B}=\frac{R^{3} c^{3} s^{3}+2 K_{q} R^{2} c^{2} s^{2}+s\left(K_{c}{ }^{2} R c s+R c+K_{q}{ }^{2} R c\right)+K_{q}}{D(s)}
$$

5.3.2 Derivative Equations to Find $\frac{I_{0 I}}{I_{n z I a 3}}=\frac{I_{0 I}}{I_{n Y Q a}}=\frac{I_{0 I}}{I_{n z Q b 1}}=\frac{I_{0 I}}{I_{n z Q a 1}}$ of Figure 17

(b):

KCL at input point of I path first stage ;

$$
\begin{aligned}
& I_{x}=\frac{-K_{q} I_{x}-I_{o I}+K_{c} I_{y}}{R c s} \\
& I_{x}\left(R c s+K_{q}\right)=-I_{o I}+K_{c} I_{y}
\end{aligned}
$$

KCL at input point of I path second stage ;

$$
\begin{aligned}
I_{O I} & =\frac{I_{x}+K_{c} I_{O Q}}{R c S} \\
I_{x} & =\operatorname{Rcs} I_{O I}-K_{C} I_{O Q}
\end{aligned}
$$

KCL at input point of $\mathrm{Q}$ path first stage ;

$$
\begin{aligned}
& I_{y}=\frac{-K_{c} I_{x}+I_{n z I a 3}-I_{o I}-K_{q} I_{y}}{R c s} \\
& I_{y}\left(R c s+K_{q}\right)=-I_{o Q}-K_{c} I_{x}+I_{n z I a 3}
\end{aligned}
$$

$\mathrm{KCL}$ at input point of $\mathrm{Q}$ path second stage ;

$$
\begin{aligned}
I_{o Q} & =\frac{I_{y}-K_{c} I_{o Q}}{R c s} \\
I_{y} & =\operatorname{Rcs} I_{o Q}+K_{c} I_{O I}
\end{aligned}
$$


Now substitute (5.17) \& (5.19) in (5.16) \&(5.18)

$$
\begin{aligned}
& \left(R c s I_{o I}-K_{c} I_{o Q}\right)\left(R c s+K_{q}\right)=-I_{o I}+K_{c}\left(R c s I_{o Q}+K_{c} I_{O I}\right) \\
& R^{2} c^{2} s^{2} I_{o I}+K_{q} R c s I_{o I}-K_{c} R c s I_{o Q}-K_{c} K_{q} I_{o Q}=-I_{o I}+K_{c} R c s I_{o Q}+K_{c}{ }^{2} I_{o I} \\
& I_{O I}\left(R^{2} c^{2} s^{2}+K_{q} R c s+1-K_{c}{ }^{2}\right)=I_{o Q}\left(2 K_{c} R c s+K_{c} K_{q}\right) \\
& I_{O Q}=\frac{I_{o I}\left(R^{2} c^{2} s^{2}+K_{q} R c s+1-K_{c}{ }^{2}\right)}{\left(2 K_{c} R c s+K_{c} K_{q}\right)}
\end{aligned}
$$

And equation (5.18)

$$
\begin{gathered}
\left(R c s I_{o Q}+K_{c} I_{o I}\right)\left(R c s+K_{q}\right)=-I_{o I}-K_{c}\left(R c s I_{o I}-K_{c} I_{o Q}\right)+I_{n z I a 3} \\
R^{2} c^{2} s^{2} I_{o Q}+K_{q} R c s I_{o Q}+K_{c} R c s I_{o I}+K_{c} K_{q} I_{o I} \\
=-I_{o Q}-K_{c} R c s I_{o I}+K_{c}{ }^{2} I_{o Q}+I_{n z I a 3} \\
I_{o Q}\left(R^{2} c^{2} s^{2}+K_{q} R c s+1-{K_{c}}^{2}\right)+I_{o I}\left(2 K_{c} R c s+K_{c} K_{q}\right)=I_{n z I a 3}
\end{gathered}
$$

Substitute (5.20) in (5.21)

$$
\begin{gathered}
\frac{I_{o I}\left(R^{2} c^{2} s^{2}+K_{q} R c s+1-K_{c}^{2}\right)}{\left(2 K_{c} R c s+K_{c} K_{q}\right)}\left(R^{2} c^{2} s^{2}+K_{q} R c s+1-K_{c}{ }^{2}\right) \\
+I_{o I}\left(2 K_{c} R c s+K_{c} K_{q}\right)=I_{n z I a 3}
\end{gathered}
$$

Now multiply by $\left(2 K_{c} R c s+K_{c} K_{q}\right)$

Let $\mathrm{A}=\left(R^{2} c^{2} s^{2}+K_{q} R c s+1-K_{c}{ }^{2}\right) \cdot\left(R^{2} c^{2} s^{2}+K_{q} R c s+1-K_{c}{ }^{2}\right)=R^{4} c^{4} s^{4}+$ $2 K_{q} R^{3} c^{3} s^{3}+s^{2}\left(2 R^{2} c^{2}-2 K_{c}{ }^{2} R^{2} c^{2}+K_{q} R^{2} c^{2}\right)+s\left(2 K_{q} R c-2 K_{c}{ }^{2} K_{q} R c\right)+$ $\left(1+K_{c}^{4}-2 K_{c}^{2}\right)$ 
Let B $=\left(2 K_{c} R c s+K_{c} K_{q}\right) \cdot\left(2 K_{c} R c s+K_{c} K_{q}\right)=4 K_{c}{ }^{2} R^{2} c^{2} s^{2}+4 K_{c}{ }^{2} K_{q} R c s+$ $K_{c}{ }^{2} K_{q}{ }^{2}$

Let $\mathrm{C}=\left(2 K_{c} R c s+K_{c} K_{q}\right)$

$$
\begin{aligned}
\frac{I_{O I}}{I_{n z I a 3}}=\frac{I_{O I}}{I_{n Y Q a}}=\frac{I_{O I}}{I_{n z Q b 1}}=\frac{I_{O I}}{I_{n z Q a 1}} & =\frac{C}{A+B} \\
& =\frac{2 K_{c} R c s+K_{c} K_{q}}{D(s)}
\end{aligned}
$$

The other noise contributions due to four noise sources are given by (5.23) shown below through (5.26).

$$
\begin{aligned}
& \frac{I_{O I}}{I_{n X I_{a}}}=\frac{s^{3} C^{3} R^{3}+s^{2}\left(C^{2} R^{2}+C^{2} R^{2} K_{q}\right)+s\left(C R+C R K_{q}+C R K_{c}{ }^{2}\right)+\left(1+K_{c}^{2}\right)}{D(s)} \\
& \frac{I_{O I}}{I_{n X Q_{a}}}=\frac{s^{2} 2 C^{2} R^{2} K_{c}+s\left(C R K_{q} K_{c}+2 C R K_{c}\right)+K_{q} K_{c}}{D(s)}
\end{aligned}
$$

$$
\begin{aligned}
\frac{I_{O I}}{V_{n R I_{a}}} & =\frac{s^{3} C^{3} R^{2}+s^{2} C^{2} R K_{q}+s\left(C-C K_{c}{ }^{2}\right)}{D(s)} \\
\frac{I_{O I}}{V_{n R Q_{a}}} & =\frac{s^{2} 2 C^{2} R K_{c}+s C K_{q} K_{c}}{D(s)}
\end{aligned}
$$

where $\mathrm{D}(\mathrm{s})$ is given by (5.27) below. The output spectral density of the first polyphase stage $\left(I_{n o-p o l y 1}^{2}\right)$ is identical to $I_{n o-p o l y 2}^{2}$ but by substituting the proper value of $\mathrm{K}_{\mathrm{q}}$. 


$$
\begin{aligned}
& D(s)=s^{4} C^{4} R^{4}+s^{3}\left(2 C^{3} R^{3} K_{q}\right)+s^{2}\left(2 C^{2} R^{2}+C^{2} R^{2} K_{q}^{2}+2 C^{2} R^{2} K_{c}^{2}\right)+ \\
& s\left(2 C R K_{q} K_{c}^{2}+2 C R K_{q}\right)+\left(K_{q}^{2} K_{c}^{2}+K_{c}^{4}-2 K_{c}^{2}+1\right)
\end{aligned}
$$

In order to determine the noise contribution of the first stage to the output noise of the I path, the transfer function $H_{I Q}(s)=I_{O I} /\left(I_{I}+I_{Q}\right)$ is calculated for real input $\mathrm{I}_{\mathrm{I}}$ and $\mathrm{I}_{\mathrm{Q}}$ $\left(\mathrm{I}_{\mathrm{I}}=\mathrm{I}_{\mathrm{Q}}\right.$ is assumed at the end of the analysis since the noise of the I and Q paths are equal) leading to

$H_{I Q}=\frac{s^{2} C^{2} R^{2}+s\left(2 C R K_{2}+C R K_{1}\right)+\left(1+K_{1} K_{2}-K_{2}^{2}\right)}{D_{I Q}(s)}$

where $D_{I Q}(s)$ is given by $(5.29)$ shown below.

$$
\begin{gathered}
D_{I Q}(s)=s^{4} C^{4} R^{4}+s^{3}\left(2 C^{3} R^{3} K_{1}\right)+s^{2}\left(2 C^{2} R^{2}+C^{2} R^{2} K_{2}^{2}+2 C^{2} R^{2} K_{1}^{2}\right) \\
+s\left(2 C R K_{1} K_{2}^{2}+2 C R K_{1}\right)+\left(K_{1}^{2} K_{2}^{2}+K_{2}^{4}-2 K_{2}^{2}+1\right)
\end{gathered}
$$

Therefore, the total output noise spectral density is calculated by

$$
I_{n o-p o l y}^{2}=I_{n o-p o l y 2}^{2}+I_{n o-p o l y 1}^{2}\left|H_{I Q}(s)\right|^{2}
$$

Next chapter shows the values of the noise of $4^{\text {th }}$-order complex filter calculated by simulation. 


\section{CHAPTER 6}

\section{SIMULATION RESULTS AND CONCLUSION}

\subsection{Simulation Results}

The current amplifier shown in Figure 18 is utilized to build the filter of Figure 15. First, second order section is realized to verify the operation of the filter. After that a 4th order Butterworth filter is designed as demonstrating example to meet BT selectivity requirements. BT specifications require attenuations of $30 \mathrm{~dB}$ and $40 \mathrm{~dB}$ of blockers at 5 $\mathrm{MHz}$ and $6 \mathrm{MHz}$ when the center frequency is $3 \mathrm{MHz}$. The filter is simulated in a T-spice simulator. The T-spice code is given in the APPENDIX. With $I_{B}=20 u A$ and $I_{S B}=$ $2 u A$ leads to the total, filter current of approximately $448 u A$. The total power of the filter is approximately1.3 $\mathrm{mW}$.

Simulation result based of AC response of the signal is shown in Figure 19. It shows that blocker attenuations at $5 \mathrm{MHz}$ and $6 \mathrm{MHz}$ are more than $43 \mathrm{~dB}$ and $56 \mathrm{~dB}$ respectively. These are more than required for BT specifications. 


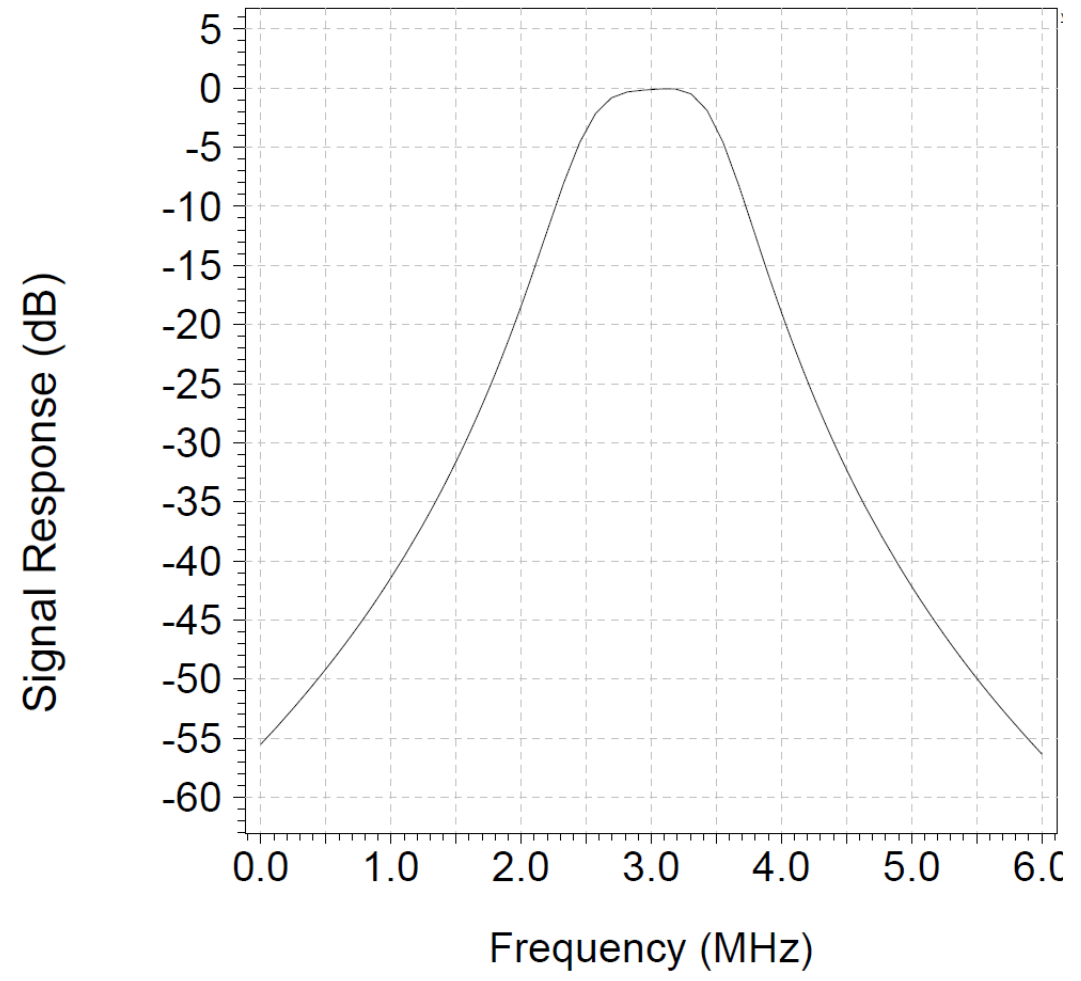

Figure 19: AC Response of the Filter

Also, the image response is shown in Figure 20. It shows attenuation of the image of around $31 \mathrm{~dB}$. 


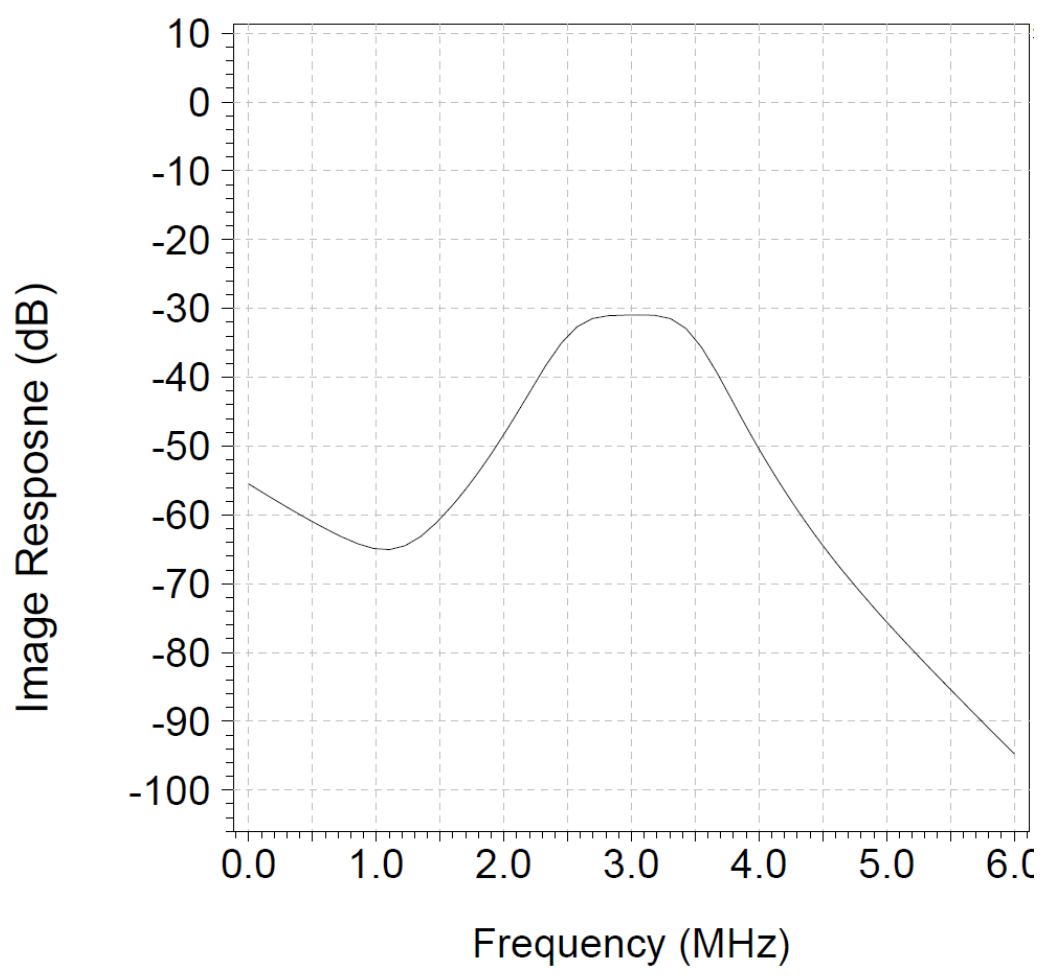

Figure 20: Imagine Response of the Filter

In addition, the output noise spectral density is shown in Figure 21. It shows that the average noise in the passband is approximate $180 \mathrm{pA} / \sqrt{\mathrm{Hz}}$. 


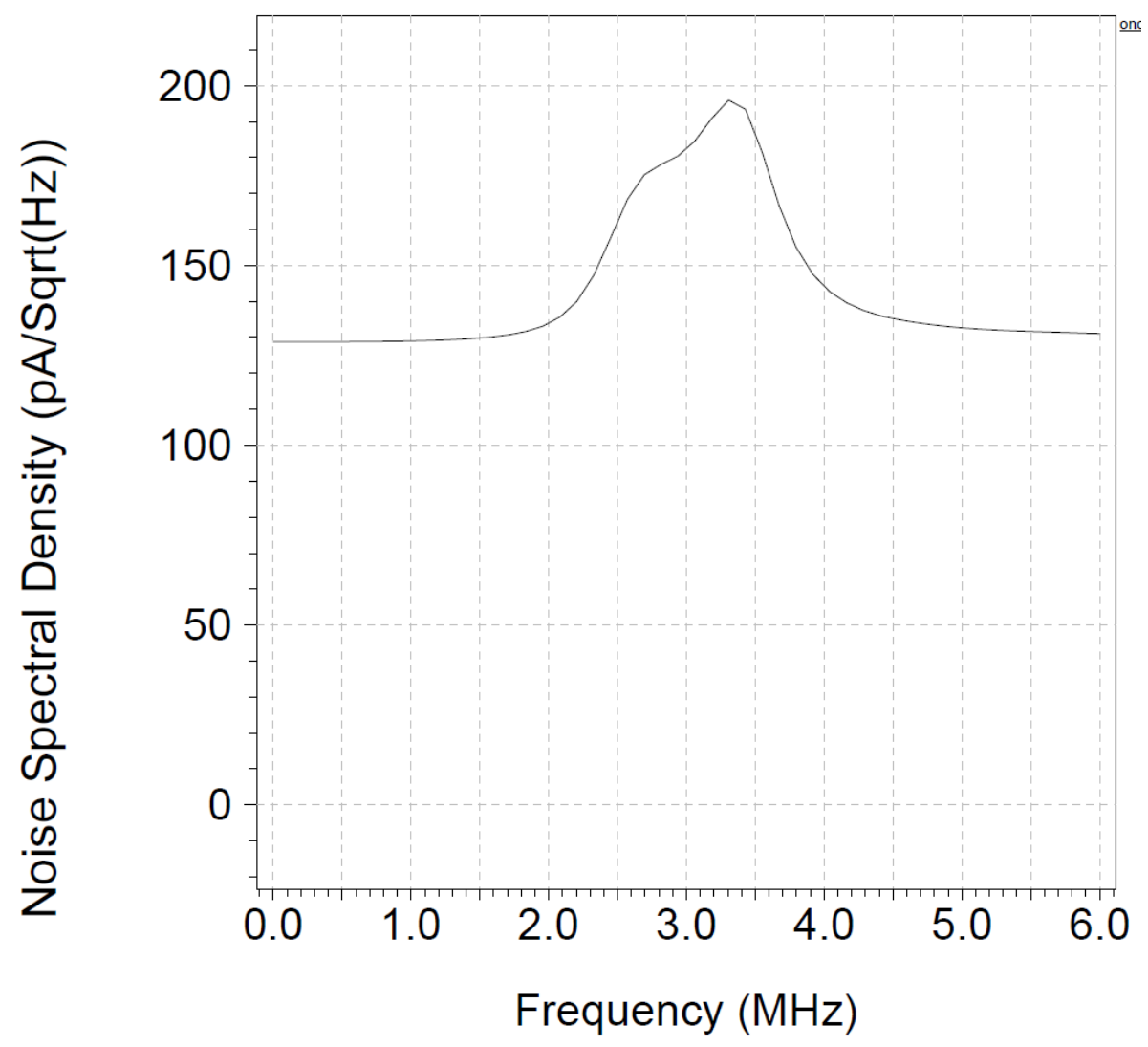

Figure 21: Noise Spectral Density of the Filter Design

Similarly, figure 22 presents a typical time domain response of the filter. An output sinusoidal signal swings of $850 \mathrm{uA}$ is shown. 


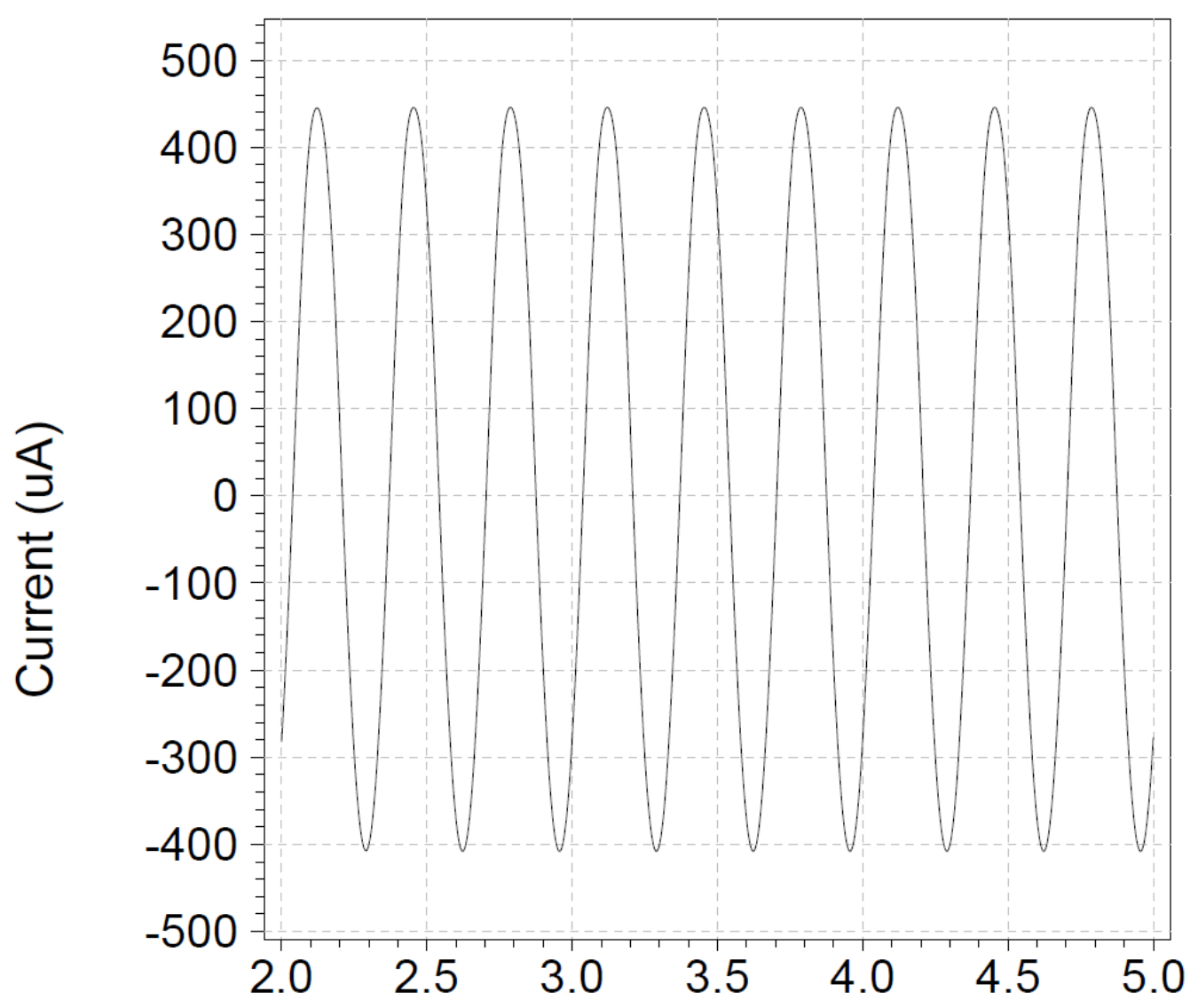

Figure 22: Maximum Swing of sinusoidal signal

The dynamic range can be calculated as follows:

Dynamic Range $=20 \log \left(\frac{\text { Max. Swing }}{\text { Total } \text { Noise }}\right)=73.5 \mathrm{~dB}$

Where Maximum swing $=850 u A \quad$ and Total Noise $=180 \frac{p A}{\sqrt{H z}} * \sqrt{10^{6}}=180$ 


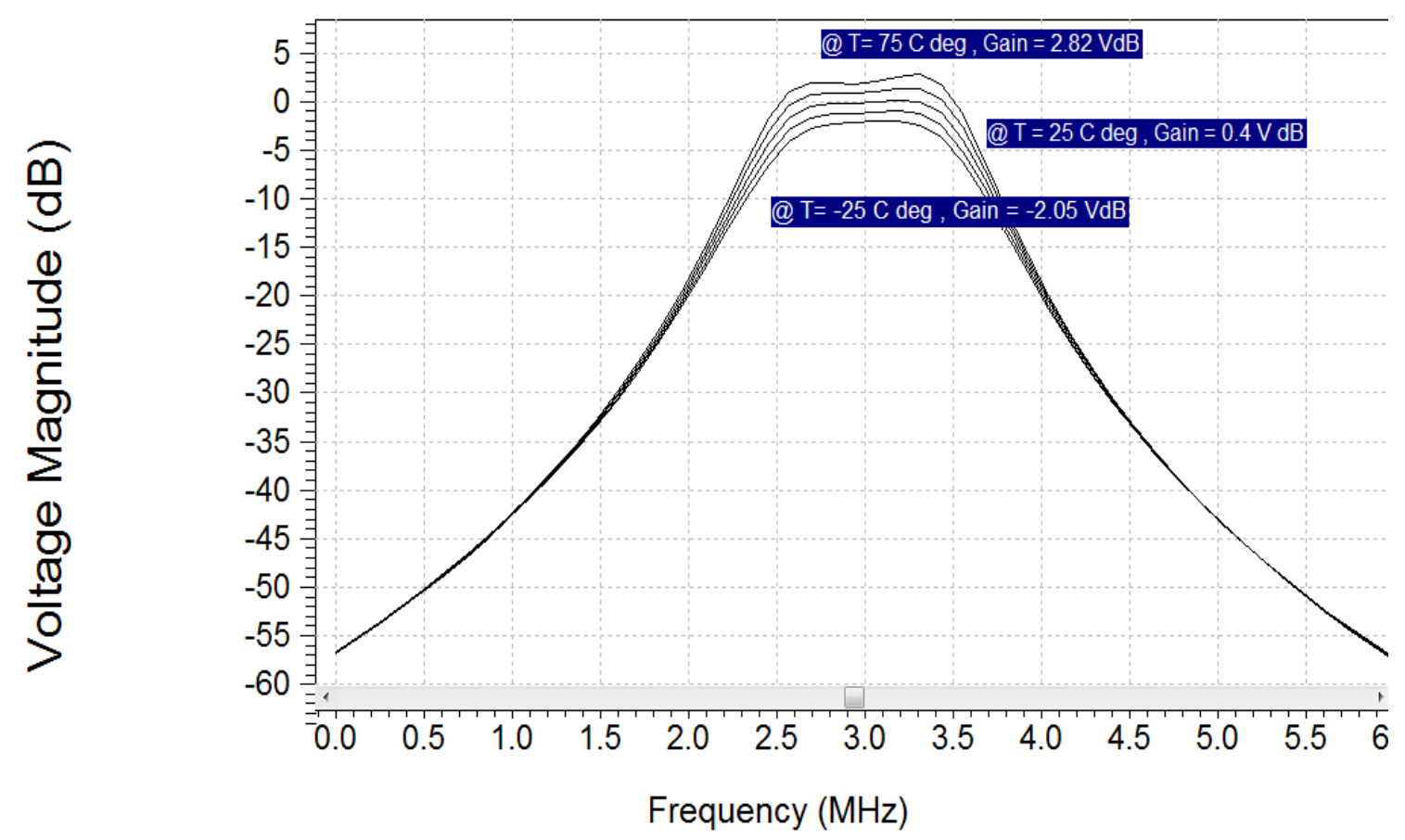

Figure 23: Temperature Effect on the Filter Design

Figure 23 shows that the signal response of the final design varies with temperature. The design is sensitive to temperature variation. 


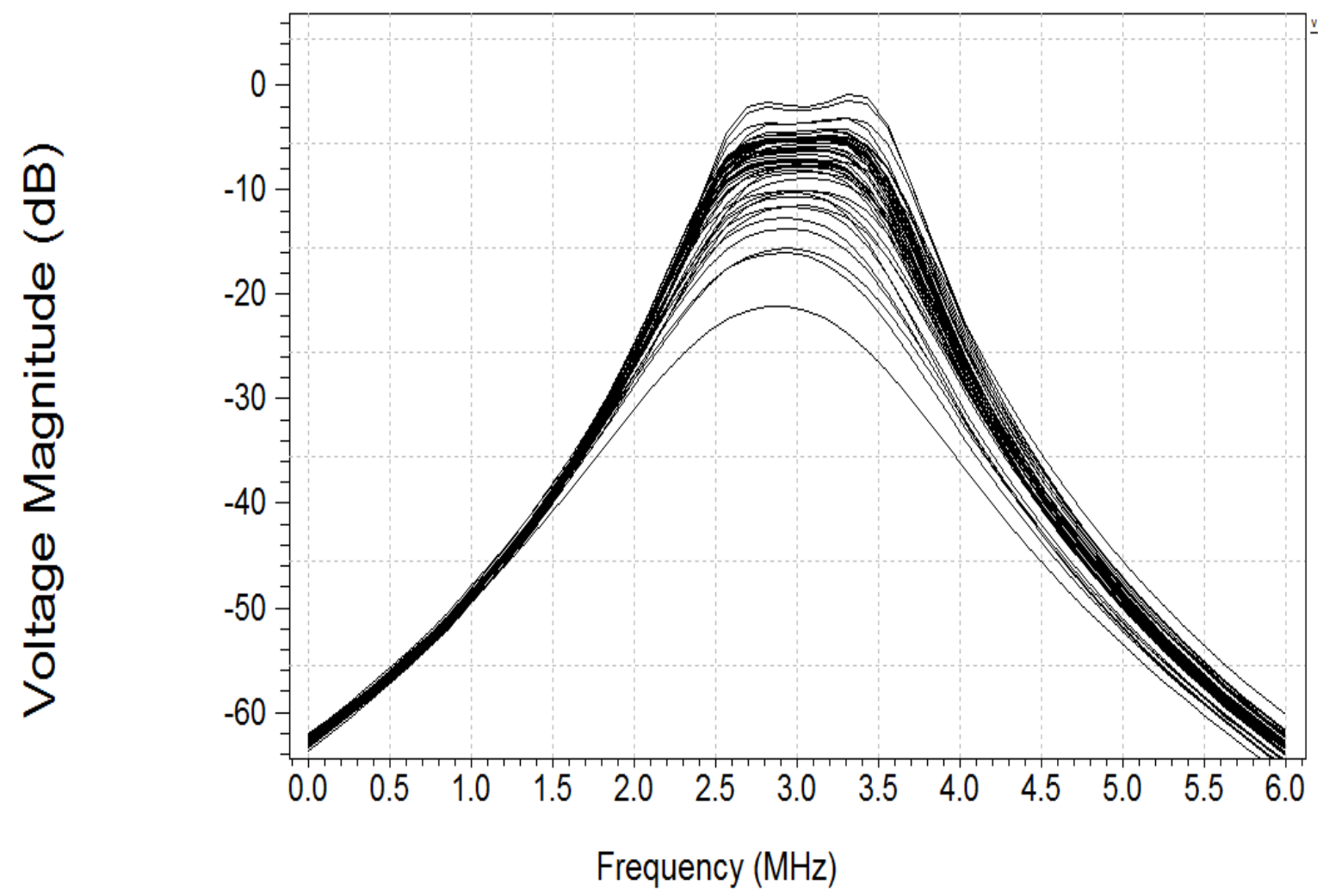

Figure 24: Monte Carlo Analysis of the Filter

As well, Figure 24 shows the Monte Carlo simulation with repeated of 50 times. It shows that most of the response is close $0 \mathrm{~dB}$ and the minimum gain is around $-21 \mathrm{~dB}$. 


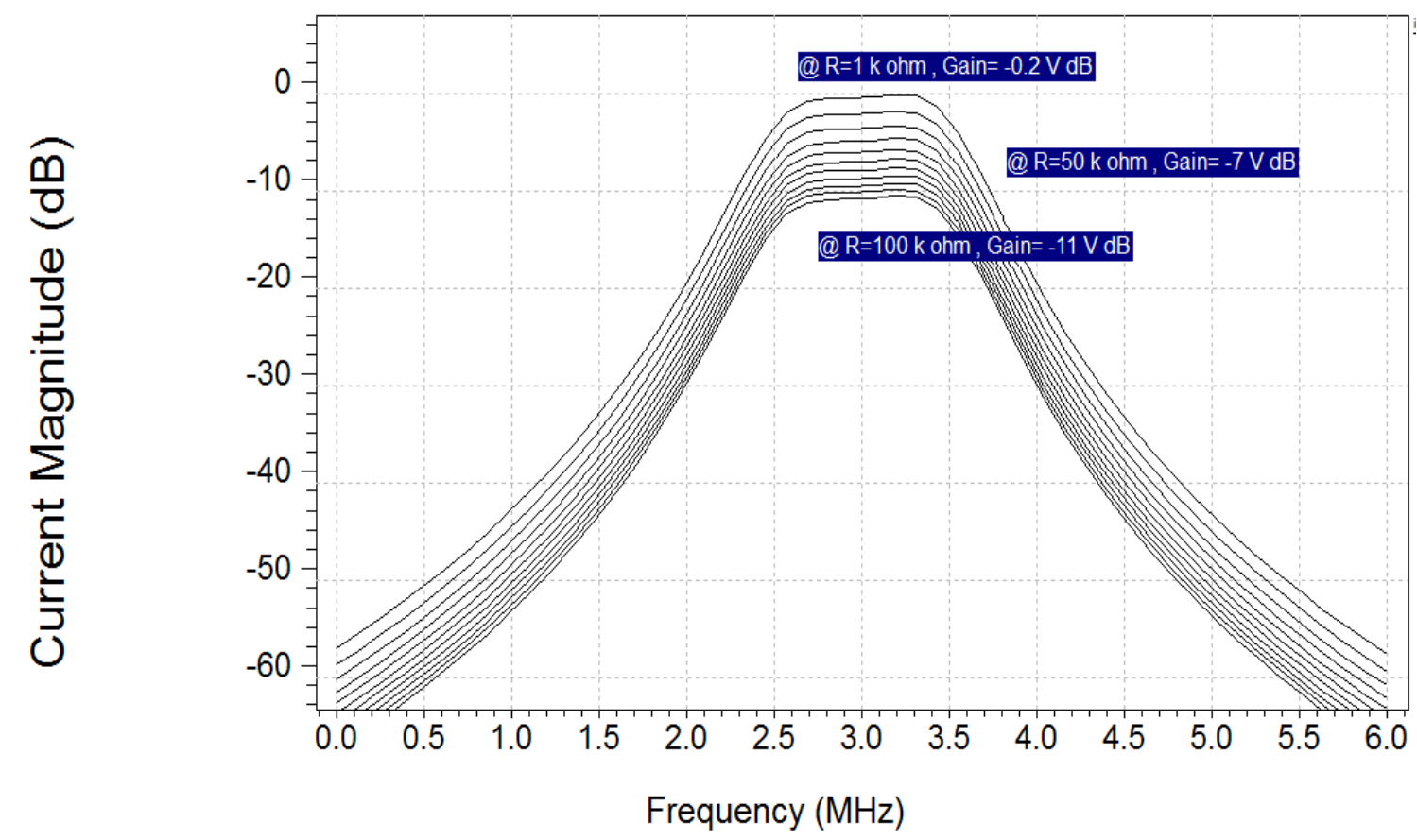

Figure 25: Load Effect on signal Response

Figure 25 shows that the signal response varies with load ass shown in the figure. The output signal of is sensitive to loading effect . 


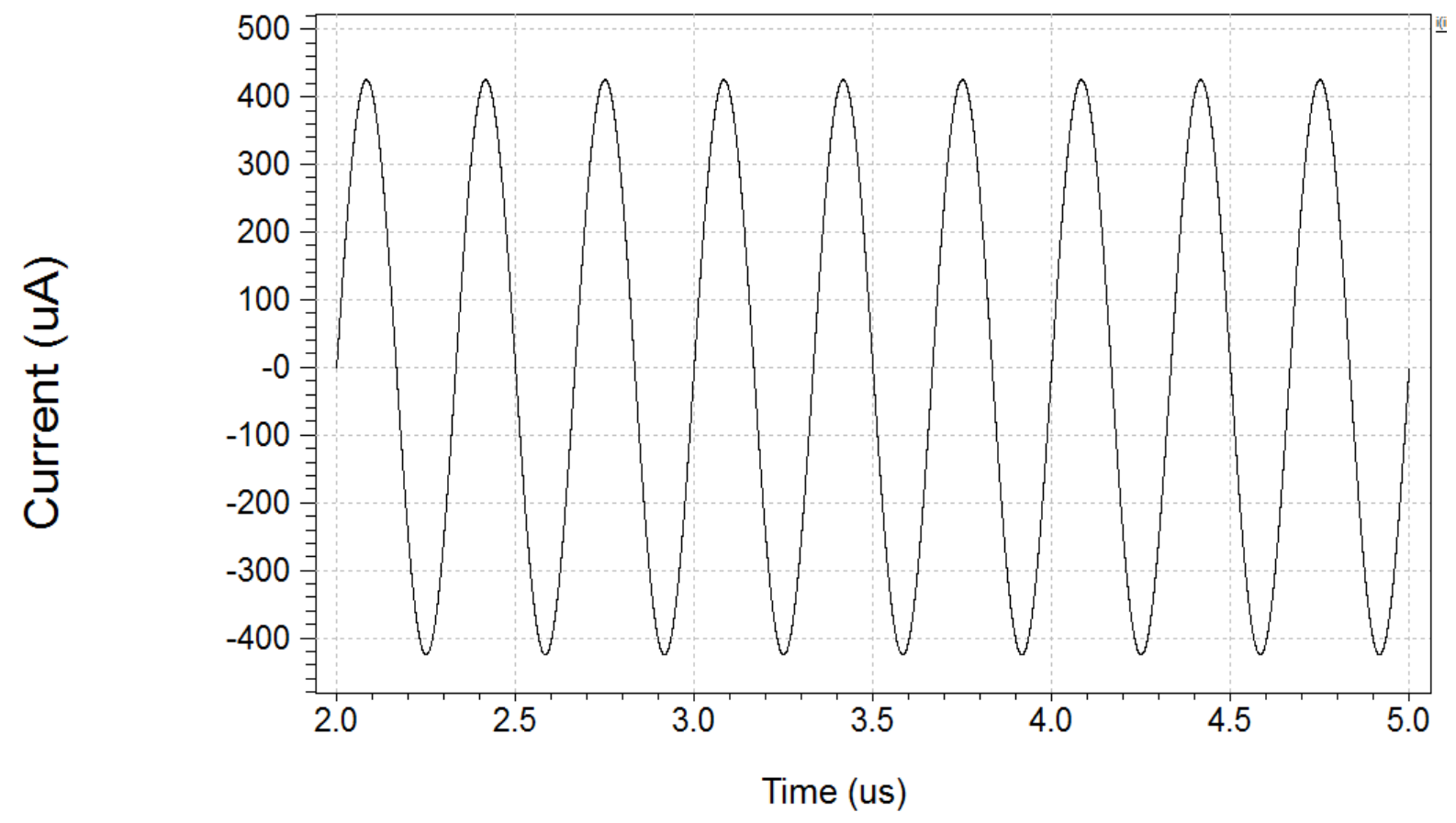

Figure 26: Sinusoidal Input Signal

Figure 26 shows the Input sinusoidal signal with amplitude $850 \mu \mathrm{A}$. The following figures will show the output of the sinusoidal signal at $3 \mathrm{MHz}, 5 \mathrm{MHz}$ and $6 \mathrm{MHz}$ to verify that the design is as per BT specifications.

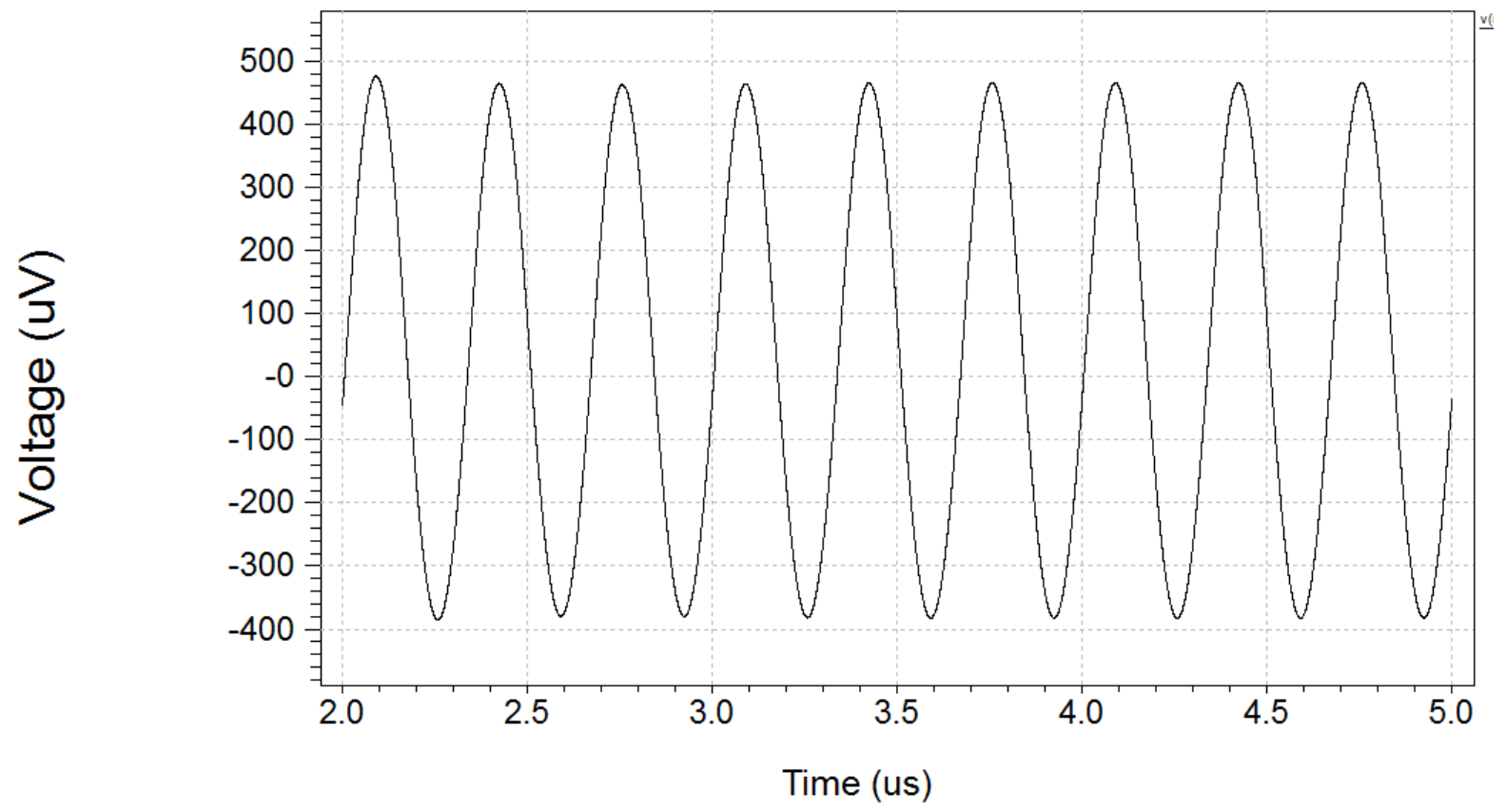


Figure 27: The output of the Sinusoidal signal at $3 \mathrm{MHz}$

Figure 27 shows that the amplitude value peak to peak is almost same as input signal which means that the gain is $0 d B$

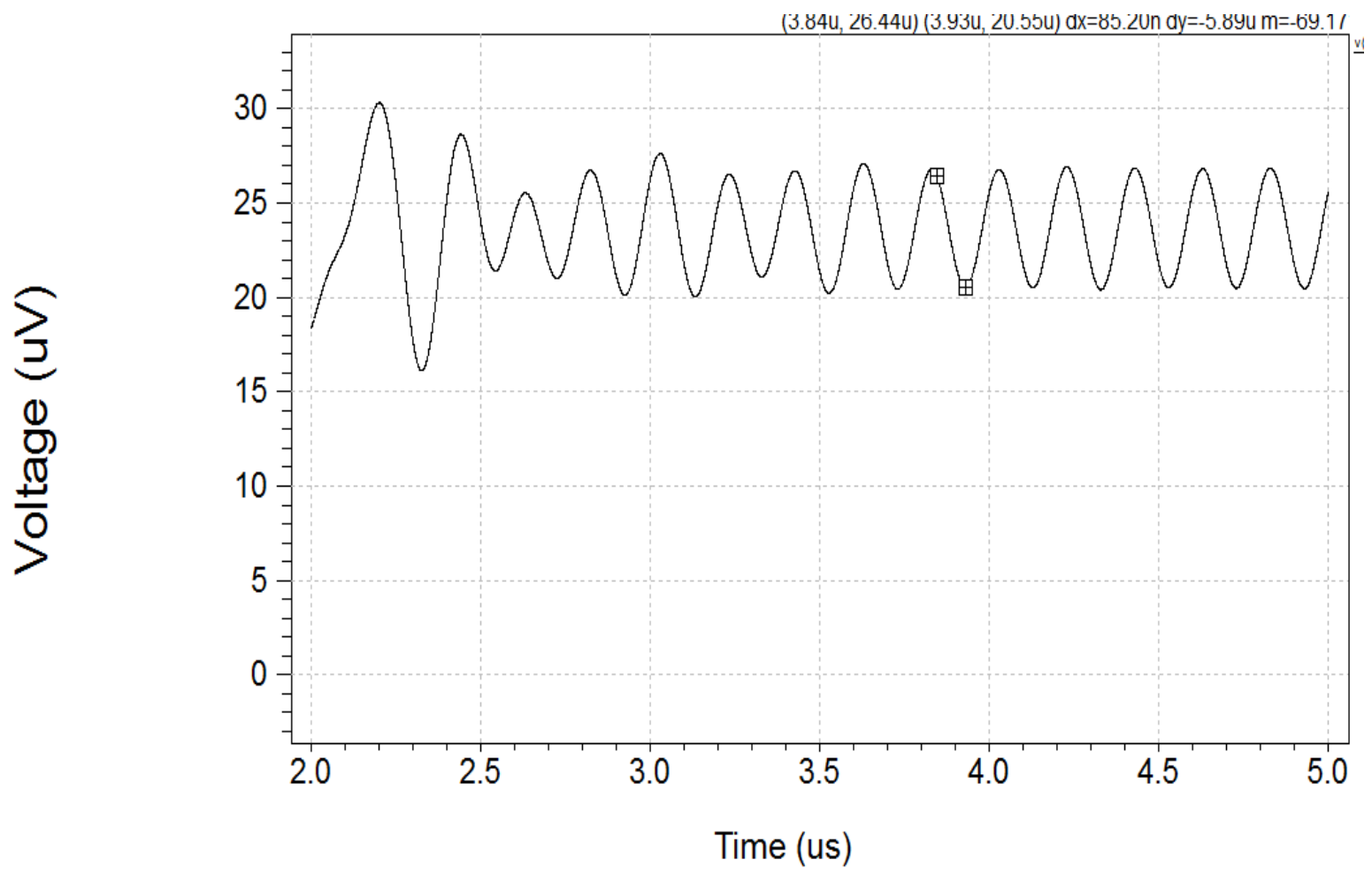

Figure 28: The output sinsodial signal at $5 \mathrm{MHz}$

Figure 28 shows that the input signal is attenuated to be $6 \mu \mathrm{v}$ peak to peak. To calculate the attenuation at $5 \mathrm{MHz}$ :

$$
20 \log \frac{6 u v}{850 u v}=-43 d B
$$

Which is same as the attenuation of figure 19 of the signal response of the filter at $5 \mathrm{MHz}$ 


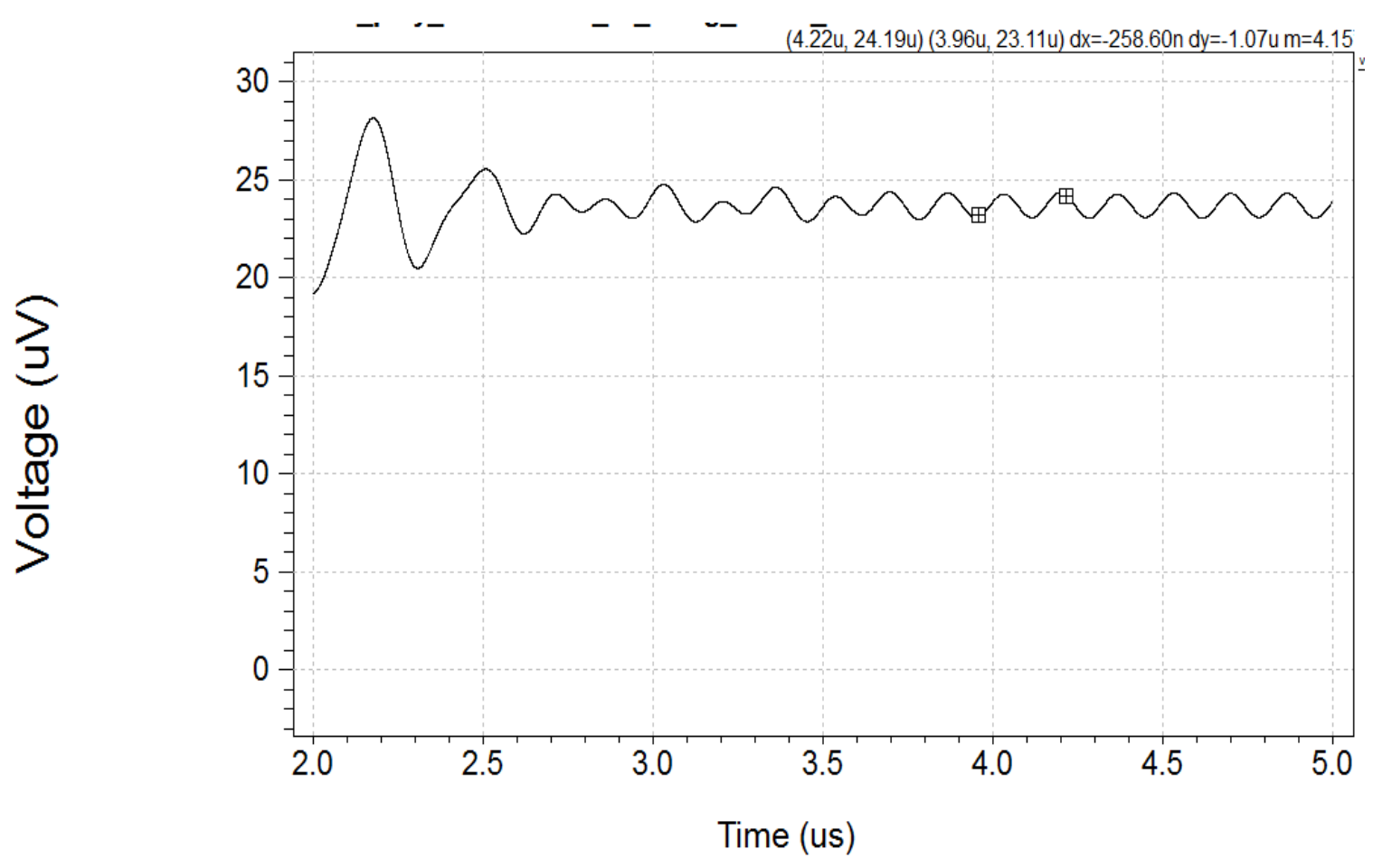

Figure 29: The output sinusoidal signal at $6 \mathrm{MHz}$

Figure 29 shows that the input signal is attenuated to be $1.2 \mu \mathrm{v}$ peak to peak. To calculate the attenuation at $6 \mathrm{MHz}$ :

$$
20 \log \frac{1.2 u}{850 u}=-57 d B
$$

Which is almost same as the attenuation of figure 19 of the signal response of the filter at $6 \mathrm{MHz}$.

\subsection{Conclusion and Future Work}

Several new complex filters based on various amplifiers are systematically developed from their two integrator loop counterparts. This approach has inherent advantages over LC approach in terms of number of active components. Also, it has clear advantages over 
their first-order counterpart in terms of selectivity characteristics and image rejections. The advantages and disadvantages of the proposed filter realizations are clearly identified. Consequently, it has been shown that the most power efficient complex filters are those obtained from CM structures based on the TCAs and CAs. With the two devices realized with same CMOS topologies (for example same CCII), it is analytically shown that CA-based filter provides better signal swing than its TCA or (CCII) counterpart. A $4^{\text {th }}$-order filter is realized by cascading two sections of the proposed filter based on CAs. This demonstrates an application example for the complex filter that could be used in Bluetooth low IF receiver. The signal response, image response, dynamic range and power consumption are determined.

This work provides the optimal low power complex filter structure since it uses minimum possible number of active elements and utilizing very simple active element type. This means it should lead to the lowest possible power consumption. Therefore, it is recommended to investigate ways to further reduce power consumption through optimizing the supply voltages and biasing current of the CMOS CA circuit. Also, This work can be extended through replacing the CA amplifier circuit by a programmable gain counterpart, adding automatic tuning circuit to the filter, and realizing a complete low IF receiver system.

Finally, This work can be extended through optimizing the supply voltage and current consumption of the current amplifier, replacing the CA amplifier circuit by a programmable gain counterpart, adding automatic tuning circuit to the filter, and realizing a complete low IF receiver system. It is worth mentioning that this work has led to the publication of a journal paper in IEEE Transactions on Circuits and Systems. 


\section{References}

[1] P. Andreani, and S. Mattisson, "On the Use of Nauta's Transconductor in LowFrequency CMOS $\mathrm{g}_{\mathrm{m}} \mathrm{C}$ Bandpass Filters," IEEE J. Solid-State Circuits, vol. 37, pp.114-124, Feb. 2002.

[2] P. Andreani, S. Mattisson, and B. Essink, "A CMOS gm-C polyphase filter with high image band rejection," Proc. ESSCIR, pp. 244-247, Sept. 2000.

[3] B. Shi, W. Shan, and P. Andreani, "A 57 -dB image band rejection CMOS $\mathrm{G}_{\mathrm{m}}-\mathrm{C}$ polyphase filter with automatic frequency tuning for Bluetooth," ISCAS, pp. V-169 II-172, May 2002.

[4] W. Sheng, B. Xia, A. Emira, C. Xin, V. López, S. Moon, and E Sánchez-Sinencio, “A 3-V, 0.35- $\mu \mathrm{m}$ CMOS Bluetooth Receiver IC," IEEE J. Solid-State Circuits, vol. 38, pp. $30-42$, Jan. 2003.

[5] A. Emira, and E. Sánchez-Sinencio, ”A Pseudo Differential Complex Filter for Bluetooth with Frequency Tuning," IEEE Trans. Circuits and Syst.-II, vol. 50, pp. 742-754, Oct. 2003.

[6] B. Guthrie, J. Hughes, T. Sayers, and A. Spencer, "A CMOS gyrator Low-IF filter for a dual-mode Bluetooth/ZigBee transceiver," IEEE J. Solid-State Circuits, vol. 55, no. 9, pp. 1872-1878, Sept. 2005.

[7] C. Psychalinos, "Low-voltage log-domain complex filters," IEEE Trans. Circuits and Syst.-II, vol. 55, no. 11, pp. 3404- 3412, Dec. 2008. 
[8] J. Hughes, A. Spencer, A. Worapishet, and R. Sitdihkorn, "1mW CMOS polyphase channel filter for Bluetooth," IEE Proceedings Circuits Devices Syst., vol. 149, no. 5/6, pp. 348-354, Oct. 2002.

[9] J. Mahattanakul, and P. Kumsat, "Structure of complex elliptic Gm-C filters suitable for fully differential implementation," IET Circuits Devices Syst., vol. 1, no.4, pp.275-282, Aug. 2007.

[10] A. Yamazaki, A. Ravindran, O. Akgun, and M. Ismail, "An active-RC reconfigurable lowpass-polyphase Tow-Thomas biquad filter," IEEE Int. Midwest Symp. on Cir. and Syst., pp. I-57-I-60, 2004.

[11] H. Alzaher, "A CMOS Highly Linear Digitally Programmable Active-RC Design Approach," IEEE Trans. Circuits and Syst.-I, vol. 58, no. 11, pp. 2636-2646, Nov. 2011.

[12] A. Balankutty, S. Yu, Y. Feng, and P. Kinget, “A 0.6-V zero-IF/Low-IF receiver with integrated fractional-N synthesizer for 2.4-GHz ISM-band applications," IEEE J. Solid-State Circuits, vol. 45, no. 3, pp. 538-553, Mar. 2010.

[13] M. Tedeschi, A. Liscidini, and R. Castello, "Low-power quadrature receivers for ZigBee (IEEE 802.15.4) applications," IEEE J. Solid-State Circuits, vol. 45, no. 9, pp. 1710-1719, Sept. 2010.

[14] W. Chuanchuan, L. Zhiqun, and H. Ningbing, "A CMOS Gm-C complex filter with on-chip automatic tuning for wireless sensor network application," Journal of Semiconductors, vol. 32, no. 5, pp. 05002-1 to 05002-6, May 2011. 
[15] C. Xin, Z. Lungui, Y. Haigang, L. Fei, and G. Tongqiang, "A pseudo differential Gm-C complex filter with frequency tuning for IEEE802.15.4 applications," Journal of Semiconductors, vol. 32, no. 7, pp. 075005-1 to 075005-8, July 2011.

[16] X. Zhang, N. Kambayashi, and Y. Shinada, "A realization of active current-mode resonator with complex coefficients using CCIIs," IEICE Transactions on Fundamentals, vol. E80-A, 1997, pp. 413-415.

[17] A. M. Abuelma'atti, and M. T. Abuelma'atti, "A current-conveyor-based polyphase filter," WSEAS Transactions on Electronics, vol. 4, 2005, pp. 656-663.

[18] S. Shahrani, and M. Gahtani, "A new polyphase current-mode filter using digitally-programmable CCCII," $18^{\text {th }}$ Int. Conf. on Microelectronics ICM-2006, pp. $142-145$.

[19] M. T. Abuelma'atti, and S. M. Al-Shahrani, "A new polyphase current-mode filter using programmable-gain current-controlled current-conveyor," WSEAS Transactions on Electronics, vol. 2, pp. 138-141, Oct. 2005.

[20] M. Un, "Implementation of polyphase filter section with CFAs," Frequenz, vol. 58, 2004, pp. 221-224.

[21] M. T. Abuelma'atti, and S. M. Al-Shahrani, "A new polyphase mixed-mode bandpass filter section using current feedback operational amplifier," WSEAS Transactions on Electronics, vol. 2, pp. 128-131, Oct. 2005.

[22] E. Soliman, and S. Mahmoud, "New CMOS fully differential current conveyor and its application in realizing sixth order complex filter," ISCAS, pp. 57-60, 2009. 
[23] H. Alzaher and N. Tasadduq, "A CMOS low power current-mode polyphase filter," Proceedings of the IEEE International Symposium on Low Power Electronics and Design (ISLPED 2009), pp. 75-79, 2009.

[24] C. Laoudias, and C. Psychalinos, "Low-Voltage Bluetooth/ZigBee Complex Filter Using Current Mirrors,” ISCAS, pp. 1268-1271, May 2010.

[25] C. Laoudias, C. Psychalinos, "1.5V Complex Filters using current mirrors,” IEEE Tran. on Circuits and Syst.-II, vol. 58, no. 9, pp. 575-579, Sep. 2011.

[26] B. Harvey, "Current Feedback opamp limitations: A state-of-the-art review," ISCAS, pp. 1066-1069, May 1993.

[27] Hans Schmid "Why current mode does not guarantee good performance", Analog Int. Cir. and Signal Processing, vol. 35, no. 1, pp. 79-90, Apr. 2003.

[28] G. Cataldo, A. Grasso, and S. Pennisi, "Two CMOS Current Feedback Operational Amplifiers," IEEE Trans. Circuits and Syst.-II, vol. 54, pp. 944-948, 2007.

[29] S. Lindfors, J. Jussila, K. Halonen, and L. Siren, "A 3-V continuous time filter with on-chip tuning for IS-95," IEEE J. Solid-State Circuits, vol. 34, pp. 1150-1154, Aug. 1999.

[30] A. Fabre, O. Saaid, F. Wiest, and C. Boucheron, "High frequency applications based on a new current controlled conveyor," IEEE Trans. Circuits and Syst.-I, vol. 43, no. 2, pp. 82-91, 1996.

[31] D. Johns and K. Martin, Analog Integrated Circuit Design. New York: John Wiley \& Sons, Inc., Chapter X, 1997. 
[32] E. Bruun, "Analysis of the noise charactersistics of CMOS current conveyors," Analog Int. Cir. and Signal Processing, vol. 12, No. 1, pp. 71-78, Jan. 1997.

[33] H. Alzaher, H. Elwan, and M. Ismail, "A CMOS highly linear channel-select filter for 3G multistandard integrated wireless receivers,” IEEE J. Solid-State Circuits, vol. 37, No. 1, pp. 27 - 37, Jan. 2002. 


\section{APPENDIX}

CA based complex filter

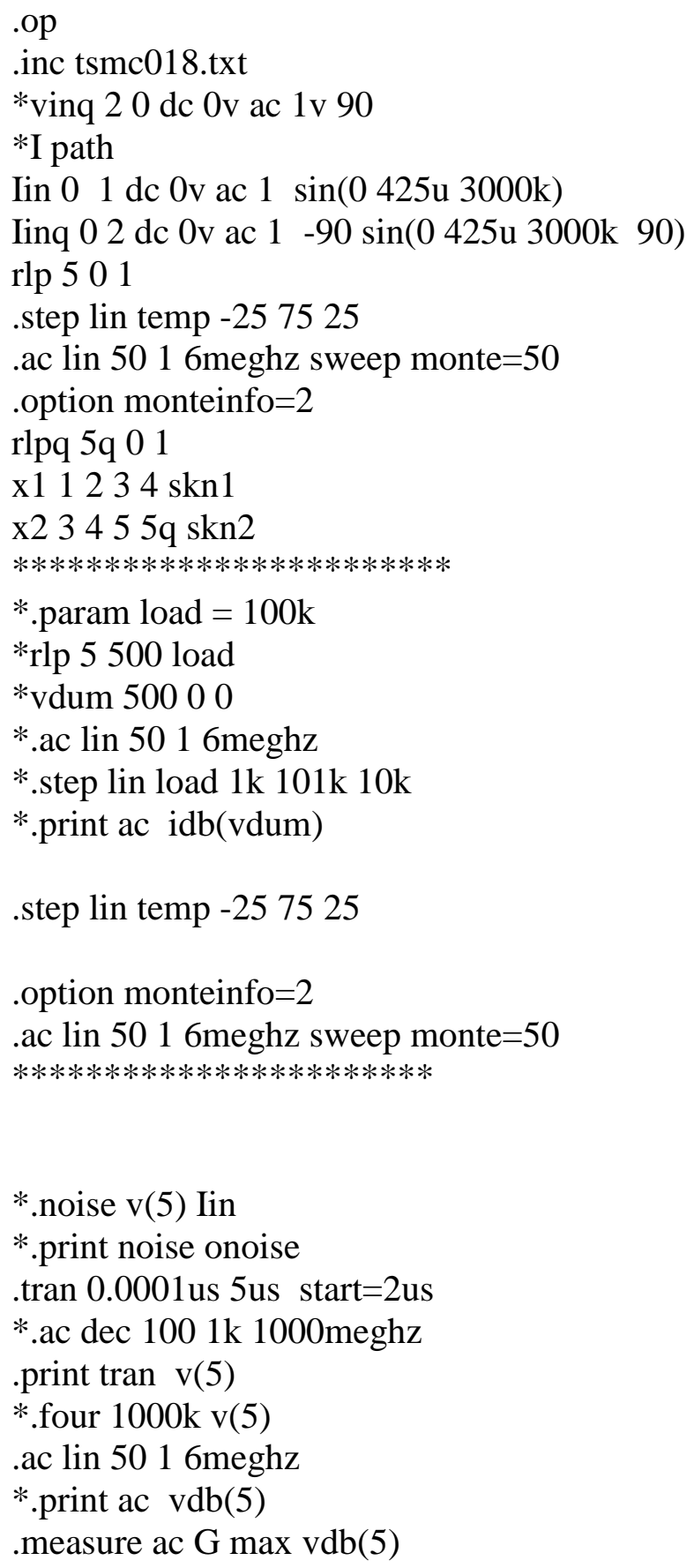




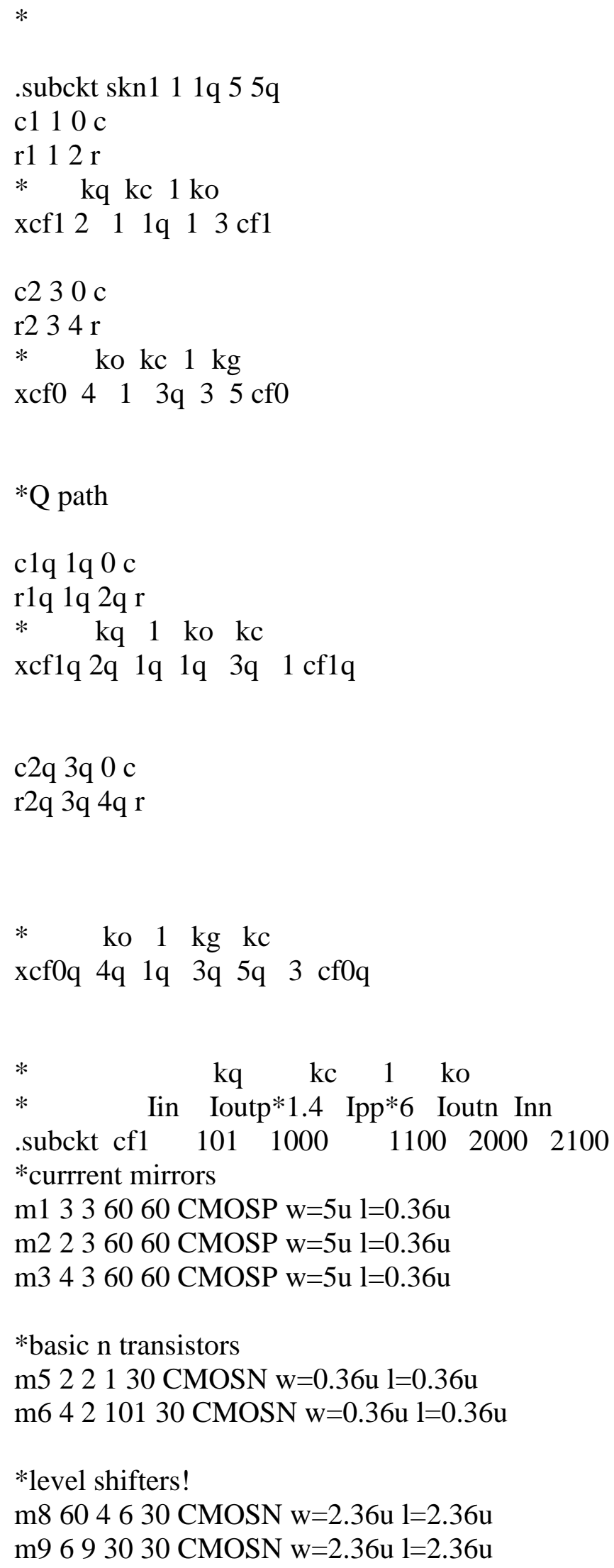


*affect peaking

*commen mode control part

$\mathrm{m} 12883030 \mathrm{CMOSN}$ w $=6 \mathrm{u} \mathrm{l}=0.36 \mathrm{u}$

m13 10183030 CMOSN w=6u l=0.36u

$*_{\mathrm{o}} / \mathrm{p}$ pushpull

m15 10046060 CMOSP $w=6 u$ l $=0.18 u$

m19 $10063030 \mathrm{CMOSN} w=1.8 \mathrm{u} \mathrm{l}=0.18 \mathrm{u}$

m16 100046060 CMOSP $\mathrm{w}=6 \mathrm{u}^{*} \mathrm{kq} 1 \mathrm{l}=0.18 \mathrm{u}$

m21 100063030 CMOSN w=1.8u*kq1 l=0.18u

m16c 110046060 CMOSP $\mathrm{w}=36 \mathrm{u} / 6 * \mathrm{kc} \mathrm{l}=0.18 \mathrm{u}$

m21c 110063030 CMOSN w=10.8u/6*kc l=0.18u

$\mathrm{m} 16 \mathrm{z} 2 \mathrm{~cm} 146060 \mathrm{CMOSP} \mathrm{w}=6 \mathrm{u} \mathrm{l}=0.18 \mathrm{u}$

$\operatorname{mzd} 99 \mathrm{~cm} 1 \mathrm{~cm} 13030$ CMOSN w=1.8u l=0.18u

mz299 $2000 \mathrm{~cm} 13030$ CMOSN w=1.8u l=0.18u

mz299c $2100 \mathrm{~cm} 13030$ CMOSN w=1.8u/ $1 *$ ko $l=0.18 \mathrm{u}$

$\mathrm{m} 88 \mathrm{c} 88 \mathrm{~cm} 263030 \mathrm{CMOSN} w=1.8 \mathrm{u} \mathrm{l}=0.18 \mathrm{u}$

$\mathrm{m} 16 \mathrm{z} 288 \mathrm{~cm} 2 \mathrm{~cm} 26060$ CMOSP $\mathrm{w}=6 \mathrm{u} \mathrm{l}=0.18 \mathrm{u}$

m16z2n88 $2000 \mathrm{~cm} 26060$ CMOSP $\mathrm{w}=6 \mathrm{u} \mathrm{l}=0.18 \mathrm{u}$

$\mathrm{m} 16 \mathrm{z} 2 \mathrm{n} 88 \mathrm{c} 2100 \mathrm{~cm} 26060 \mathrm{CMOSP} \mathrm{w}=6 \mathrm{u} / 1 * \mathrm{ko} \mathrm{l}=0.18 \mathrm{u}$

*cc $1000-7 \mathrm{p}$

*baising part

m23 1071076060 CMOSP w=6u l=0.18u

m24 107107930 CMOSN w=1.8u l=0.18u

**************************

vb1 $10 \mathrm{dc} 0 \mathrm{v}$

isb 9302 ua

ib1 38 20ua

vec $600 \mathrm{dc} 1.5 \mathrm{v}$

vss $300 \mathrm{dc}-1.5 \mathrm{v}$

$* * * * * * * * * * * * * * * * * * * * * *$

*rsc instead of cd networks!

rsc 1001011

*xcdn $1001010 \operatorname{cdn} 4$ 
.ends cf1

* $\quad \mathrm{kq} \quad 1$ ko $\quad \mathrm{kc}$

* Iin Ioutp*1.85 Ioutn Inn Innn*6

$\begin{array}{llllll}\text {.subckt cflq } & 101 & 1000 & 2000 & 2100 & 2200\end{array}$

*currrent mirrors

m1 336060 CMOSP ${ }_{w}=5 u$ l $=0.36 u$

$\mathrm{m} 2236060$ CMOSP $\mathrm{w}=5 \mathrm{u} \mathrm{l}=0.36 \mathrm{u}$

m3 436060 CMOSP w $=5 u$ l $=0.36 u$

*basic $\mathrm{n}$ transistors

m5 22130 CMOSN w=0.36u l=0.36u

m6 4210130 CMOSN w=0.36u l=0.36u

*level shifters!

m8 $604630 \mathrm{CMOSN} w=2.36 \mathrm{u} \mathrm{l}=2.36 \mathrm{u}$

m9 $693030 \mathrm{CMOSN} w=2.36 \mathrm{u} l=2.36 \mathrm{u}$

*affect peaking

*commen mode control part

$\mathrm{m} 12883030 \mathrm{CMOSN}$ w $=6 \mathrm{u} \mathrm{l}=0.36 \mathrm{u}$

$\mathrm{m} 1310183030 \mathrm{CMOSN} w=6 \mathrm{u} l=0.36 \mathrm{u}$

*o/p pushpull

m15 10046060 CMOSP ${ }_{\mathrm{w}}=6 \mathrm{u} \mathrm{l}=0.18 \mathrm{u}$

m19 10063030 CMOSN w=1.8u l=0.18u

m16 100046060 CMOSP $\mathrm{w}=6 \mathrm{u}^{*} \mathrm{kq} 1 \mathrm{l}=0.18 \mathrm{u}$

m21 100063030 CMOSN w=1.8u*kq1 l=0.18u

$\mathrm{m} 16 \mathrm{z} 2 \mathrm{~cm} 146060 \mathrm{CMOSP} \mathrm{w}=6 \mathrm{u} \mathrm{l}=0.18 \mathrm{u}$

$\operatorname{mzd} 99 \mathrm{~cm} 1 \mathrm{~cm} 13030$ CMOSN w=1.8u l=0.18u

$\mathrm{m} 88 \mathrm{c} 88 \mathrm{~cm} 263030 \mathrm{CMOSN} w=1.8 \mathrm{u} \mathrm{l}=0.18 \mathrm{u}$

$\mathrm{m} 16 \mathrm{z} 288 \mathrm{~cm} 2 \mathrm{~cm} 26060$ CMOSP $\mathrm{w}=6 \mathrm{u} \mathrm{l}=0.18 \mathrm{u}$

m16z2n88 $2000 \mathrm{~cm} 26060$ CMOSP $w=6 u ~ l=0.18 u$

mz299 $2000 \mathrm{~cm} 13030$ CMOSN w=1.8u l=0.18u

m16z2n88c $2100 \mathrm{~cm} 26060$ CMOSP $w=6 u / 1 * k o l=0.18 u$

mz299c $2100 \mathrm{~cm} 13030 \mathrm{CMOSN} w=1.8 \mathrm{u} / 1 * \mathrm{ko} \mathrm{l}=0.18 \mathrm{u}$ 
$\mathrm{mn} 16 \mathrm{z} 2 \mathrm{n} 88 \mathrm{c} 2200 \mathrm{~cm} 26060 \mathrm{CMOSP} \mathrm{w}=36 \mathrm{u} / 6 * \mathrm{kc} \mathrm{l}=0.18 \mathrm{u}$

mnz299c $2200 \mathrm{~cm} 13030 \mathrm{CMOSN} w=10.8 \mathrm{u} / 6 * \mathrm{kc} \mathrm{l}=0.18 \mathrm{u}$

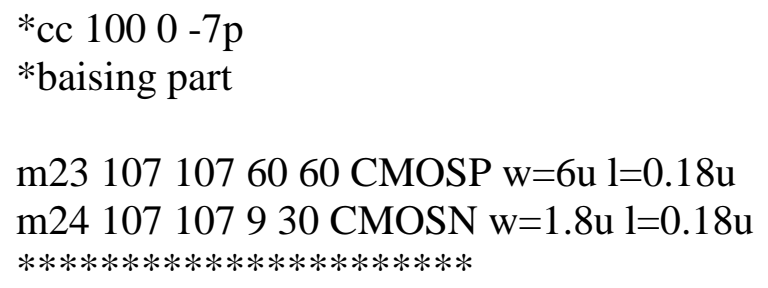

*rsc instead of cd networks!

rsc 1001011

*xcdn $1001010 \operatorname{cdn} 4$

$* * * * * *$

.ends cf1q

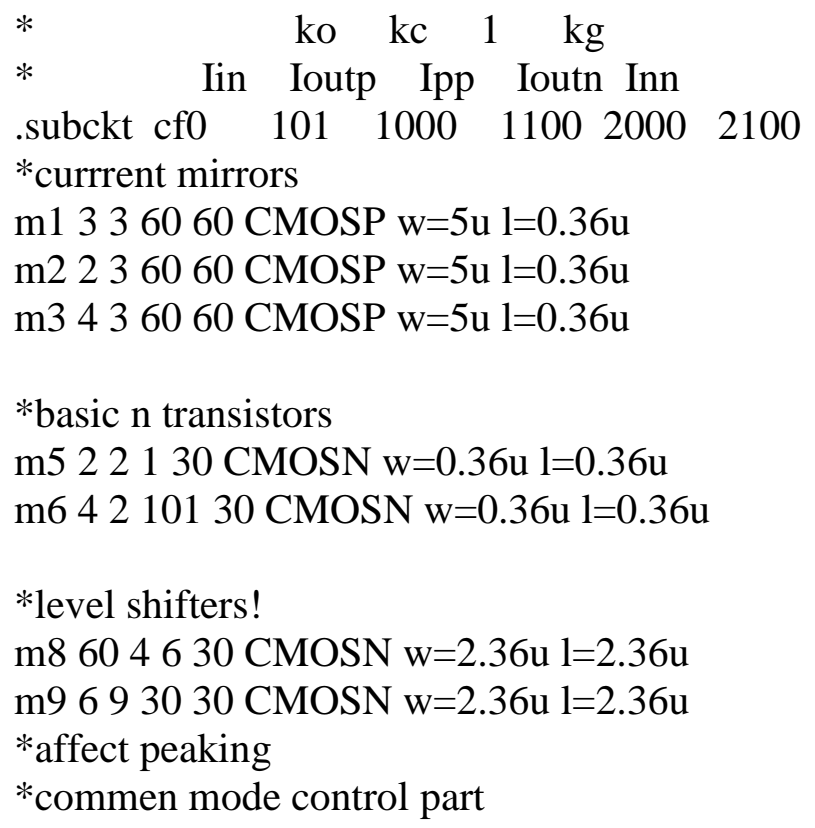


$\mathrm{m} 12883030$ CMOSN w=6u $\mathrm{l}=0.36 \mathrm{u}$

m13 $10183030 \mathrm{CMOSN} w=6 \mathrm{u} l=0.36 \mathrm{u}$

*o/p pushpull

m15 10046060 CMOSP $w=6 u$ l=0.18u

m19 10063030 CMOSN w=1.8u l=0.18u

m16 100046060 CMOSP $w=6 u * k o l=0.18 u$

m21 100063030 CMOSN w=1.8u*ko l=0.18u

m16c 110046060 CMOSP w=36u/6*kc l=0.18u

m21c 110063030 CMOSN w=10.8u/6*kc l=0.18u

$\mathrm{m} 16 \mathrm{z} 2 \mathrm{~cm} 146060 \mathrm{CMOSP} \mathrm{w}=6 \mathrm{u} \mathrm{l}=0.18 \mathrm{u}$

$\operatorname{mzd} 99 \mathrm{~cm} 1 \mathrm{~cm} 13030$ CMOSN w $=1.8 \mathrm{u} \mathrm{l}=0.18 \mathrm{u}$

mz299 $2000 \mathrm{~cm} 13030 \mathrm{CMOSN} w=1.8 \mathrm{u} \mathrm{l}=0.18 \mathrm{u}$

mz299c $2100 \mathrm{~cm} 13030$ CMOSN w=1.8u/ $1 * \mathrm{~kg} \mathrm{l}=0.18 \mathrm{u}$

$\mathrm{m} 88 \mathrm{c} 88 \mathrm{~cm} 263030 \mathrm{CMOSN}$ w $=1.8 \mathrm{u} \mathrm{l}=0.18 \mathrm{u}$

$\mathrm{m} 16 \mathrm{z} 288 \mathrm{~cm} 2 \mathrm{~cm} 26060$ CMOSP $\mathrm{w}=6 \mathrm{u} \mathrm{l}=0.18 \mathrm{u}$

$\mathrm{m} 16 \mathrm{z} 2 \mathrm{n} 882000 \mathrm{~cm} 26060$ CMOSP $\mathrm{w}=6 \mathrm{u} \mathrm{l}=0.18 \mathrm{u}$

$\mathrm{m} 16 \mathrm{z} 2 \mathrm{n} 88 \mathrm{c} 2100 \mathrm{~cm} 26060 \mathrm{CMOSP} w=6 \mathrm{u} / 1 * \mathrm{~kg} \mathrm{l}=0.18 \mathrm{u}$

*cc $1000-7 p$

*baising part

m23 1071076060 CMOSP $w=6 u$ l=0.18u

m24 $107107930 \mathrm{CMOSN}$ w=1.8u l=0.18u

$* * * * * * * * * * * * * * * * * * * * * *$

vb1 $10 \mathrm{dc} 0 \mathrm{v}$

isb 9302 ua

ib1 38 20ua

vec $600 \mathrm{dc} 1.5 \mathrm{v}$

vss $300 \mathrm{dc}-1.5 \mathrm{v}$

$* * * * * * * * * * * * * * * * * * * * * *$

*rsc instead of cd networks!

rsc 1001011

*xcdn $1001010 \operatorname{cdn} 4$

$* * * * * *$ 
.ends cf0

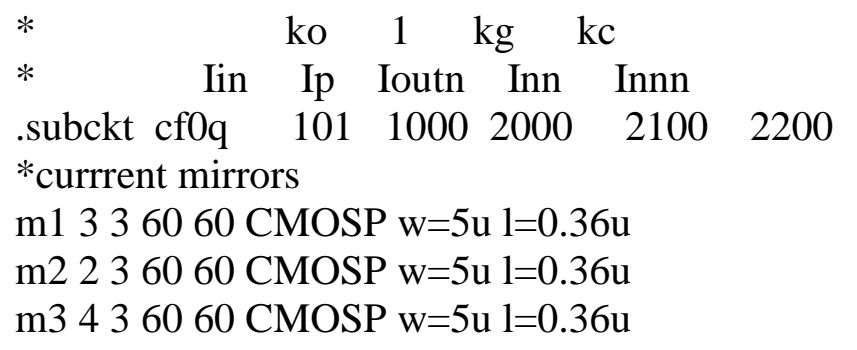

*basic $\mathrm{n}$ transistors

m5 22130 CMOSN w=0.36u $\mathrm{l}=0.36 \mathrm{u}$

m6 4210130 CMOSN w=0.36u l=0.36u

*level shifters!

m8 $604630 \mathrm{CMOSN} w=2.36 u \mathrm{l}=2.36 \mathrm{u}$

m9 $693030 \mathrm{CMOSN} w=2.36 \mathrm{u} \mathrm{l}=2.36 \mathrm{u}$

*affect peaking

*commen mode control part

$\mathrm{m} 12883030 \mathrm{CMOSN}$ w=6u $\mathrm{l}=0.36 \mathrm{u}$

m13 10183030 CMOSN w=6u l=0.36u

$*_{\mathrm{o}} / \mathrm{p}$ pushpull

m15 10046060 CMOSP $w=6 u$ l=0.18u

m19 10063030 CMOSN w=1.8u l=0.18u

m16 100046060 CMOSP w=6u*ko l=0.18u

m21 100063030 CMOSN w=1.8u*ko $l=0.18 u$

$\mathrm{m} 16 \mathrm{z} 2 \mathrm{~cm} 146060 \mathrm{CMOSP}_{\mathrm{w}=6 \mathrm{u}} \mathrm{l}=0.18 \mathrm{u}$

$\operatorname{mzd} 99 \mathrm{~cm} 1 \mathrm{~cm} 13030$ CMOSN w=1.8u l=0.18u

$\mathrm{m} 88 \mathrm{c} 88 \mathrm{~cm} 263030 \mathrm{CMOSN}$ w $=1.8 \mathrm{u} \mathrm{l}=0.18 \mathrm{u}$

$\mathrm{m} 16 \mathrm{z} 288 \mathrm{~cm} 2 \mathrm{~cm} 26060 \mathrm{CMOSP}_{\mathrm{w}}=6 \mathrm{u} \mathrm{l}=0.18 \mathrm{u}$

m16z2n88 $2000 \mathrm{~cm} 26060$ CMOSP w=6u l=0.18u

mz299 $2000 \mathrm{~cm} 13030 \mathrm{CMOSN}$ w=1.8u l=0.18u

$\mathrm{m} 16 \mathrm{z} 2 \mathrm{n} 88 \mathrm{c} 2100 \mathrm{~cm} 26060$ CMOSP $\mathrm{w}=6 \mathrm{u} / 1 * \mathrm{~kg}$ l=0.18u 
mz299c $2100 \mathrm{~cm} 13030 \mathrm{CMOSN} w=1.8 \mathrm{u} / 1 * \mathrm{~kg} \mathrm{l}=0.18 \mathrm{u}$

$\mathrm{mn} 16 \mathrm{z} 2 \mathrm{n} 88 \mathrm{c} 2200 \mathrm{~cm} 26060 \mathrm{CMOSP} \mathrm{w}=36 \mathrm{u} / 6 * \mathrm{kc} \mathrm{l}=0.18 \mathrm{u}$

mnz299c $2200 \mathrm{~cm} 13030 \mathrm{CMOSN} w=10.8 \mathrm{u} / 6 * \mathrm{kc} \mathrm{l}=0.18 \mathrm{u}$

*cc $1000-7 \mathrm{p}$

*baising part

$\mathrm{m} 231071076060$ CMOSP $\mathrm{w}=6 \mathrm{u} \mathrm{l}=0.18 \mathrm{u}$

m24 107107930 CMOSN w=1.8u l=0.18u

$* * * * * * * * * * * * * * * * * * * * * *$

vb1 $10 \mathrm{dc} 0 \mathrm{v}$

isb 9302 ua

ib1 38 20ua

vec $600 \mathrm{dc} 1.5 \mathrm{v}$

vss $300 \mathrm{dc}-1.5 \mathrm{v}$

***************************

*rsc instead of cd networks!

rsc 1001011

*xcdn $1001010 \operatorname{cdn} 4$

$* * * * * *$

.ends cf0q

.ends skn1

.subckt skn2 1 1q $55 q$

c1 $10 \mathrm{c}$

r1 12 r

xcf12 21 1q 13 cf12

c2 $30 \mathrm{c}$

r2 $34 \mathrm{r}$

xcf02 $413 q 35$ cf0

*Q path

clq $1 \mathrm{q} 0 \mathrm{c}$

rlq 1q 2q r 
*xcffff 2q $1 \mathrm{q} 1$ 1q $3 \mathrm{q}$ cf 12

xcf1q2 2q 1q 1q 3q 1 cflq2

c2q 3q $0 \mathrm{c}$

r2q $3 q 4 q$ r

xcf0q2 4q 1q 3q 5q 3 cf0q

* $\quad$ Iin Ioutp*0.7634 Ipp*6 Ioutn Inn

$\begin{array}{llllll}\text {.subckt cf12 } & 101 & 1000 & 1100 & 2000 & 2100\end{array}$

*currrent mirrors

m1 336060 CMOSP $w=5 u$ l $=0.36 u$

m2 236060 CMOSP $w=5 u l=0.36 u$

m3 436060 CMOSP $w=5 u l=0.36 u$

*basic $\mathrm{n}$ transistors

m5 22130 CMOSN w=0.36u $1=0.36 u$

m6 4210130 CMOSN w=0.36u l=0.36u

*level shifters!

$\mathrm{m} 8604630 \mathrm{CMOSN} w=2.36 \mathrm{ul}=2.36 \mathrm{u}$

m9 $693030 \mathrm{CMOSN} w=2.36 \mathrm{u} l=2.36 \mathrm{u}$

*affect peaking

*commen mode control part

m12 883030 CMOSN w=6u l=0.36u

m13 10183030 CMOSN w=6u l=0.36u

$*_{\mathrm{o}} / \mathrm{p}$ pushpull

m15 10046060 CMOSP $w=6 u$ l $=0.18 u$

$\mathrm{m} 1910063030 \mathrm{CMOSN} \mathrm{w}=1.8 \mathrm{u} \mathrm{l}=0.18 \mathrm{u}$

m16 100046060 CMOSP $w=6 u * k q 2 ~ l=0.18 u$

m21 100063030 CMOSN w=1.8u*kq2 l=0.18u

m16c 110046060 CMOSP $w=36 u / 6 * k c l=0.18 u$

$\mathrm{m} 21 \mathrm{c} 110063030 \mathrm{CMOSN} \mathrm{w}=10.8 \mathrm{u} / 6^{*} \mathrm{kc} \mathrm{l}=0.18 \mathrm{u}$ 
$\mathrm{m} 16 \mathrm{z} 2 \mathrm{~cm} 146060 \mathrm{CMOSP} \mathrm{w}=6 \mathrm{u} \mathrm{l}=0.18 \mathrm{u}$ $\operatorname{mzd} 99 \mathrm{~cm} 1 \mathrm{~cm} 13030$ CMOSN w $=1.8 \mathrm{u} \mathrm{l}=0.18 \mathrm{u}$ mz299 $2000 \mathrm{~cm} 13030$ CMOSN w=1.8u l=0.18u mz299c $2100 \mathrm{~cm} 13030$ CMOSN w=1.8u*ko l=0.18u $\mathrm{m} 88 \mathrm{c} 88 \mathrm{~cm} 263030 \mathrm{CMOSN} w=1.8 \mathrm{u} \mathrm{l}=0.18 \mathrm{u}$ $\mathrm{m} 16 \mathrm{z} 288 \mathrm{~cm} 2 \mathrm{~cm} 26060 \mathrm{CMOSP} \mathrm{w}=6 \mathrm{u} \mathrm{l}=0.18 \mathrm{u}$ m16z2n88 $2000 \mathrm{~cm} 26060$ CMOSP w=6u l=0.18u

$\mathrm{m} 16 \mathrm{z} 2 \mathrm{n} 88 \mathrm{c} 2100 \mathrm{~cm} 26060$ CMOSP $\mathrm{w}=6 \mathrm{u} * \mathrm{ko} \mathrm{l}=0.18 \mathrm{u}$

*cc $1000-7 \mathrm{p}$

*baising part

m23 1071076060 CMOSP w=6u l=0.18u

m24 107107930 CMOSN w=1.8u l=0.18u

$* * * * * * * * * * * * * * * * * * * * * * *$

vb1 $10 \mathrm{dc} 0 \mathrm{v}$

isb 9302 ua

ib1 38 20ua

vec $600 \mathrm{dc} 1.5 \mathrm{v}$

vss $300 \mathrm{dc}-1.5 \mathrm{v}$

**************************

*rsc instead of cd networks!

rsc 1001011

*xcdn 1001010 cdn4

$* * * * * *$

.ends cf12

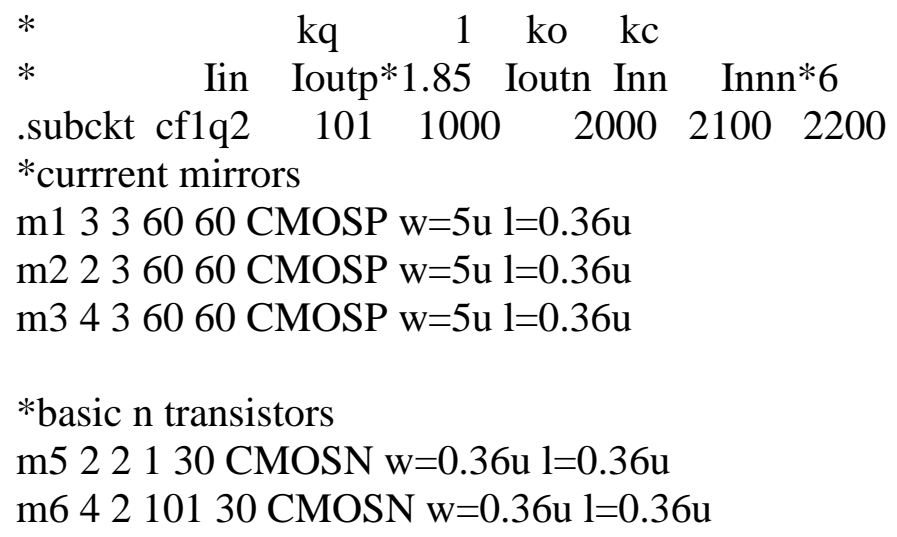




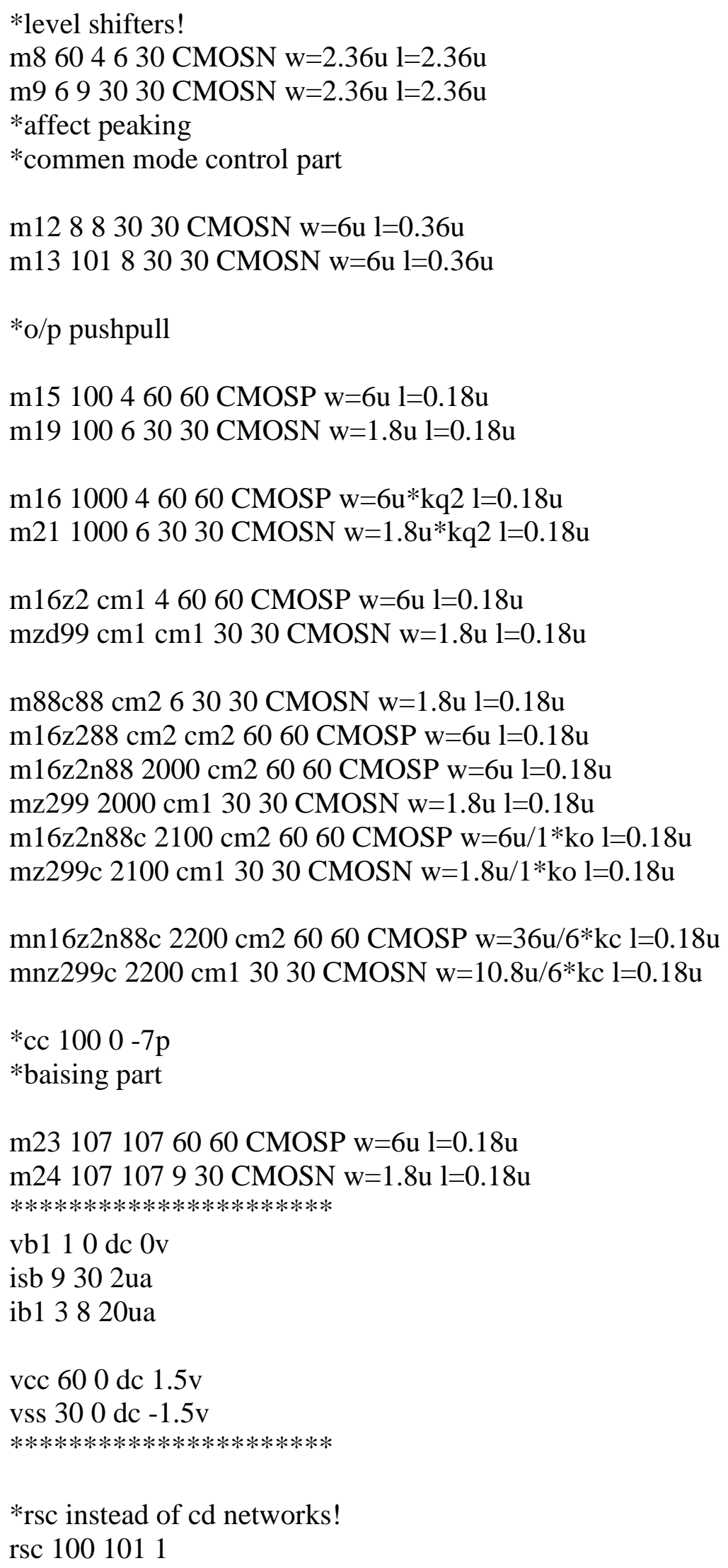


*xcdn $1001010 \operatorname{cdn} 4$

$* * * * * *$

.ends cf1q2

.ends skn2

.param $\mathrm{gc}=6$

.param $\mathrm{c}=102.5 \mathrm{p}$

.param $\mathrm{r}=3.2 \mathrm{k}$

.param $\mathrm{kc}=6.1$

.param $\mathrm{kg}=1.12$

.param $\mathrm{ko}=1$

.param kq1 $=0.7 / 0.5412$

.param kq2=1/1.307

.end 


\section{Vitae}

Name

Nationality

Date of Birth

Email

Address

Academic Background
:FARES SULAIMAN ALAMMARI

:SAUDI Arabia

$: 8 / 19 / 1986$

:AMMARIFS10@GMAIL.COM

:JUBAIL

:The author of the thesis has received his Bachelor of

Electrical Engineering from KFUPM since February 2009 with GPA of 3.8 out of 4.00. In addition, his thesis work has led to the publication of a journal paper in IEEE Transactions on Circuits and Systems on 13 August 2012. 